\title{
PULSE DRYING EXPERIMENT AND BURNER CONSTRUCTION
}

\author{
U.S. DEPARTMENT OF ENERGY \\ INVENTIONS AND INNOVATION PROGRAM \\ SOLICITATION NUMBER DE-PS36-02G092008
}

FINAL REPORT:

DOE Project Number:

PRINCIPAL INVESTIGATOR:
December 19, 2006 (Rev. 4)

DE-FG36-03G013009

ROBERT C. STATES, M.S. ${ }^{3}$, P.E.

5 MOHAWK AVENUE

CORTE MADERA, CA 94925

415-927-2739 OFFICE, 415-927-2722 FAX rstates@ispwest.com - primary email

rstates@mail.com - backup email

CONGRESSIONAL DISTRICT: SIXTH CONGRESSIONAL DISTRICT OF CALIFORNIA

FILE NAME:

G092008-STATES-FINAL.DOC

CATEGORY:

2, 2-YEAR PROJECT

BUDGET:

April 15, 2003 - April 15, 2006

$\$ 200,000$ FEDERAL FUNDS, \$222,401 COST SHARE FROM APPLICANT

\begin{abstract}
Non steady impingement heat transfer is measured. Impingement heating consumes $130 \mathrm{~T}-\mathrm{BTU} / \mathrm{Yr}$ in paper drying, but is only $25 \%$ thermally efficient. Pulse impingement is experimentally shown to enhance heat transfer by 2.8, and may deliver thermal efficiencies near $85 \%$. Experimental results uncovered heat transfer deviations from steady theory and from previous investigators, indicating the need for further study and a better theoretical framework. The pulse burner is described, and its roll in paper drying is analyzed.
\end{abstract}




\section{EXECUTIVE SUMMARY}

PC Engineering

Paper drying consumes .6\% of America's entire energy budget, but drying hood and steam cylinder technologies are only $25 \%$ to $50 \%$ efficient. This grant investigated pulsed impingement drying which may improve efficiencies by $100 \%$ to $300 \%$.

This grant is the first time an apparatus has been built specifically to measure pulsed impingement over a broad range of flow conditions. The most significant scientific discoveries made during this project were:

1) A new resonance phenomena that enhances, and sometimes lowers, heat transfer rate was discovered.

2) A new parameter, the Wave Number (Wn), was invented, and it accurately characterizes sinusoidal pulsed flow.

3) The standard model for scaling steady flow is inaccurate in the pulsed regime, showing the need for an improved theory.

4) Pulsed flows investigated here offer a practical way to dramatically improve drying efficiency in the paper industry.

Past experimenters have reported drying efficiency improvements at extreme levels of pulse intensity [3], but these are impractical for industrial use. The current grant has detected these improvements at low pulse intensities, making them practical. For paper drying, a retrofit of existing equipment improves efficiency $23 \%$, pays back in 5 months, and eventually saves the industry 48 Trillion BTU/Yr. Annual carbon dioxide emissions would be reduced by 4.4 million tons, as well as reductions of .9 million pounds of volatile organic compounds, and 48 million pounds of particulates.

Drying equipment optimized for pulse impingement could improve energy efficiency by over $100 \%$, saving the industry 234 Trillion BTU/Yr, or .2\% of the total US energy budget. This translates into an annual $\mathrm{CO} 2$ reduction of 21.5 millions tons, as well as reductions of 5.8 million pounds of volatile organic compounds, and 234 million pounds of particulates. Though attractive, these energy savings do not pay for the capital expense of replacing existing paper dryers.

The resonance phenomena discovered in this grant helps explain failure of the pulse drying tests performed by Proctor and Gamble, in collaboration with the Institute of Paper Science and Technology. This high profile test detected no drying efficiency improvements in the pulse domain, but the resonances found in the current study were unknown to that research team. They may have accidentally fallen into a resonance trough without knowing it.

Two basic hurtles now prevent commercialization of pulse drying in the paper industry. First, the pulse evaporation process must be measured in greater detail and characterized mathematically. Secondly, the pulse burner now used in the powder industry must be re-engineered for paper drying. 
DE-FG36-03G013009

PC Engineering

\section{TECHNICAL SUMMARY}

This is the first comprehensive examination of the pulse impingement variable space using an experimental apparatus. Past experiments have examined pulsed impingement in a limited area [2,3], but the current effort was designed to map an entire region of the process space, in frequency, Reynolds number, pulse intensity, and Fourier characteristics of the pulse.

This grant produced numerous scientific discoveries. First, the variable space was nondimensionalized using two new mathematical constructs, the Wave Number, abbreviated "Wn", and the Enhancement Factor "En". The Wave Number is a deceptively simple parameter that permits steady flow impingement to be mapped into the complicated variable space of pulsed impingement. The Wave Number was used to build the experimental apparatus in this study, and is shown to characterize the data accurately. The Enhancement Factor is a convenient parameter for reporting data, but more fundamental parameters will supersede it as our understanding of the pulsed impingement process matures.

The data presented here contains many firsts. The resonance phenomena discovered with this grant was previously unknown, and a breakthrough for this field. The study also confirmed that the Reynolds number is a valid nondimenionalizing parameter for pulsed impingement. The mathematics now used to predict steady impingement heat transfer is not rigorous in the pulsed domain, indicating the need for a more comprehensive theory. The air valve designed specifically for this experiment successfully produced all of the impingement wave forms it was designed for, and all experimental limits were located away from the valve in the stepper motor, in fans, and in the liquid stability of the impingement plate.

The paper drying industry uses steady impingement hoods that operate at a Reynolds number of 10,000. The current study covers Reynolds numbers from 5,000 to 15,000, and Wave Numbers from 0 (steady flow) to 3.5, or an instantaneous Reynolds number of 45,000 . However, frequency of pulse was limited to $30 \mathrm{~Hz}$ and data at higher frequencies is needed. Also, the pressure measurement probes chosen for this experiment were much noisier than their design specifications and prevented the experiment from operating in the fully automatic mode it was originally designed for. 
OVERVIEW OF GOALS, OBJECTIVES, AND VARIANCES

The grant contained two physical deliverables, and a mathematical analysis task. These were accomplished per the grant proposal, with minor deviation.

MILESTONE 1 - Evaporator Experiment

The experimental apparatus originally specified in the grant was constructed and operated, though the design evolved as schedule and engineering problems were solved.

MILESTONE 2 - Modeling

The programming, regression, and data analysis tasks in the grant were accomplished per the original grant proposal. The ADINA modeling was performed, but software problems prevented creation of meaningful data.

MILESTONE 3 - Pulse Burner Construction

The burner constructed conforms to the original grant proposal, but was modified from its original task of performing a scale up test, into a parametric test burner designed to advance the understanding of pule combustion.

\section{VARIANCE FROM ORIGINAL GOALS AND OBJECTIVES}

During the first year, the grantee attended two trade shows which greatly expanded insights into the paper industry. Unlike other equipment markets, the paper industry performs virtually no basic research and instead focuses on fine tuning and incremental improvements of existing plants.

The paper industry relies on expensive full scale testing to prove technology before adopting it. For pulse drying, this is a $\$ 350,000$ test that must work the first time, so all technical and marketing efforts must support this goal.

Though the original grant aimed at commercialization, the knowledge gained shows the need for more research. We are not ready for full scale testing.

\section{REPORT FORMAT}

The remainder of this report is a detailed tutorial on pulse impingement drying, on important publications, and on its use in the paper drying process. Experimental results from this grant follow, with an outline for how the data supports commercialization in the paper manufacturing industry. A thermodynamic analysis of pulse drying used in conjunction with gasification and bio-producion is presented. Lastly, the burner constructed for this grant is characterized in the context of a larger parametric study.

Much of the mathematics performed during this grant are post doctorate level. To avoid slowing the pace of the report, the bulk of these analysis are included in appendices at the end of this report. 


\section{TABLE OF CONTENTS}

1.0 DRYING TECHNOLOGY

1.1 STEADY IMPINGEMENT DRYING

1.2 WAVE NUMBER (Wn) AND ENHANCEMENT FACTOR (En)

1.3 DRYING DYNAMICS

1.4 STEAM CYLINDER DRYING

1.5 PULSE DRYING LITERATURE

1.5.1 AZEVEDO STUDY

1.5.2 EIBECK STUDY

1.5.3 EIBECK $Z / D=2$ STEADY EXPERIMENTAL RESULT

1.5.4 EIBECK $h / D=4$ PULSED EXPERIMENTAL RESULT

1.5.5 EIBECK DISCOVERY - TOROIDS

1.5.6 EIBECK CONCLUSION

1.6 PULSE PROCESS

2.0 GRANT PROPOSAL

2.1 GRANT PRELIMINARIES

2.2 MARKETING DISCOVERIES

2.3 MARKETING IMPACT ON GRANT DELIVERABLES

2.4 TAPPI TRADE SHOW RESULTS

2.5 FINITE DIFFERENCE MODELING (TASK 2 DELIVERABLE) 22

3.0 MILESTONES $1 \& 2$

3.1 EVAPORATOR OVERVIEW

3.1.1 EVAPORATOR CONSTRUCTION

3.1.2 CONSTRUCTION DETAILS

3.1.3 PROBLEMS AND MODIFICATIONS TO THE CONSTRUCTION PID 25

3.1.4 PLATE GEOMETRY 26

3.2 VERIFICATION RUNS

3.3 DYNAMIC DATA

3.4 THERMODYNAMIC IMPLICATIONS

3.4.1 RETROFIT MARKET

$\begin{array}{ll}\text { 3.4.2 NEW EQUIPMENT MARKET } & 32\end{array}$

4.0 MILESTONE 3

$\begin{array}{ll}\text { 3.4.3 LONG TERM MARKET IMPACT } & 35\end{array}$

4.1 PULSE BURNER CONSTRUCTION

4.2 NEA BURNER DESIGN

$\begin{array}{ll}\text { 4.3 PULSE BURNER TUNING } & 39\end{array}$

4.4 BURNER IMPEDANCE EXPERIMENTS $\quad 40$

4.5 BURNER DESIGN GOALS $\quad 41$

$\begin{array}{ll}5.0 \text { COMMERCIAL INTRODUCTION } & 42\end{array}$

5.1 SCHEDULE AND FUTURE RESEARCH OPTIONS

5.2 COMMERCIALIZATION PROOF TEST

APPENDICES

A. B. FINAL TASK SCHEDULE AND FINAL SPENDING SCHEDULE

C. FINAL COST SHARING CONTRIBUTIONS $\quad 47$

D. ENERGY SAVING MATRIX

$\begin{array}{ll}\text { E. BIBLIOGRAPHY } & 49\end{array}$

F. AIR FLOW CALCULATIONS $\quad 50$

G. FAN SELECTION

H. VARIABLE SPACE

I. ISENTROPIC EXPANSION SOLUTION 56

J. THERMODYNAMIC BALANCE SUMMARY $\quad 59$

K. BURNER TEST PID $\quad 60$

L. EVAPORATOR TEST PID

M. EVAPORATOR RAW DATA $\quad 62$

N. PHOTOGRAPHS 


\subsection{DRYING TECHNOLOGY}

\subsection{STEADY IMPINGEMENT DRYING}

The thermodynamics of steady impingement hoods were documented by Martin (Advances in Heat Transfer, 1977) [1], and his heat transfer equations have optimized today's paper dryer. Typical design parameters in paper drying are 3\% open area, .25 [in] nozzles, $10 \mathrm{~K}$ Reynolds number, and $900 \mathrm{~F}$ impinging gas temperature.

Martin documents the ratio of conduction to impingement heat transfer. Conduction, for a $900 \mathrm{~F}$ plate separated by 0.25 inches from a $120 \mathrm{~F}$ plate, is easy to calculate:

$$
\begin{aligned}
\mathrm{Q} & =\mathrm{KdT} / \mathrm{dx}=0.032\left[\mathrm{BTU}-\mathrm{ft} / \mathrm{Hr}-\mathrm{ft}^{2}-\mathrm{F}\right]^{*}(900-120)[\mathrm{F}] /(.25 / 12)[\mathrm{ft}] \\
& =1230\left[\mathrm{BTU} / \mathrm{ft}^{2} \mathrm{Hr}\right]
\end{aligned}
$$

One square foot of conductive area delivers enough heat to evaporate $1.27[\mathrm{lb}]$ of water per hour.

Martin's figure 4C (right) shows that steady impingement enhances conduction by about 50 times ( $R e=10 \mathrm{~K}$, forth curve from the bottom). When corrected for nozzle gap and circular area, the true Enhancement Factor is 46.3 (details omitted). So our impingement model predicts that a $900 \mathrm{~F}$ impinging nozzle transfers $46.3 \times 1230=56,950[\mathrm{BTU} / \mathrm{Hr}-\mathrm{SqFt}]$, which evaporates $58.7[\# / \mathrm{Hr}]$.

The efficiency of this process is mediocre. One square foot of hood area consumes $249 \mathrm{~K}$ BTU/Hr, but evaporation only absorbs $59 \mathrm{~K}$, so 178K BTU's bypass the process altogether. The efficiency of this steady flow hood is a dismal $24 \%$ (4082 BTU/\#).

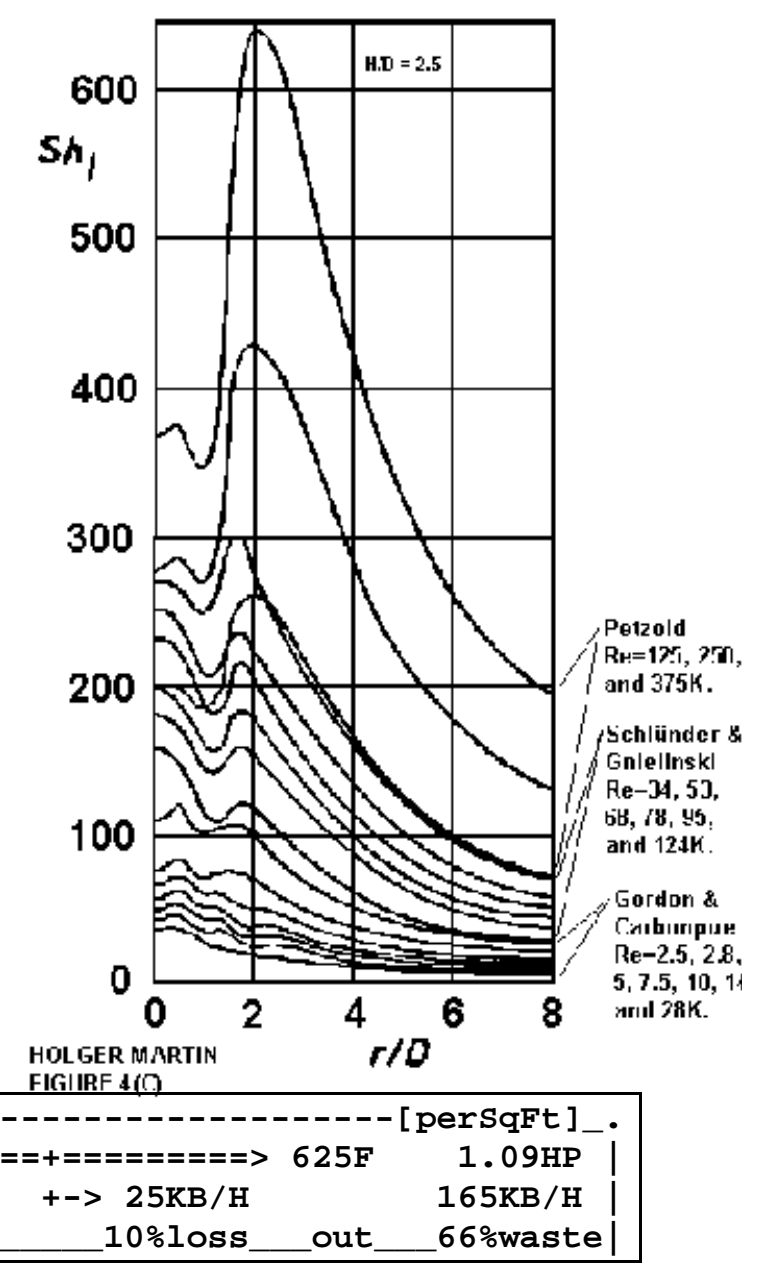

The above diagram summarizes the thermodynamic parameters of the Martin calculations for a one square foot impingement area. Lets briefly review it. Heat enters the diagram as $249,000 \mathrm{BTU} / \mathrm{Hr}$ in an air stream of 264 SCFM, or Standard Cubic Feet per Minute. This combustion process yields a hot gas temperature of $900 \mathrm{~F}$, which has an inherent internal dew point of 74F from combustion products. The hot gas absorbs 61 pounds per hour of water with a heat transfer of 59,000 BTU/Hour, yielding a wet gas temperature of $708 \mathrm{~F}$ with an internal dew point of $117 \mathrm{~F}$. Subsequently, $10 \%$ of the original heat is lost to ambient mixing, radiation, and convection to the environment. The net product of this process is a gas stream with a temperature of $625 \mathrm{~F}$. The one 
square foot section requires $1.09 \mathrm{HP}$ of fan energy, and the waste stream contains $165,000 \mathrm{BTU} / \mathrm{Hr}$ of heat, or $66 \%$ of the original heat supplied to the one square foot section.

The high exhaust temperature of this process requires a heat recovery system. However, let us change one characteristic of this impingement process, the Nusselt number. Instead of the predicted value of 46.3 , lets see the effect of a 117 Nusselt number.

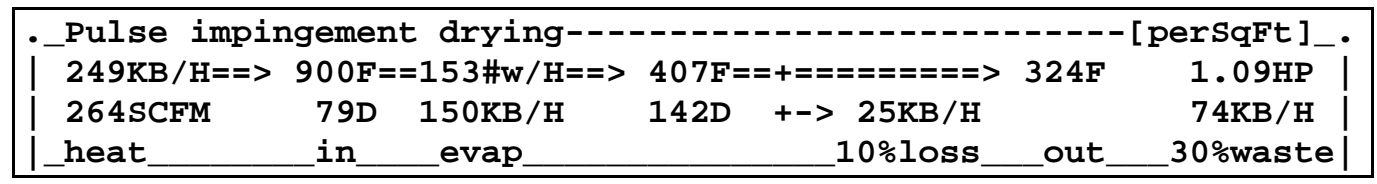

The thermodynamic effect of this single parameter change is striking. Instead of evaporating $61 \# / \mathrm{Hr}$ of water, the one square foot section evaporates $153 \mathrm{\#} / \mathrm{Hr}$, an evaporation acceleration that is linear with Nusselt number. The exhaust stream is a tolerable 324F, a much less expensive heat stream to recover. The heat penalty for evaporating water drops from 4082 BTU/\# to 1627 BTU/\#, a remarkable drop of $60 \%$ in the cost of evaporation. In short, this steady flow impingement process is starved for heat transfer.

The process design engineer has few options for remedying this in a steady flow environment. If one increases Reynolds number to increase turbulence and heat transfer, the heat flow increases linearly, thereby creating an even worse heat loss problem, not to mention increased fan power consumption.

This theoretical examination is a prelude to the practical advantage of pulse impingement, where the design engineer can independently control heat flow and heat transfer rate, thereby tuning the system for optimal heat use, minimal heat loss, and a least cost heat recovery system.

Two factors contribute to the inefficiency of steady flow impingement drying. First, when hot gas emerges from the nozzle, it immediately mixes with cold surrounding air, avoiding the paper surface entirely while increasing hot gas entropy. Second, when the hot gas hits the surface, a small ring under the nozzle has excellent thermal contact with the surface, but further out, cool wet air becomes trapped next to the paper, preventing hot dry air from touching the surface.

The heat recovery system employed by the paper making industry recirculates hot air back to the surface multiple times until all the heat eventually ends up as evaporation. This process consumes significant fan energy. A typical impingement hood (18' Dia, 20' wide) requires a $2000 \mathrm{HP}$ recirculation fan, which consumes $1470 \mathrm{Kw}$, or $\$ 1760$, per day (@5ф Kw-Hr). This electrical consumption equates to about 1200 BTU/\# of evaporated water being consumed at the electric generating plant feeding the fan, or an industry heat consumption of 36 [Trillion BTU/Yr] at power plants.

\subsection{WAVE NUMBER (Wn) AND ENHANCEMENT FACTOR (En)}


Later we will need a bridge from steady flow gas dynamics to nonsteady flow. The factors invented by the grantee for this purpose are the Wave Number $(\mathrm{Wn})$ and the Enhancement Factor (En). A detailed treatment of the Wave Number is included in an appendix to this report. This advanced treatment is useful for engineers who need to size fans, piping, and valves that are used in nonsteady flow equipment. These design tools were used in the performance of this grant, and were found to be accurate.

Martin's work with impinging flows is useful because it links an easily calculated value, the conduction heat flow, to a value one cannot easily calculate, the convection heat flow of an impinging jet. In keeping with this progression, the Wave Number maps a Martin flow, which is calculable, into the nonsteady regime which here to for has been unknown or sparsely measured.

\section{The Wave Number is defined as the ratio of the oscillating flow's peak velocity divided by the steady mass flow equivalent velocity.}

The steady flow velocity is defined by the net mass flow, or the integral of mass flow over the entire cycle. By eye, this is the "Average Gas Flow" in the Wave Number diagram. A Wn=0 flow is steady flowing, or, a pure Martin flow. A $W n=1$ flow oscillates about the same mass flow as its $\mathrm{Wn}=0$ counterpart, but fluctuates from a maximum gas velocity of twice its average, down to an instantaneously zero flow, and back. All flows above $\mathrm{Wn}=1$ are reversing flows, where, during a portion of the cycle gas is actually flowing backward.

The average Reynolds number of an oscillating flow is defined as the equivalent Reynolds number of its steady flow companion (its $\mathrm{Wn}=0$ companion). The instantaneous Reynolds number oscillates from the steady flow value to a maximum of its product with the Wave Number plus one.

$$
\operatorname{Re}(\text { maximum })=\operatorname{Re}(\text { steady flow }) \times(W n+1)
$$

Though the diagram shows the Wave Numbers of a group of sinusoidal gas flows, the $\mathrm{Wn}$ applies to a velocity profile of arbitrary shape. In general, we cannot expect that a gas flow that is dominated by higher Fourier harmonics will have the same heat transfer characteristics as those dominated by its Fourier fundamental, even though their Wave Numbers may be identical. As the science of nonsteady flow advances, it remains to be WAVE NUMBER DEFINITION seen if higher harmonic flows are commercially valuable. For now, first harmonic sinusoidal flows have demonstrated their importance, so the Wave Number has a durable place in nonsteady gas dynamics.

The Enhancement Factor (En) is a much less inspired nondimensional parameter. Here, we merely ratio the heat transfer of a Martin flow with the heat transfer of a 
nonsteady flow. Since the Martin heat transfer value is more commonly termed the Nusselt number, we can write:

$\mathrm{Nu}$ (nonsteady flow) $=\mathrm{En}$ X Nu (steady flow)

\subsection{DRYING DYNAMICS}

In all evaporation processes, two regions concern the process engineer, the constant rate drying zone, and the falling rate drying zone. In the constant rate zone, liquid water is mobile in the matrix giving the paper high heat transfer characteristics. Wet paper in your hand feels cool.

As water leaves the fiber matrix, the remaining water becomes less mobile and the van Der Waals bonds between fiber and water dominate.

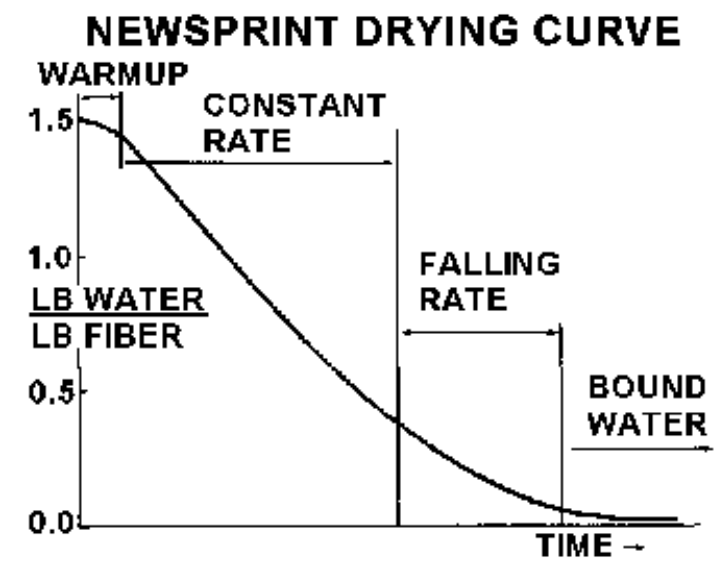

The impingement drying process above optimizes both of these zones because the drying media, air, is in intimate contact with the fiber matrix. Drying technologies that rely on conduction slow down in the falling rate drying zone. They pay a double penalty because conduction within the paper falls, and the surface water which promotes external conduction disappears leaving an insulating surface film coefficient. Pulse drying avoids this process penalty.

\subsection{STEAM CYLINDER DRYING}

The majority of paper machines world wide use steam heated cylinders to evaporatively dry paper. Here, steam is piped to a rotary joint in a rotating cylinder, typically six feet in diameter and twenty feet long, mounted on a horizontal rotating axis. Paper is fed onto the outer diameter of the steam cylinder and pressed in place by a "felt", a tension belt that moves with the paper and forces it onto the cylinder.

Inside the cylinder, a pool of liquid condensate is splashing at the bottom. Incoming steam partially condenses and exits the cylinder through a siphon located concentric with the steam inlet rotary joint. A mixture of live steam and condensate droplets exit the cylinder.

A heavy grade paper such a box board, used to package breakfast cereal, may use 50 drying cylinders. This is fifty chances for steam to leak from the rotary joint, down the cylinder, and onto the paper drying surface. In addition, each cylinder must maintain a nearly mirror smooth surface or paper quality suffers. The tension in the felts relaxes with use and must be retensioned regularly. The rotation rate of adjacent cylinders is closely controlled to slightly stretch, or "draw" the paper as it transits from one cylinder to another. In short, this is a high maintenance and capital intensive part of the paper making process, and a consistent source of complaint when paper manufacturers 
generate a wish list of process improvement, as they did in Agenda 2020, the industry's road map of desired technology.

A typical steam cylinder evaporates 2-4 \#/f2-Hr of water, while steady impingement drying evaporates $61 \# / \mathrm{f} 2-\mathrm{Hr}$, and pulsed impingement raises that to $153 \mathrm{H} / \mathrm{f} 2-\mathrm{Hr}$. These are astronomical drying rates, fully 30 to 75 times the steam cylinder rate. Though industry analysts have recognized these drying rate accelerations [Douglas 4], the technology has not caught on because of heat waste. Pulsed impingement has the potential for capitalizing on these aggressive drying rates, without the waste heat penalty, by making single pass air drying economically viable.

Gavelin (Paper Machine Design and Operation, 1998) [5] has published an inventory of heat consumed in a modern steam cylinder drying system (below), which delivers an evaporative efficiency of 1.25 [\#-steam/\#-evaporated water], an excellent efficiency for this technology, and achieved over decades of fine tuning.

\section{\#-STEAM CONSUMPTION PER \#-WATER EVAPORATION}

(1) Water preheat and evaporation $\quad 1.09$

(2) Desorbtion 0.01

(3) Air heating 0.06

(4) Steam to vacuum condenser $\quad 0.03$

(5) Heat lost with paper sheet $\quad 0.03$

(6) Heat losses from hood 0.03

TOTAL [\#-STEAM / \#-EVAPORATED WATER] $\mathbf{1 . 2 5}$

The steam in this balance is generated by a conventional boiler, so one must include boiler efficiency, combustion efficiency, and boiler ancillaries as part of the heat balance. Lets calculate the actual heat content of one pound of steam.

\section{HEAT REQUIRED TO GENERATE A POUND OF STEAM}
(1) Heat of phase change
$970[\mathrm{BTU} / \#]$
(2) Combustion efficiency $85 \%$
$1141[\mathrm{BTU} / \#]$
(3) Boiler efficiency $85 \%$
(4) Forced draft fan $1.5 \%$

Using this efficiency for steam generation, we discover that the true thermodynamic cost of evaporating one pound of water in a steam cylinder dryer is 1704 [BTU/\#]. This efficiency applies to a well serviced plant with sealed steam traps, insulated steam runs, descaled boiler, surfaced cylinders, tight felt tension, $15 \%$ excess air flame, and no steam gland leaks (which can put water right back onto the paper web). An industry average for steam cylinders is closer to $2400 \mathrm{BTU} / \#$, and older plants with inefficient boilers, poor air control, and steam leaks could easily be over 4000 BTU/\#.

To summarize, pulse drying accelerates the rate of water removal, and simultaneously increases efficiency and reduces maintenance. In most industrial markets, this would be an automatic path to technology acceptance, but as we will learn later, the paper industry is not noted for its acceptance of innovation. 
DE-FG36-03G013009

PC Engineering

\subsection{PULSE DRYING LITERATURE}

Past researchers have patented pulse devices, conducted industrial trials, and published studies on the technology. Despite these efforts, pulse combustion has made virtually no market penetration. Manufacturers of pulse combustion devices have only achieved modest sales of home heaters (Lenox) and industrial dryers (PCS, Unison). Published studies have addressed a variety of pulse technologies, but only two have directly studied pulsed impingement, Eibeck [3] and Azevedo [2]. Proctor and Gamble funded a major study [6], and patented pulse drying of paper [6085437, 6308436] partly as a result of the Eibeck study.

The studies published by Eibeck and Azevedo investigated the heat transfer behavior of pulse impingement in narrow regions, both being much less ambitions than the current grant report. Let us compare these studies, and form a baseline for comparing those results with those of this grant project.

\subsubsection{AZEVEDO STUDY}

Azevedo built a test stand where the gas flow was turned on and off by a rotating cylinder. No reversing flows were studied, so all nonsteady flows in the Azevedo study had a Wave Number of one $(W n=1.0)$. Also, Azevedo only studied the heat transfer value along the centerline of the jet, unlike Martin who characterized the heat transfer as a function of radial distance from the jet centerline using the nondimensional radial distance $(r / D)$, $D$ being the impingement nozzle ID, and $r$ the distance from centerline.

Azevedo's impingement target consisted of an aluminum foil sheet heated by a controlled electric current. This makes the foil sheet a heat source, so the impinging jet is cooling the plate. This reversal of heat flow is mathematically identical to a warm jet transferring heat to a cool plate. The grantee has no argument with this reversal. In gas dynamics, flow behavior differs vastly if the pressure gradient is reversed, but in Azevedo's study the pressure gradient of the Martin flow was preserved.

Azevedo found that nonsteady jets $(\mathrm{Wn}=1)$ slightly decreased the heat transfer rate along centerline. He investigated Reynolds numbers from 1000 to 100,000, and oscillation frequencies from steady flow to $183 \mathrm{~Hz}$, and for a variety of spacings between the nozzle and plate ( $\mathrm{h} / \mathrm{D}$ ratios). He found a maximum heat transfer degradation of $20 \%$, or an Enhancement Factor of $0.8(E n=0.8)$. In no case did Azevedo measure a heat transfer enhancement greater than one, he only measured heat transfer degradation.

Azevedo's results are academically important but not commercially important. In any industrial application, an impinging flow is transferring heat to a finite area, and the detailed behavior of the imaginary point along the jet's centerline becomes insignificant.

Azevedo's measurements show a well behaved decline in En as height above the heated plate increases, a finding consistent with Martin, and merely demonstrating the drop in jet intensity as it mixes with intervening air. Azevedo also shows a decline in En as jet frequency increases. This is a generally well behaved drop, with minor deviations from strictly monotonic. He does not discover any resonance points, though some En 
declines climb slightly as frequency increases, an indication that a resonance phenomena may be influencing his test but that the resonance has weak influence on the centerline Nusselt number.

In summary, the grantee regards the Azevedo study as academically competent, and authorship of the study in Experimental Thermal and Fluid Science as thorough and sufficient to duplicate the findings. However, the study is not relevant to industrial processes that would use nonsteady flows because the impinging jet's heat transfer characteristics were only examined at a theoretical point along the jet's centerline, and the region away from centerline was ignored.

\subsubsection{EIBECK STUDY}

The Eibeck [3] study is radically different from Azevedo, both in industrial significance, and in quality of authorship.

Eibeck (et. al.) built a pulse fired burner that impinged on an instrumented plate. The burner was a premixed Helmholtz design, so it operated at a single frequency, and a limited range of combustion temperatures.

The Eibeck study has significant industrial value because a positive heat transfer enhancement $(E n=2.5)$ was measured. However, the Eibeck paper has none of Azevedo's completeness in authorship, and

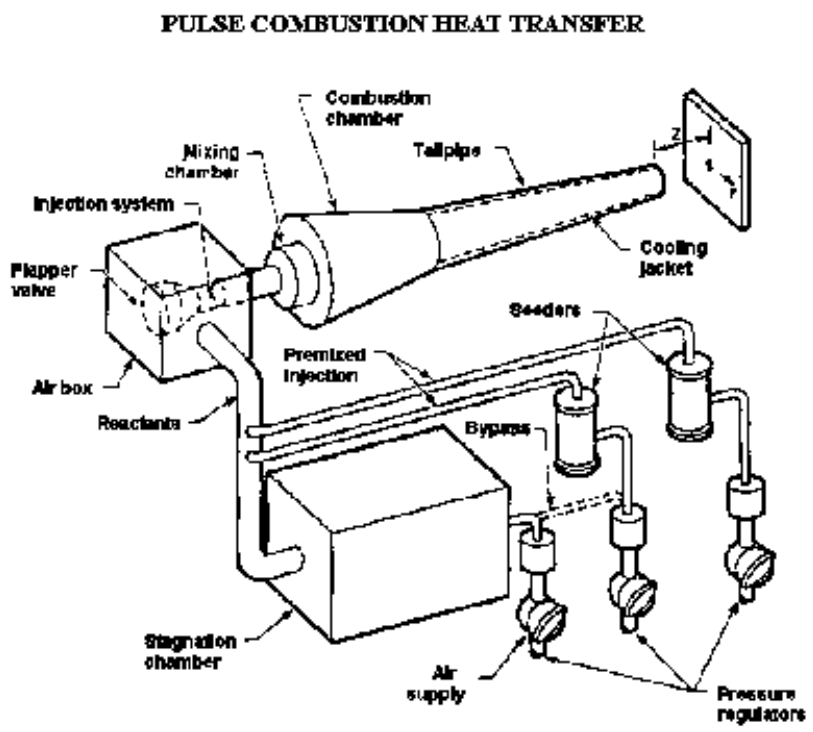
one would be hard pressed to duplicate the Eibeck result by merely using the data published in his paper. The published study makes extensive use of nondimensional results, and meticulously avoids raw data. Though nondimensional results and analysis are common in gas dynamics, convention dictates some traceability to raw data so another researcher could duplicate the findings. In Eibeck, this is systematically missing.

This becomes even more significant because some of Eibeck's results are not self consistent. Clearly, Eibeck was not fully compensating gas properties like heat capacity, viscosity, density, and diffusivity for state variables like local temperature, pressure, turbulence, and species concentration. After two weeks of reverse engineering, the grantee was able to deduce what experiment Eibeck had actually performed.

To calculate Eibeck's "steady" process, start with the published Reynolds number (6630), temperature (1709F), and diameter $(1.97 \mathrm{In})$, and calculate the steady gas velocity (68.3 fps) and mass flow (21.2 SCFM). Combine these with the heat release (75 K-BTU/Hr-sf) to calculate the adiabatic flame temperature $(2595 \mathrm{~F})$ and tailpipe heat loss (28.3 K-BTU/Hr). 
DE-FG36-03G013009

PC Engineering

To find plate heat flow, balance hot jet absorption with black body radiation (estimated $70 \mathrm{~F}$ surroundings). This yields plate temperatures that agree with the paper's "nondimensional" data, and confirms the grantee's calculations of ambient temperature, adiabatic flame temperature, mass flow, tailpipe heat loss, average plate temperature, and plate emissivity. These are not published in the paper.

\subsubsection{EIBECK Z/D=2 STEADY EXPERIMENTAL RESULT}

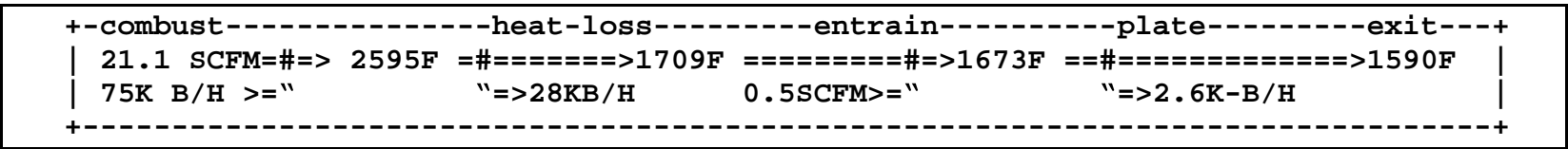

The above balance is obtained for Eibeck's steady flow heat transfer, an experiment that should agree with Martin's equations. This result is obtained for a nozzle height of $h / D=2$, that is, the height of the impinging nozzle above the impingement plate " $h$ " is two times the diameter of the impinging nozzle.

In the steady case above, only $3.5 \%$ of the input heat convects onto the plate, and heat absorption is nearly isothermal ( $1673 \mathrm{~F}$ to $1590 \mathrm{~F})$. Despite this, the steady heat transfer result agrees within $10 \%$ of Martin's model. The other steady cases $(h / D=3,4)$ agree within $50 \%$ of Martin's model, and are credible.

\subsubsection{EIBECK $h / D=4$ PULSED EXPERIMENTAL RESULT}

Eiebeck's pulsed case Reynolds Number is not consistent with other data in the paper, and several observations by the author are unsupported. Despite these drawbacks, the pulsed $h / D=2,3$ data appears to genuinely show a $2.1 \mathrm{X}$ to $2.5 \mathrm{X}$ heat transfer enhancement $(E n=2.1->2.5)$.

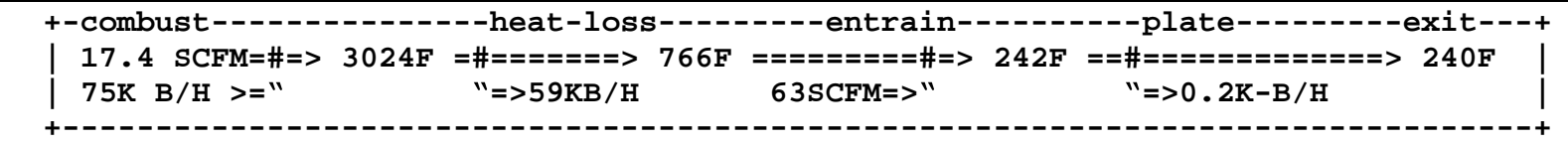

The $\mathrm{h} / \mathrm{D}=4$ pulsed case above produces a $3.1 \mathrm{X}$ heat transfer enhancement, but is not credible. Only $0.27 \%$ of the input heat convects to the plate, a difficult heat flow to measure. Heat loss and mixing cools the $3024 \mathrm{~F}$ combustion gas to only $242 \mathrm{~F}$ at the alumina plate's surface. The plate's average surface temperature is $223 \mathrm{~F}$, well below the accuracy range of a two wave length infrared thermometer. 


\subsubsection{EIBECK DISCOVERY - TOROIDS}

The Eibeck paper contains a finite difference (FD) model of his impinging flow regime. The model was clearly performed in the FLUENT environment. Documentation of the model is better than the paper's overall standards, and one could reproduce his result from the documentation. However, the boundary conditions of the model do not match the boundaries of his experiment, a condition not mentioned in the paper. In the model, the gas domain is trapped between the impinging plate and a wall parallel with the impingement surface. In the experiment, the nozzle exited into open air with no boundary parallel to the impinging plate, the boundary conditions used by Martin in his single nozzle data (see diagram at right).

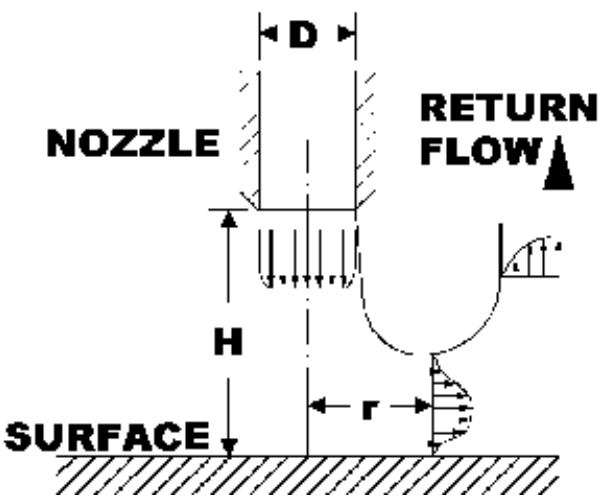

The FD model shows the pulsing flow forming a toroid at the nozzle and propagating to the impingement surface where it attaches, spreads, and propagates outward. The value of this flow pattern is not dwelled upon in the Eibeck paper, but the grantee views this as a major discovery, and crucial to ongoing research and eventual commercialization.

For readers unfamiliar with gas dynamics, the toroid is an "irrotational" flow, a counterintuitive behavior because toroid flows, like smoke rings, appear to rotate.

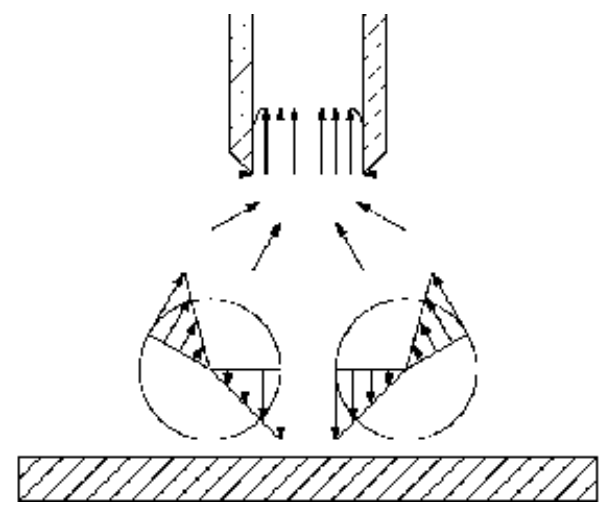
However, inside the a toroid, concentric layers of gas are moving without frictional dissipation, so a toroid is a long lived and coherent phenomena. The wing tip vortex from an airplane is a toroid stretched out into a line, and these have the reputation for lingering near a runway, and disturbing subsequent airplanes.

Eibeck's toroid explains why pulsed flow has such promise. In Martin flow, the incoming gas begins to back mix with ambient air as soon as it exits the nozzle. In toroid flow, the incoming gas is "locked" inside the toroid, and travels to the impingement surface largely unmixed. Once Martin flow impinges, it turns ninety degrees, scrubbing the surface, and creating the heat transfer peak seen so prominently at $r / D=2$, after which cold wet air is trapped next to the surface. In stark contrast, the toroid flow encounters the impingement surface and attaches under Bernoulli forces, and subsequently spreads like a conveyor belt, forcing hot dry gas onto the impingement plate, then lifting the cold wet gas up and replacing it with more virgin gas. This "conveyor belt flow" may appear in the evaporation data taken for this grant, but higher resolution impingement data is needed to confirm this finding.

In short, the toroid flow is a major component to pulse impingement drying, and is both a valuable asset in its presence, and an engineering challenge to understand, control, and exploit. 


\subsubsection{EIBECK CONCLUSION}

Despite numerous problems, Eibeck's experiment does support a $2 X-2.5 X$ heat transfer enhancement. This robust heat transfer enhancement occurs at a Wave Number of 7 $(\mathrm{Wn}=7.0)$, an extremely aggressive reversing flow. Although this heat transfer enhancement would be economically valuable for the paper industry, the extreme Wave Number would invite surface damage to the paper, and a major noise abatement issue.

\subsection{PULSE PROCESS}

The Eibeck result was obtained with a pulse burner. By the grantee's standards, the Eibeck burner is primitive, using premixed air fuel and a flapper valve. The modern pulse burner uses a mechanical air valve and direct fuel injection, giving modern burners much better turn down in firing rate, typically $300 \%$. This provides pulse burners much wider access to downstream processes, like pulse drying. The Eibeck burner could never be used in commercial operation because its turn down is shallow (about $50 \%$ ), its flapper valve breathing has high pressure drop, and the flapper valve itself has a very short service life.

The Eibeck result does provide the paper manufacturing industry with a significant profit opportunity. Finally, heat flow can be decoupled from heat transfer rate by using pulsed air flows, so the $25 \%$ efficient impingement drying process can be re-engineered into a $70 \%$ thermally efficient pulse drying process, merely by oscillating the impinging hot gas. Let us examine how this effects the paper drying process.

Hot gas is generated for paper drying by a preheated air burner, and flows through graduated cross section piping, through the impingement nozzles and onto the moving paper surface. Typical hot zone nozzle flow is $900 \mathrm{~F}, \mathrm{Re}=10 \mathrm{~K}, 3 \%$ open area, with .25 [in] nozzles at .625 [in] height $(\mathrm{h} / \mathrm{D}=2.5)$. The pressure drop for this nozzle is about 13 [in W.C.].

Let's assume a Wave Number of seven is required (the Eibeck result). This gives a peak Reynolds number of 70,000, or an increase in peak gas velocity from 23000 [FPM] to 161,000 [FPM], which exceeds the speed of sound for this gas temperature $\left(\mathrm{a}=(\gamma \mathrm{RT})^{5}\right)$, or 109,000 [FPM]. For those readers unfamiliar with compressible gas dynamics, this velocity is not only way above what the sheet of paper could realistically endure, the pressures required to generate a Mach wave at this temperature (about 15PSI) puts an enormous electric penalty on the fan that must drive the nozzle, not to mention the shock wave damage that would accumulate at the nozzle exit, along with the mach wave damage that would also occur upstream in the piping whenever the local sound speed exceeded Mach 1.

In short, the Eibeck finding of excess heat transfer at a Wave Number of 7 is of virtually no practical value to the paper manufacturing industry.

If we assume that the Eibeck result of heat transfer enhancement can be demonstrated at a lower Wave Number, then a similar calculation can be performed to size the fan required to drive the process. But even at a Wave Number of 3.5, the gas flow is in the compressible range, and fan pressures are in the 5 [PSI] range, an order of magnitude 
greater than fans in the tissue industry, which already consume enormous energy. Lets examine the process ramifications of fan pressures in this range.

First, we must examine the market to find what fan styles are available in this pressure range, and the choices are few. The process engineer would like to choose a radial flow fan with aerodynamic blades, a "Cadillac" fan with high efficiency and low maintenance, because no bearings are exposed to the hot gas flow. However, even in extreme cases, the pressures available from a single stage centrifugal fan is limited to less than 1 [PSI]. This means we must use a multi stage centrifugal stack, like a Lamson fan, which is significantly more expensive than a single stage centrifugal. Also, the fan will need water cooled bearings, and every time the water cooling fails, the plant must be shut down for repairs because the bearings seize soon after coolant failure. Though possible, this process solution is not commercially attractive.

A second fan choice would be to use a positive displacement fan, like a Roots blower, a radial vane blower, or a piston style compressor. These are all high friction devices with relatively short service lives so they would need a steady supply of planned maintenance. More seriously, these positive displacement fans require a steady gas flow to pump properly, and the intermittent flow of the pulse process would require exotic decoupling piping or reservoirs. A potential match is available between the pulsed output of a piston compressor and the flow requirements of the pulse drying process. However, this is a high friction solution with a modest service life and limited efficiency. Once again, a less than satisfactory choice.

Although the Eibeck pulse burner would not last in an industrial environment, a modern mechanically valved pulse burner would The grantee has build eight such burners that have accumulated over 250,000 hours of industrial use. Several of the burners operated for five years before even having an inspection, and often that was voluntary and not caused by burner failure. This style of burner is more reliable than the piping train that controls its fuel supply.

The grantee desired to know what the theoretical limits were to the pressure and temperature envelopes of a mechanically valved pulse burner. Laboratory tests have generated pressures of 5 [PSI], but the theoretical maximum pressure is only calculable from a six simultaneous equation transcendental calculus problem. The solution to that problem required two weeks of engineering time, and is included in the appendix of this report. The net result was that a pulse burner operating at the modest output temperature of $2000 \mathrm{~F}$ is capable of generating 90 [PSI] internal pressure, and yet operating pulse burners at this temperature seldom exceed 5 [PSI], even when gas dynamic resonance is amplifying the peak pressure. This result tells us that past pulse burners are mixing limited, as are conventional register burners.

This result first points out that pulse burners are theoretically capable of generating the entire range of pressures and temperatures that a pulse drying process would require. However, the engineering details of how to precisely match the burner with the drying process is currently unexplored. Given the complete lack of commercial use of pulse burners, there are virtually no manufacturers that are in a cash flow position to invest in developing this knowledge. We will discuss this problem in the commercialization 
phase of this report. Though gas modeling is helpful in modeling the evaporation process, it is highly limited as a tool for modeling the pulse burner process, so we are left with physical construction and bench top testing to advance the variable space of pulse burners.

The grantee has been keeping a personal journal of pulse burner inventions since September 19, 1998 when the intellectual property agreement with his last employer expired. Since then, the invention journal has expanded to 149 pages of inventions spanning a wide range of burner designs, including externally fired burners, steam driven oscillators, and others perfectly capable of generating the entire 90 [PSI] that is theoretically available to a mechanically valved pulse burner. However, among these inventions, the cost and engineering complexity of the designs varies greatly.

The above discussion suggests that the design of a pulse burner that is well matched to the pulse drying process is a necessity for successful commercialization of the technology, and this design will require some form of experimental development. There are currently no identifiable industrial sources of support for this radical of a product development project.

\subsection{GRANT PROPOSAL}

The proposal for the current grant resulted from the footnote on the Eibeck study attributing the DOE's Inventions and Innovation program for funding the study. At that time, academia had two sources of pulsed impingement data, one near $\mathrm{Wn}=1$ [2], and a single data point at $\mathrm{Wn}=7$ [3]. Between these, there was no data and nothing like the complete analysis and design guides that Martin had published on steady impingement in 1975 [1].

The grantee proposed measuring pulsed

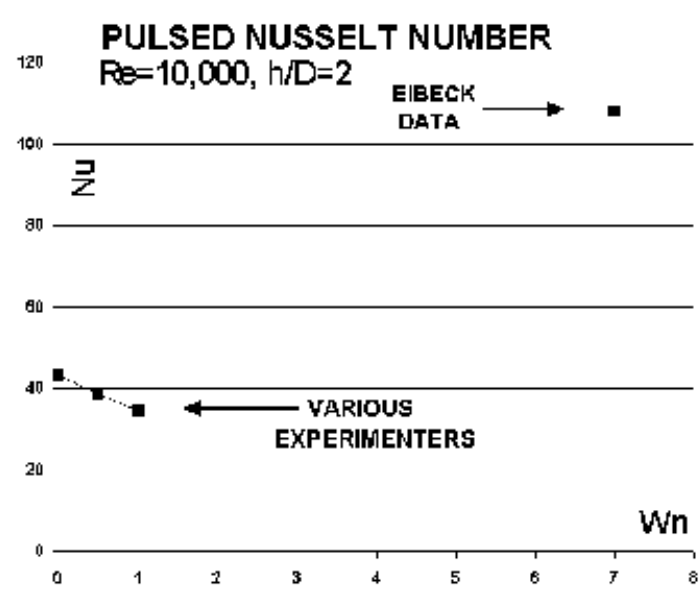
impingement in the intervening data space between these two studies by building a test stand that would measure evaporation in a wide range of Reynolds Numbers and Wave Numbers over the surface of an impingement plate.

The proposal also included construction of a pulse burner designed to demonstrate enhanced evaporation in a scaled up test for an unspecified paper manufacturer. The grantee has extensive experience designing equipment in the industrial fields of chemicals, animal feed milling, $3 \mathrm{~A}$ consumable foods, incinerators, powder heat transfer, pneumatic conveying, pulse drying, biological fermentation, ceramics calcining, kiln burners, and hazardous volatile processing. These industries require a scaled test before committing to a production scaled equipment in a live factory.

Three deliverables were defined in the grant proposal. The milestone table from the proposal is reproduced here. 
DE-FG36-03G013009

PC Engineering

\begin{tabular}{|l|l|l|l|l|l|}
\hline $\begin{array}{l}\text { Task } \\
\text { Number }\end{array}$ & Task Title & $\begin{array}{l}\text { Est. Finish } \\
(\text { Mos. })\end{array}$ & $\begin{array}{l}\text { Responsibl } \\
\text { e Individual }\end{array}$ & $\begin{array}{l}\text { Federal } \\
\text { Cost }\end{array}$ & $\begin{array}{l}\text { Shared } \\
\text { Cost }\end{array}$ \\
\hline Milestone 1 & Evaporator experiment & & States & & \\
\hline Task 1.1 & Build / buy parts & $3(3-03)$ & & $\$ 60,000$ & \\
\hline Task 1.2 & Assemble & $4(4-03)$ & & & \\
\hline Task 1.3 & Run manually & $6(6-03)$ & & $\$ 8,000$ & \\
\hline Task 1.4 & Program controls & $10(10-03)$ & & $\$ 59,000$ & \\
\hline Task 1.5 & Finish data runs & $15(3-04)$ & & & \\
\hline Milestone 2 & Modeling & & States & & \\
\hline Task 2.1 & Program data file transfer & $6(6-03)$ & & & $\$ 8,000$ \\
\hline Task 2.2 & Regression analysis & $16(4-04)$ & & & $\$ 34,000$ \\
\hline Task 2.3 & Data plots and report & $17(5-04)$ & & $\$ 2,000$ & $\$ 8,000$ \\
\hline Task 2.4 & ADINA model & $21(9-04)$ & & $\$ 35,000$ & $\$ 25,000$ \\
\hline Milestone 3 & Build pulse burner & & States & & \\
\hline Task 3.1 & Design burner & $21(9-04)$ & & & $\$ 25,000$ \\
\hline Task 3.2 & Supervise buyouts & $22(10-04)$ & & $\$ 36,000$ & \\
\hline Task 3.3 & Assemble & $24(12-04)$ & & & \\
\hline TOTAL & & & & $\$ 200,000$ & $\$ 100,000$ \\
\hline
\end{tabular}

To briefly summarize the milestone table, $42 \%$ of the grant funds were devoted to building and running the evaporator experiment, $37 \%$ devoted to analysis of the evaporator data, including finite difference modeling using the ADINA environment, and $20 \%$ devoted to construction of a demonstration scale burner, although the grant deliverables did not include buyouts of utilities or ancillaries for the burner (like the piping train, controls, etc.) or operation of the burner. The intent was to operate the burner at test facility where ancillaries and controls would already exist, and the burner would be built to conveniently accommodate the existing equipment.

\subsection{GRANT PRELIMINARIES}

After formal notification of the award, the grantee performed an exhaustive review of the documentation, FAR regulations, intellectual property guidelines, and reporting requirements. The grantee had performed several million dollars in industrial research and consulting in the past, but this was the first grant application and award of a federal project.

The grant included support contract from two service organizations, New Horizons, which performed a market survey, and Vista Ventures, who had ancillary contact during the grant period.

The grantee had committed to presenting pulse drying papers at two trade shows before receiving the grant, one at the TAPPI conference in Chicago on May 15, 2003, and the second at the ISA 2003 Expo in Houston Texas, October 22, 2003. These were pivotal in understanding the financial and marketing characteristics of the paper manufacturing industry.

\subsection{MARKETING DISCOVERIES}


The grant proposal contained no milestones, budget, or reference to marketing or market research in the paper manufacturing industry. The proposal did describe a cold call marketing campaign the grantee performed in 1999, where thirteen major paper manufacturers were contacted and eventual telephone interviews were conducted with their research departments, partly to discover their current areas of investigation, and partly to inform them of the availability of pulse drying technology. The knowledge gained during those telephone conversations was the source of the grant's marketing strategy.

The first trade show, the TAPPI conference in Chicago, completely changed the grantee's understanding of the paper equipment market, how equipment is developed and sold, and how equipment is operated commercially. The revelations from that trade show were the most important marketing information in this grant project.

It is perhaps most instructive to compare the paper industry with other US industrial markets. Paper manufacturers have been doing virtually the same thing for four decades. With minor modifications, pulp is still extracted using the Kraft process, the paper web is still deposited from a head box in a water suspension that is mechanically and then evaporatively dewatered. Innovations in the paper industry are generally incremental, particularly the current practices of wet coatings, post drying deformation and finishing, vacuum dewatering, and a host of ancillary improvements.

Because the paper making process is fundamentally unchanged since the 1950's, the market is "mature", meaning saturated with production capacity, competitively vigorous at bidding prices and costs down, and generally producing profits at or below the capital asset line of money markets. Though a few specialty paper markets perform financially well, the overall market is barely performing above what a certificate of deposit would return, and the CD holder merely collects interest and has no factory to run.

Contrast this market with the chemical industry, similar in that both are capital intensive, and both require manufacturing equipment that is unique to their end product. However, few chemicals now produced had even been discovered in the 1950's, so few sectors of the chemical market are "mature". Most chemicals produced today sell at a significant premiums over cost, many are covered by patents which allow them to be priced as monopoly goods, while others are so difficult to produce that trade secrets are adequate for protecting their market.

Selling equipment into the chemical industry is difficult, but comparatively simple compared to the arduous, expensive, and nearly perpetual process of selling equipment to the paper manufacturing industry. Without belaboring the details, a prevailing attitude among paper manufacturing companies is that all the good ideas have already been discovered, and what is left are small improvements to the existing system, which is already well optimized from forty years of use.

This attitude is so pervasive in the paper industry that the majority of paper manufacturing companies don't even employ a Research and Development department. When the grantee attended the TAPPI conference in 2003, only two of the 23 scientists surveyed in 1999 were still employed in their respective research departments. In the 
interim, most domestic paper manufacturers had been acquired, merged, or sold assets off in the active acquisition environment brought on by low profits in the industry. Despite these major industry shifts, no company division in the newsprint market showed a single dollar of profit from 1999 through 2003, despite billions invested.

In the chemical industry, a scale test is perfectly acceptable for demonstrating a production technology. The purchasing companies often employ top notch engineers and research chemists that actively participate in the development of equipment that will be sold to them. When equipment is installed in the field, both the buyer and the seller expect a period of "initial" startup where performance will be acceptable, but eventual performance will be much better as experience with the equipment accumulates.

The paper industry is nearly the opposite of this. The industry has no research scientists, although they do have an abundance of "scientific technicians" who's major purpose is to optimize the performance of capital equipment the company currently owns, or to appraise the health of capital equipment the company may be evaluating for acquisition.

Before a paper manufacturing company invests in any piece of production equipment, they require a nearly full scale test on their product. Though companies used to maintain test facilities, or paper plants that could accommodate testing, it is nearly universal now that all tests of prospective equipment are performed at the dozen or so commercial test facilities around the country. These test facilities will configure their paper manufacturing equipment to resemble the target facility, including style of pulp extraction, head board style, and dewatering equipment.

\subsection{MARKETING IMPACT ON GRANT DELIVERABLES}

This market understanding had its first impact on the grant's burner construction task. Since the industry is only interested in a full scale test, a scaled down burner is of no use in performing tests, advancing commercialization, or of even advancing understanding of the pulse burner's exotic gas dynamic transfer function. Therefore, the end goal of the burner construction experiment was useless for its originally intended purpose, scale demonstration of pulse drying.

The end goal of the burner construction task was then altered, to an actually valuable goal of measuring the complex gas impedance of the pulse burner at a wide variety of temperatures, dilution rates, and stoichiometric ratios. Past burners have been used in the powder market where reverse flow could not be tolerated. We see that the paper market requires reverse flow, so this adds a process demand to the pulse burner that had not previously existed.

Instead, the burner constructed under this grant is strictly a test object meant to help evaluate its variable space. Before the technology can be demonstrated, an evaluation of the pulse burner's performance in low temperature, high cooling air operation must be conducted. The rational for this test is described later in this report. The grant proposal was intentionally written with a burner deliverable that was not specified in thermal size or operating envelope, although it proposed that a demonstration scale 
burner is a likely candidate. So, construction of the bench test scale burner was consistent with the original grant's written deliverables and commercialization goals.

\subsection{TAPPI TRADE SHOW RESULTS}

Part of the reason for attending the 2003 TAPPI trade show in Chicago was to gain first hand knowledge about the marketing characteristics of the paper manufacturing industry and its equipment buying requirements. The second reason for attending the TAPPI conference was to follow the P\&G - IPST project [6]. Lets examine the significance of that event.

While the grantee was Chief Engineer of the J. Jireh Corporation (1995-1998, now called PCS, short for Pulse Combustion Systems), we received a call from Proctor and Gamble. They discussed, in vague and couched terms, a pulse project they were working on. Over the ensuing three years, we signed NDA's with P\&G, and eventually became aware of their project to pulse dry paper. Though it took a while to understand, the vision of their project was the identical vision of the current grant, to marry a pulse burner to a paper drying machine.

Six years later, at the TAPPI conference, P\&G had abandoned the technology and given their test apparatus, patents, and development revenue to IPST, an independent paper research organization that is now part of the Georgia Institute of Technology. The TAPPI conference was the first public presentation of the results of the P\&G - IPST study. P\&G had previously performed successful tests before the IPST collaboration, using an air valved Rijke burner, and the TAPPI results were from a scaled up test with a mechanically valved burner.

The TAPPI presentation was given by Dr. Fred Ahrens, and ironically, it was at the same technical session that the grantee presented his analysis of the pulse drying process. The detailed reports of the P\&G collaboration were contained in the conference proceedings [6].

The Ahrens presentation was insightful, and nearly unbelievable. In the twenty minute span of the presentation, the grantee recognized six major process mistakes the team had built into the test apparatus. Any one of the mistakes was sufficient to significantly damage, or completely prohibit, heat transfer enhancement effects. The net result of all of them was a systematic and organized experimental failure. In Reynolds territory above 7000, the turbulent zone, all heat transfer coefficients were below the Martin steady state values. The presentation of the data by IPST was generally confusing in their choice of abscissa and ordinate. The paper was somewhat sufficient to reverse engineer what was done during most of the tests, but the confusing data presentation indicated that they knew to look for heat transfer enhancement, but didn't understand what factors drove it.

The grantee's eleven years of experience in the pulse powder industry gave a perspective on nonsteady gas dynamics that neither IPST nor $P \& G$ possessed during their brief three year collaboration. 
DE-FG36-03G013009

PC Engineering

Though a family of insights were transmitted that day, the most fundamental of all was a vindication of the grantee's approach - first measure when the pulse drying process works, and only then should you build an expensive burner and test apparatus. In direct opposition to this development philosophy, the P\&G strategy was to put a nozzle on a pulse burner, aim it at some wet paper, and measure what happens.

If one examines the Azevedo result, the $P \& G$ approach does not seem all that unrealistic. Azevedo found a pulse process that was single valued, monotonic, and free of resonance behavior. However, the results that are detailed in this report show that Azevedo was an optimist. His results only pertain to the stagnation point in a low Wave Number impingement process. When one applies pulse drying to a real world situation, there is abundant evidence that the process is not single valued, not monotonic, and contains at least two resonance phenomena. Randomly placing a pulse driver into this variable space is asking for good luck, not commercial success. The machine is just as likely to hit a heat transfer hole as to hit a heat transfer hill, and it is statistically unlikely to capitalize on one or more of the processes resonance peaks. If these peaks have negative stability, the P\&G approach will never work.

\subsection{FINITE DIFFERENCE MODELING (MILESTONE 2 DELIVERABLE)}

Milestone 2 of the proposal deliverables contains a variety of data modeling projects, including an ADINA finite difference model of the impingement flow field. Most of the data modeling goals of Milestone 2 were performed as proposed, but the modeling milestone failed to produce valuable results.

ADINA is an exotic finite element and finite difference modeling environment noted for its nearly limitless user options to perform nonlinear analysis and linked models. It permits time varying boundary conditions and time marched solutions, so it should make short work of the impingement zone modeling.

The impingement domain is complicated because it is time varying, but simple because it is axially symmetric and can be modeled in two dimensions. The 2D characteristic saves enormously on model setup time and model computational time, and can be performed on ADINA's low node count model, which permits the user 900 nodes. The full version of ADINA costs $\$ 35 \mathrm{~K}$, while the low node version is only $\$ 100$.

Soon into the modeling effort, the grantee encountered problems getting the domain to solve for rotational flows. This is a standard feature in Fluent and Blue Ridge Numerics. The grantee is factory trained in all three environments.

After contacting ADINA support, we learned that ADINA does not support rotational flows in their 2D computational domains, and they Emailed a "pie slice" 3D domain model. This is generated using ADINA's SKEWSYSTEM and requires radial boundary conditions to be defined twice, once for each surface of the pie slice.

This 3D modeling environment truly crippled the plan for modeling the impingement zone. The plan was to get a single model with time varying boundary conditions to correlate with a corresponding heat transfer result from the experiment. Then the model would be used to perform sensitivity analysis for a variety of flow situations that were 
not built into the evaporator experiment, but showed promise in the modeling environment.

The absence of 3D swirl flows in ADINA's 2D environment effectively stopped the fundamental usefulness of this portion of the project. Although considerable engineering effort was expended in this modeling effort, no deliverable modeling results were produced.

ADINA commented that swirl flows in their $2 \mathrm{D}$ environment would be a useful feature. The grantee will monitor their product to see when this feature is integrated into ADINA.

It is unusual to find a modeling shortcoming like this in the ADINA environment.

\subsection{MILESTONE 1}

\subsection{EVAPORATOR OVERVIEW}

Past experimenters have created pulsed flows in the laboratory and measured heat transfer coefficients. In all previous cases, limited locations in process space were measured. The present grant project is the first time an apparatus was specifically designed to measure impingement heat transfer in a generalized way over a broad range of Reynolds numbers, Wave Numbers, radial distances from the impingement nozzle, nozzle heights above the evaporation plate, and for a complicated array of Fourier harmonics in the impinging wave form.

Parts of the experiment worked flawlessly, including the solenoid micro-pumps, the Umack controller (with the exception of a QMX and a ROM failure), the fans and the regulating manifold arrays, the automatic water reservoir fill system, and the orifice plate and Dwyer 460 pressure sensor used to calibrate air flow in each run. The air valve piping worked well after the fourth piping iteration.

Although this first try generated breakthrough results, several experimental problems limited the experiment's overall variable space coverage, accuracy, and Fourier flexibility. Briefly, the major problems encountered included:

1) pressure probe $D C$ drift,

2) stepper motor frequency response, and

3) air valve balance.

These problems, and their solutions, will be detailed below, but their overall effect on the data gathered was limiting, but not fatal.

The original experiment was designed to operate unattended for days or weeks, meticulously gathering highly accurate heat transfer data that would later be uploaded to an analysis environment for consolidation and analysis. However, the DC drift behavior of the pressure probes made the evaporation rate unobservable by the controller, even if the pressure signals were ARIMA filtered. This meant that each run had to be started individually, terminated by manual command, and the individual pressure readings captured to the PC based analysis environment where the evaporation rates were determined manually. In this environment, slight differences in 
PC Engineering

air valve speed were beyond the resolution of evaporation rate detection, so the experiment was limited to large frequency differentials, like 10's of Hertz, instead of subtle frequency differentials under 1 Hertz. DC drift placed similar limits on Wave Number resolution, Fourier harmonic resolution, and Reynolds number resolution.

The stepper motor's specifications implied, and the manufacturer's technical representatives confirmed, that the motor was capable of shaft speed up to 10,000 RPM. After extended experiments, failures, and troubleshooting with the manufacturer, it became clear the actual limit to stepper motor shaft speed was closer to 1200 RPM. The net effect of this problem was a near prohibition on higher Fourier harmonic analysis. However, even if the motor had performed at 10,000 RPM, the resolution of the pressure probes was insufficient to distinguish subtle contributions to heat transfer rate from third and forth air flow harmonics, the most likely secondary contributors.

The air valve was manufactured from aluminum bar stock by a fully automated and numerically controlled milling machine. The entire stator was milled correctly, and all micrometer measurements conformed to design drawings. Four rotors were produced for the valve, and the high resolution rotor designed for the evaporator had significant machining and balance problems that were not detected during initial inspection at the vendor. The rotor had 5 mills of run out, in an assembly designed for 3 mills of concentric clearance. This run out was the result of a manual chuck operation in the milling machine, so the two most tightly controlled surfaces on the rotor were not cut with the same machine setup.

Once the rotor was dynamically tested, it was soon clear that the blind balance the rotor was designed for was insufficient. In a "blind balance", the density of the rotor's bar stock is assumed uniform, and an accurate machine operation leaves the rotor's mass tensor directly in line with its rotational axis. It was almost unbelievable how off this assumption was. The rotor was eventually hand balanced by the grantee, a delicate operation that consumed nearly three weeks. In a rotor that weighed 120 grams, the balance weights added to reduce mass tensor alignment to under 0.05 gram inches was over twenty grams.

Once the rotor was dynamically balanced, and the motor mount shimmed to compensate for the manufactured 5-mill run out, the grantee discovered the stepper motor face was machined 3 mills out of perpendicular with the shaft axis.

Overall, balance and assembly of the air valve consumed five weeks of the project schedule, while original schedule estimates placed the assembly time at a few minutes. In retrospect, the rotor should have been dynamically balanced and operated live by the machining vendor, or quality inspected by an outside agent.

The experiment's original variable space coverage was over designed to exhaustively cover the areas of interest to the paper manufacturing industry, along with a wide variety of extensions to this space. After coping with experimental difficulties, the variable space was reduced, but complete coverage of the prime area of interest was still accomplished. The industry operates their dryers at a Reynolds number of 10,000 
and a Wave Number of 0 . The experiment covered Reynolds numbers from 5,000 to 15,000, Wave Numbers from 0 through 4.5, and frequencies from zero to 30 Hertz.

\subsubsection{EVAPORATOR CONSTRUCTION}

Let us now examine the results generated by the evaporation experiment. First, we will document the construction details, control philosophy, and apparatus successes and failures. The reader is reminded that construction details of the air valve are not included in this report because its design predated the grant application and is part of a larger intellectual property strategy that pertains to pulse drying.

\subsubsection{CONSTRUCTION DETAILS}

A low resolution version of the evaporator's PID (Piping and Instrumentation Diagram) is shown at right for reference, while a full resolution version is included in the Appendices of this report. The PID conforms to ISA standard S5.1.

The design has two circuits, the air circuit shown above, and the water circuit shown below. The air circuit draws ambient air through a filter, an air conditioner (designed to control the dew point), and fans, then into an

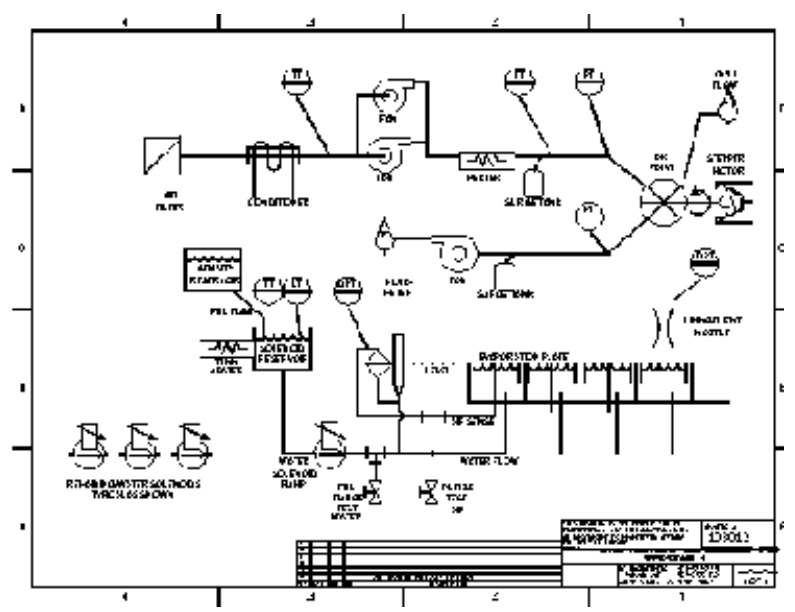
electric heater, decoupling reservoirs and into the stepping motor controlled air valve.

The water circuit draws temperature controlled water from a reservoir, pipes it through a micro-solenoid pump and into a segment of the evaporator plate. A tubed hole in the plate's segments sense stagnation air pressure.

The control element of the water circuit is a differential pressure sensor which is located level with the impingement plate. The water circuit is tubed to one side of the pressure sensor, and the stagnation pressure is tubed to the opposite side. The evaporator plate has four segments, so the pressure and solenoid circuits are repeated four times.

\subsubsection{PROBLEMS AND MODIFICATIONS TO THE CONSTRUCTION PID}

Early operation of the evaporator uncovered numerous problems with the instrumentation. Most notable were DC drift problems with the pressure sensors, Freestyle model MPX5010. These were specified to be sensitive to the differential pressures in the experiment, but in practice their pressure signal periodically and without warning drifted. An example pressure signature at right shows normal segment operation where water evaporates creating a steadily declining pressure signal, followed by a

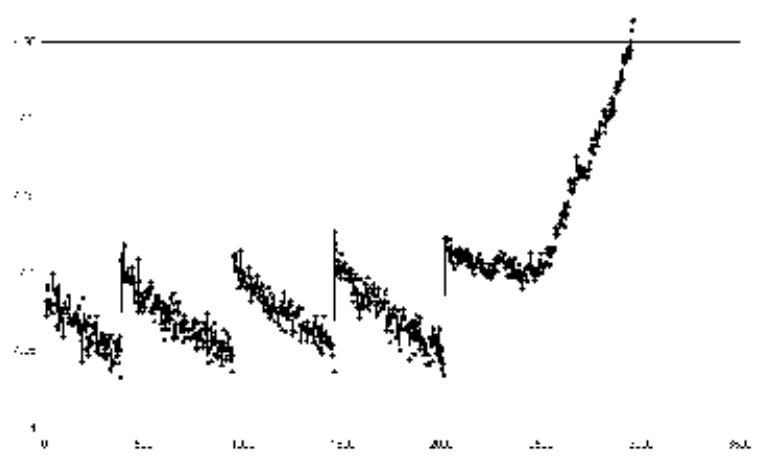

page - 25 -

of 64 
solenoid fill cycle shown as a vertical pressure rise. After the forth fill cycle, the differential pressure sensor begins to drift, no longer tracking the actual pressure in the segment. The only usable data in this run was taken before the DC drift occurred.

The pressure sensors were highly integrated into the evaporator when this behavior was discovered. They were soldered into a PC board that the grantee designed, along with manufacturer recommended filter elements on power and signal. The probe was excited by a well controlled switching power supply (+5V DC) and located well away from sources of electrical interference. The pressure signal was digitized by an Analog Devices Umack 5000 board configured with a QMX-03 analog input. This analog to digital converter operated reliably, so all problems originated with the pressure probes.

The problem was clearly exacerbated by temperature changes. When an external heat source excited the probes, all four began to drift within seconds. During operation, the probe on Segment 2 was generally reliable, those on Segment 1 and 3 less so, and the Segment 4 probe seldom tracked water pressure. The grantee changed out the Segment 4 sensor with a spare, but its subsequent operation was only marginally improved.

The evaporator was designed like the Martin experiment, where the water vapor saturation point of the inlet air matched the ambient air. This works out to an inlet dew point of $50 \mathrm{~F}$, and a heater exit of $104 \mathrm{~F}$. The 104F impinging air would have wreak havoc on the DC drift problem of the pressure sensors, essentially stopping the entire experiment. So, the process space of the experiment was modified to use ambient air instead of dew point controlled air heated to $104 \mathrm{~F}$. In this experimental mode, each trial requires a steady flow evaporation measurement, followed by nonsteady measurements. In this experimental mode, the data is self calibrating. All Enhancement Factors cited in this report are ratios between the nonsteady evaporator data, and a corresponding steady flow data that was gathered within minutes of the nonsteady data, in identical state variable conditions.

In a minor change to the water circuit, better pressure sensitivity was achieved when the circuit downstream of the solenoid pump contained no free meniscus. Also, no heater was placed on the water reservoir, it always operated at ambient temperature to avoid aggravating pressure probe drift. The pressure sensors were not located directly level with the evaporator plate, but were situated 1.5 inches below it to place the pressure sensors in a range with optimal linearity. Lastly, the pressure probes were found to have significantly different linearity in large scale pressure calibration (from .05 through 3.0 [WC]), as measured by a Dwyer Mark II, when compared to actual evaporator operation. This difference in pressure linearity is clearly related to meniscus effects on the evaporator plate itself.

\subsubsection{PLATE GEOMETRY}

For this grant, the impingement plate, impingement nozzle, and nozzle height remained fixed. The h/D used by the paper manufacturing industry is 2.5 , so with an experimental nozzle ID of 0.59 [in], the matching height is 1.5 [in]. The segment ID and OD dimensions are given below. Location of the stagnation pressure taps are given in the 3D diagram below. 
DE-FG36-03G013009

PC Engineering

\begin{tabular}{|rllll|}
\hline SEGMENT & 1 & 2 & 3 & 4 \\
ID & 0 & 1.315 & 2.875 & 4.5 \\
OD & 1.049 & 2.47 & 3.97 & 7.06 \\
\hline
\end{tabular}

The impinging nozzle is .59 [in] ID, with a length of six inches. This yields a gas path aspect ratio of 10.2, assuring us that low Reynolds number impinging flows have negligible turbulence, and higher Reynolds number flows have turbulent wall boundaries and parabolic velocity profiles. Once the flows impinge, one can expect turbulent impingement plate flow. Control of impinging air turbulence was a major factor in failure of the IPST experiments, but intentionally controlled in the current experiment.

The evaporator bed was packed with aquarium gravel. The mean sieve diameter is 0.14 , which permitted high Wave Number impinging flows without gravel movement in the packed beds. Spherical packed beds give a volumetric ratio of 0.21 (interstitial volume to gross volume). The irregularly packed gravel bed gave a volumetric ratio of 0.16 , as measured by solenoid filling.

\section{IMPINGEMENT PLATE GEOMETRY}

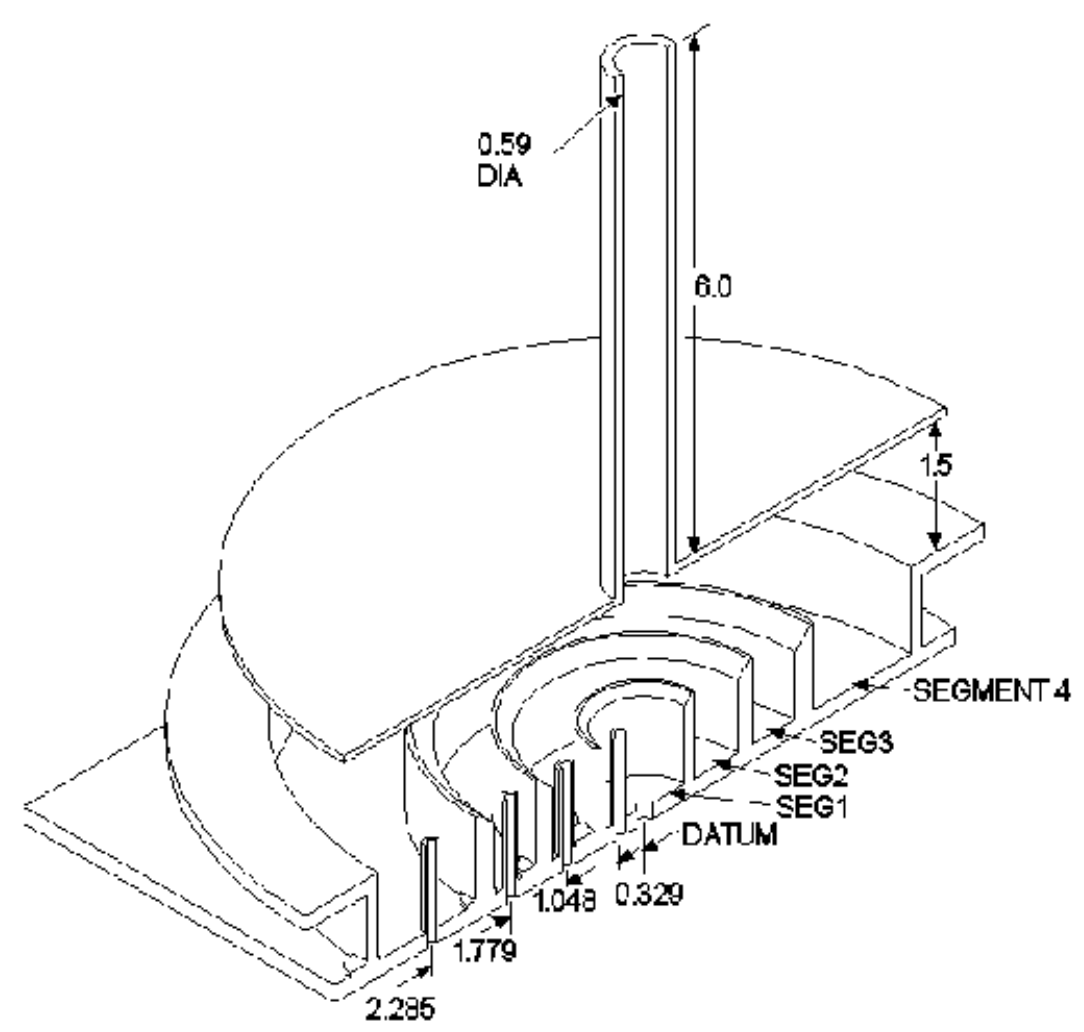

\subsection{VERIFICATION RUNS}

Verification runs establish the validity of the experiment's instrumentation and calibration. The literature's established standard in this field are the Martin regressions for steady flow. We will present calibrations of the evaporator experiment with these models. A total of four verification runs were performed at Reynolds numbers 5,7,10, and 15,000. Pressure transducer drift invalidated much data in segments 1,3 and 4 . Segment 2, located at a radial distance of $r / D=1.7$, was reliable in all verification runs, 
DE-FG36-03G013009

PC Engineering

and permitted a calculation of the data set's mean linear regression line and standard deviation. The data plots for the verification runs, and for subsequent live data runs in the nonsteady mode, are denominated in units of EVAP, or pounds of water the segment would evaporate in one hour if its area were one square foot. The range of EVAP measured in this experiment was 0.25 - 0.02 [\#/f2-Hr]. The data's internal standard error, for segment 2, was 0.02 . Minimum error is $+/-10 \%$ of measured EVAP, while maximum error is about $100 \%$ of measured EVAP, mostly in low Reynolds number flows and in Segment 4.

\section{EVAP STANDARD ERROR $=+/-0.02$ [\# of water evaporated $/ \mathrm{Sq} \mathrm{Ft}-$ Hour ] EVAP RANGE $=0.25-0.02$}

In each verification plot, the evaporation rate measured in the experiment is plotted along with the Martin prediction, matched in Reynolds number, $h / D, r / D$, and thermodynamic absorption rate (a function of the ambient dew point and temperature). The Martin predictions are consistently $35 \%$ below experimental measurements due to the turbulence induced by the excessive surface roughness of the experiment's packed gravel bed. These verifications are significantly better than those obtained by Eibeck.
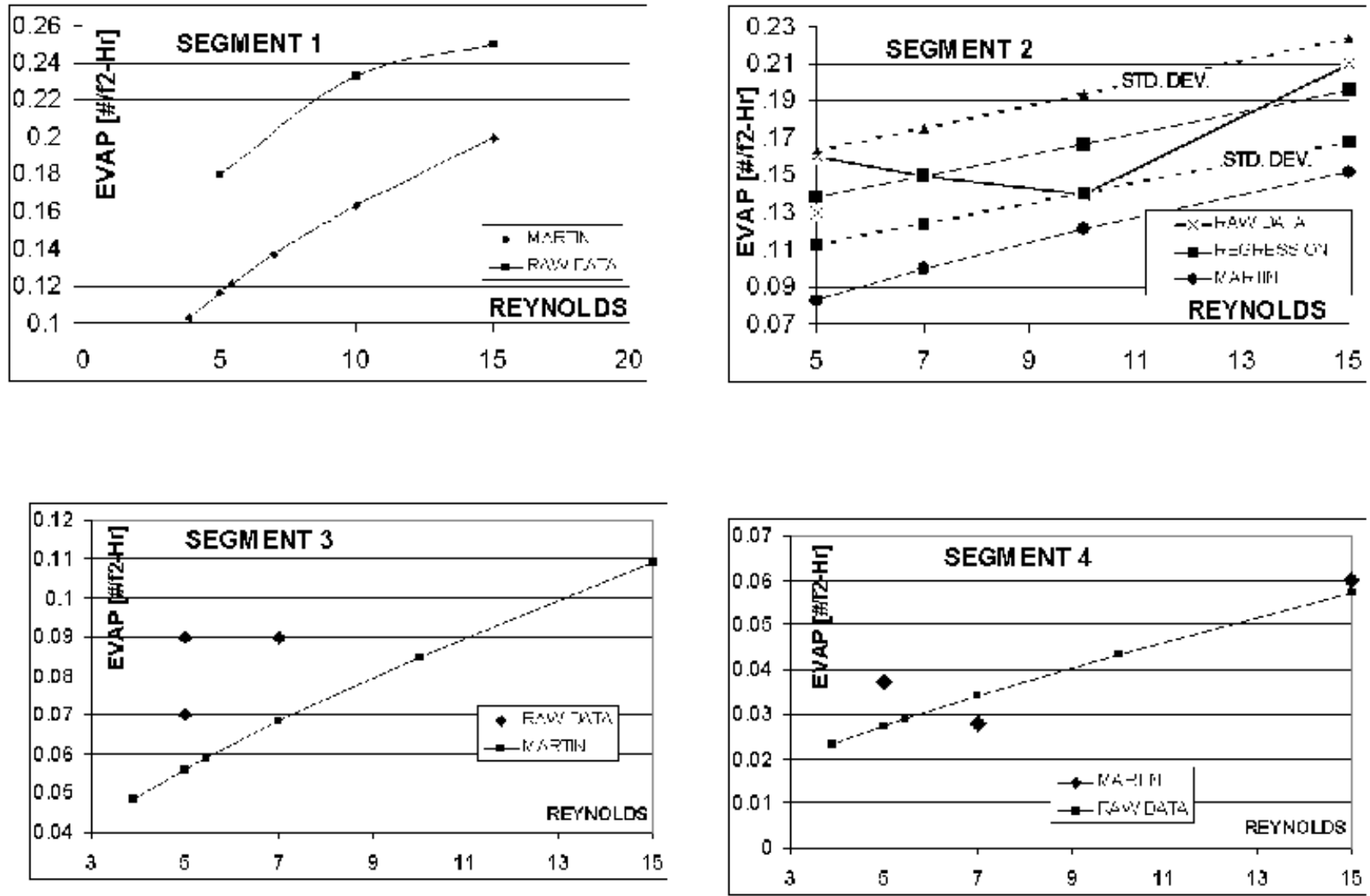

For the Reynolds number range of these tests, the measured evaporation rate shows consistent correlation with previously published data. The sparse distribution of data 
points in Segments 1,3,and 4 is a consequence of their unreliable pressure transducers. Even in Segment 4, where measurement mean is on the order of the standard deviation, raw data generally agrees with theory, both in absolute level and in data trend.
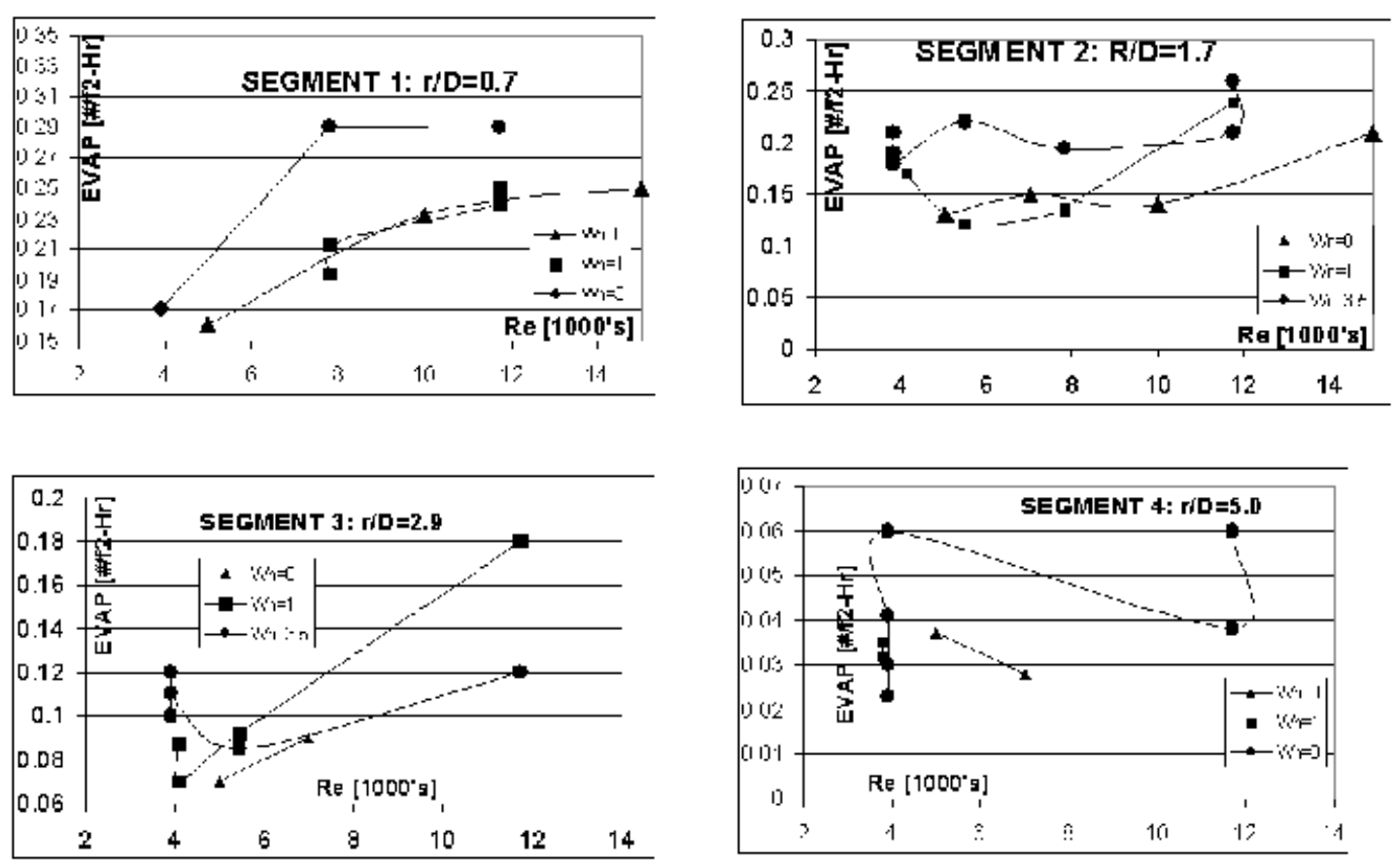

\subsection{DYNAMIC DATA}

The nonsteady data above covers three cases, the steady flow case for verification, the $\mathrm{Wn}=1$ case where nonsteady flow is simply pulsed forward flow, and the $\mathrm{Wn}=3$ (or $\mathrm{Wn}=3.5$ ) case. The first observation is how well the Wave Number nondimensionalization works. In most cases, the $\mathrm{Wn}=1$ case follows the Azevedo findings of little or slightly negative heat transfer enhancement. The $\mathrm{Wn}=3$ (or 3.5) cases consistently show heat transfer enhancement. The Segment 4 data is confusing because mean EVAP measurements are about equal to the experiment's standard error, so the data is swamped by noise. Repeated measurements could have established slightly better accuracy, but an improved experiment with an order of magnitude decline in standard error would do much better in resolving these evaporation rates, not to mention advancing the resolution of Hertz and Fourier harmonic measurements. 
When arranged as a function of Wave Number, the dynamic data shows a clear relationship with EVAP rate. However, the relationship with pulse frequency is not monotonic. The labels in the graph at right show the pulse frequency [Hz], and data there is chaotic. Lets take a detailed look at the heat transfer as a function of frequency.

The data at right was collected at Reynolds 4,000 for Wave Numbers 1.0, 3.0, and 3.5, over a pulse frequency range of $10 \mathrm{~Hz}$ to $30 \mathrm{~Hz}$, in Segment 2 . The regression fit of the data shows a rising trend in Wave Number up to $\mathrm{Wn}=2$, where EVAP peaks and then declines. In frequency, this EVAP rate peaks at 20 $\mathrm{Hz}$, and declines elsewhere. The peak evaporation rate measured during this experiment was $0.23[\# / \mathrm{f} 2-\mathrm{Hr}]$ at $\mathrm{Wn}=3$,

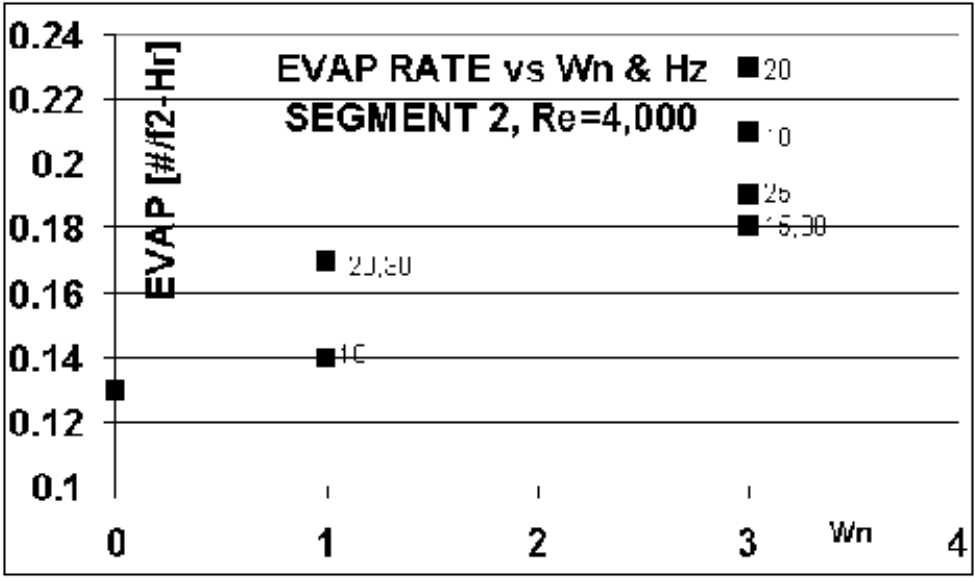
$\mathrm{Hz}=20$, so standard error is $9 \%$ of signal. The grantee observed the data for this peak EVAP case, and was impressed by the constant stream of solenoid fill cycles for Segment 2. This was clearly an exaggerated evaporation rate because water did not accumulate in the segment, despite the frequent solenoid fills triggered by the control system. This peak shows major EVAP variability with frequency, a clear indication of a time varying phenomena. A gas dynamic resonance explains this data. The grantee is hard pressed to explain this peak in any other way.

The most important finding of this regression surface is the close resemblance it bares to highly damped resonant behavior. This fits the expectation that pulse excitation would produce resonances, particularly since the driven mechanism, a toroidal vortex, has low internal dissipation and high entrained momentum. A second resonance, with more damping, must occur in the EVAP rate when the toroid has completed one full revolution. During the second revolution, cold wet air is performing evaporation, or heat transfer, and a decline in EVAP rate is expected. This second resonance is too subtle to have been detected with the current experiment's crude sensitivity, and spotty pressure probe performance.

The detection of a resonance behavior in this experiment is a breakthrough, both in understanding of the process's underlying theoretical behavior, and in practical application of this process to the paper manufacturing industry. Clearly, if Proctor and Gamble, in concert with IPST, were alert to the possibility of resonant peaks and valleys in the EVAP rate, they would have abandoned their "shotgun" approach to the process 
in favor of a more surgical analysis of the underlying phenomena, just as the grantee has pursued.

A more informative measure of pulse impingement's commercial value is the Enhancement Factor (En), the ratio of pulse heat transfer to steady flow heat transfer. In commercial drying, this is also the ratio of steady to pulses evaporation rate for the same incoming heat flow. Recall that an $\mathrm{En}=2.53$ results in an overall drying energy savings of $23 \%$, even under conservative engineering assumptions.

The graph at right compares En at a variety of Wave Numbers and pulse frequencies. Clearly, the plot shows a rising relationship between $\mathrm{Wn}$ and En, but again the relationship has a chaotic behavior in frequency that is symptomatic of an unexplored mechanism in this process.

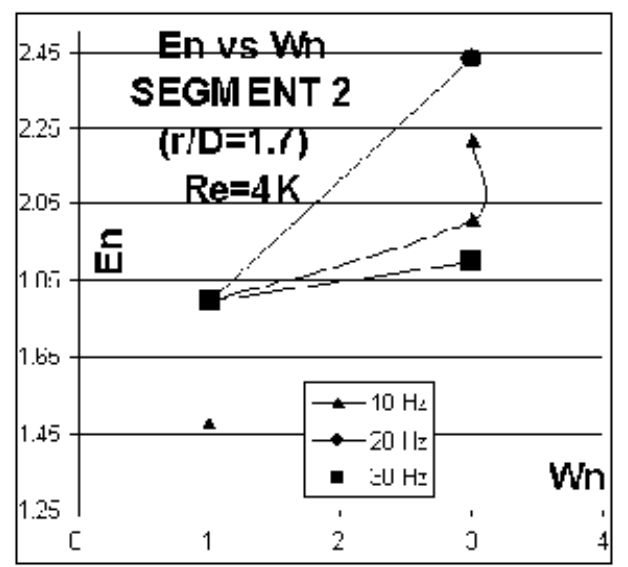

\subsection{THERMODYNAMIC IMPLICATIONS}

\subsubsection{RETROFIT MARKET}

The appendix contains the raw data. The peak En measured was 2.8 for Seg1 at $\mathrm{Re}=4 \mathrm{~K}, \mathrm{Wn}=3$, and $\mathrm{Hz}=10$. Though En above 2.0 were common, the experiment found a "hole" at $\mathrm{Re}=12 \mathrm{~K}$, where $\mathrm{En}=1.3$ at $\mathrm{Wn}=3.0$ and $\mathrm{Hz}=30$. Assuming we could capitalize on an En peak, it is reasonable to assume we could find an En=2.2 for industrial use. In a paper drying, this produces the following thermodynamic balance.

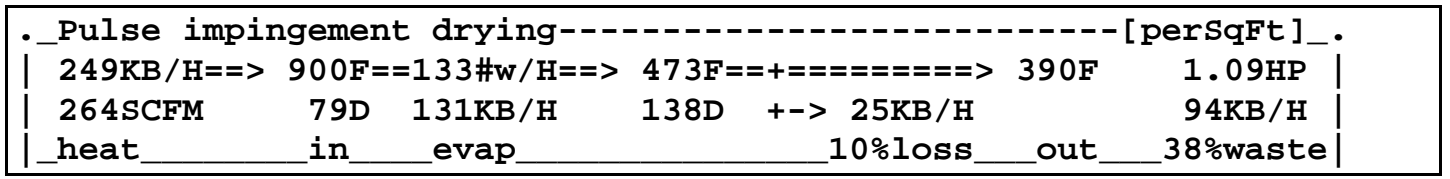

Steady impingement yields a drying efficiency of $4082 \mathrm{BTU} / \#$, while this conservative engineering estimate yields 1872 BTU/\#, over double the efficiency. With careful process searching, and a better understanding of the underlying resonance phenomena, it is reasonable to expect even this efficiency could be improved.

Past researchers who have looked into impingement drying as an acceleration tool in paper drying have naturally gravitated toward the higher Reynolds number flows and aggressive drying regimes. In steam cylinder assist, lower Reynolds number assist may actually be more attractive. The experiment found a relative $E n=2.4$ peak at $R e=4 \mathrm{~K}$, $\mathrm{Hz}=20$ and $\mathrm{Wn}=3$. The thermodynamic process for these conditions, applied to a steam cylinder, follows.

\begin{tabular}{|c|c|c|c|c|c|}
\hline _Pulse imp & nge & & ーーーーーーーーーーーーーーーーー & & \\
\hline $100 \mathrm{~KB} / \mathrm{H}==>$ & $900 \mathrm{~F}==$ & $79 \# w / H==>$ & $260 \mathrm{~F}==+=========>$ & 177F & $0.07 \mathrm{HP}$ \\
\hline 105SCFM & 79D & $77 \mathrm{~KB} / \mathrm{H}$ & $150 \mathrm{D}+\rightarrow 10 \mathrm{~KB} / \mathrm{H}$ & & $12 \mathrm{~KB} / \mathrm{H}$ \\
\hline heat & in & evap & $10 \%$ loss & _out. & $12 \%$ waste \\
\hline
\end{tabular}


This mild enhancement factor delivers a spectacular drying efficiency of 1270 [BTU/\#], a $33 \%$ improvement over steam cylinder technology, and an acceleration of the water removal rate per square foot of $4,000 \%$.

This thermodynamic balance is mathematically correct, but almost certain to run into thermodynamic limits. That paper exit temperature of $260 \mathrm{~F}$ is very low, and only provides a 110F temperature differential over dew point.

When applying Martin Nusselt numbers to thermodynamic calculations, one never encounters a thermodynamic limit, that is, a heat transfer rate that leads to a predicted exit temperature below the local dew point. This never occurs because the Martin process never rises above $25 \%$ thermodynamic efficiency, and gas flow in steady impingement has a single valued path through the domain. In sharp contrast, pulsed impingement predicts much higher efficiencies, and the domain is double valued, that is, gas that has already evaporated water and cooled is allowed to circulate back to the surface a second time. The implications of these higher efficiencies is that an entirely new nondimensionalizing mathematics is needed to successfully predict the efficiencies and process characteristics of a real world pulsed flow.

This is yet another major finding of the current grant project, but it is not as important a priority in advancing pulse impingement as other mysteries, particularly resonance behavior and its nondimensional driving equations. To predict this dew point limit, one probably needs hot evaporation experiments, a major change in the current experimental approach. For now, pulse impingement has so many unknowns, that dew point limits are just one more constraint that can probably be accounted for by an efficiency factor. Eventually, a closed form solution to dew point limits will be needed.

Steady flow impingement drying commonly achieves water removal rates 15 to 18 times that of steam cylinders. The laboratory measurements in this report routinely double this. So this process can realistically offer the steam cylinder user a spectacular improvement in water removal, and a substantial improvement in efficiency, and at the same time improve reliability because impingement drying does not require felts or steam joints.

Given the apparent "home run" characteristics of this process, one would expect rapid commercial acceptance. However, the commercialization report attached to this technical report examines the steps remaining to introduce it into the retrofit market, including intangibles like customer acceptance and industry buying characteristics.

\subsubsection{NEW EQUIPMENT MARKET}

The above analysis has assumed pulse impingement drying is implemented as a retrofit to existing paper making equipment, and the model shows a favorable thermodynamics. However, most of the economic justification comes from increased production rates, not from energy savings. In the new equipment market, there is simply no economic case for replacing existing paper machines. However, it is instructive to speculate about what thermodynamic performance is possible if the entire drying cycle is optimized for pulsed impingement, in the event that energy prices eventually make this market viable. 
As with many technologies in this report, the exact details of this process are proprietary to the grantee, having been invented years before the grant application. However, we can generally describe the process without breaking confidentiality.

Lets start with the pulsed impingement cycle on the wet end of the drying process. Here the thermodynamic balance used in this report is:

\begin{tabular}{|c|c|c|c|c|c|}
\hline \multirow{3}{*}{\multicolumn{3}{|c|}{$\begin{array}{l}\cdot \text { Pulse impingement drying-- } \\
249 \mathrm{~KB} / \mathrm{H}==>900 \mathrm{~F}==170 \mathrm{HW} / \mathrm{H}==> \\
264 \mathrm{SCFM} \quad 79 \mathrm{D} 167 \mathrm{~KB} / \mathrm{H}\end{array}$}} & \multirow{3}{*}{\multicolumn{2}{|c|}{$\begin{array}{l}351 \mathrm{~F}==+=========>268 \mathrm{~F} \\
146 \mathrm{D}+->25 \mathrm{~KB} / \mathrm{H}\end{array}$}} & \multirow{3}{*}{$\begin{array}{c}{[\text { perSqFt] }} \\
1.09 \mathrm{HP} \\
58 \mathrm{~KB} / \mathrm{H}\end{array}$} \\
\hline & & & & & \\
\hline & & & & & \\
\hline _heat & -in & _evap & & _ $10 \%$ loss__out_ & 23\%waste \\
\hline
\end{tabular}

In other parts of this report, this process is treated as a waste flow. It can be cycled through a heat exchanger as a source of low grade heat for various process in a paper mill, like preheating water for the pulping stage, preheating air for the boiler, and preheating the head box water.

However, the falling rate portion of the paper drying cycle requires a low grade heat source. If there was a way to use this waste flow to drive a pulsed impingement process on the dry end of the process, we could reuse this waste heat for evaporation.

Two problems confront the process engineer attempting this feat. First, the waste stream is moisture saturated, so it has little dew point drive, or temperature differential between temperature and saturation point, and will deposit water on the paper instead of removing it. Secondly, driving a pulsed impingement process requires PV work, and this leads to high fan loads, again complicating this process.

The solution to the first problem of high waste stream dew point is to run the above waste stream through a counter current heat exchanger. This requires minimal fan work. However, note that water in the hot side of the heat exchanger begins to condense at $146 \mathrm{~F}$. This permits us to heat a much larger mass flow of incoming cold air than outgoing hot air because we begin to capture the hot gas's heat of vaporization.

The wet end of the process can probably tolerate a higher inlet temperature. Pulsed drying spreads evaporation more evenly over a wider area, so the wet paper can tolerate much higher contact temperatures. In pulsed powder drying, it is common to see a $900 \mathrm{~F}$ spray dry product tolerate $1200-1400 \mathrm{~F}$ in pulse atomization and drying.

If the wet end of paper drying tolerates $1400 \mathrm{~F}$ contact, the thermodynamic balance produces a waste stream with a $169 \mathrm{~F}$ dew point.

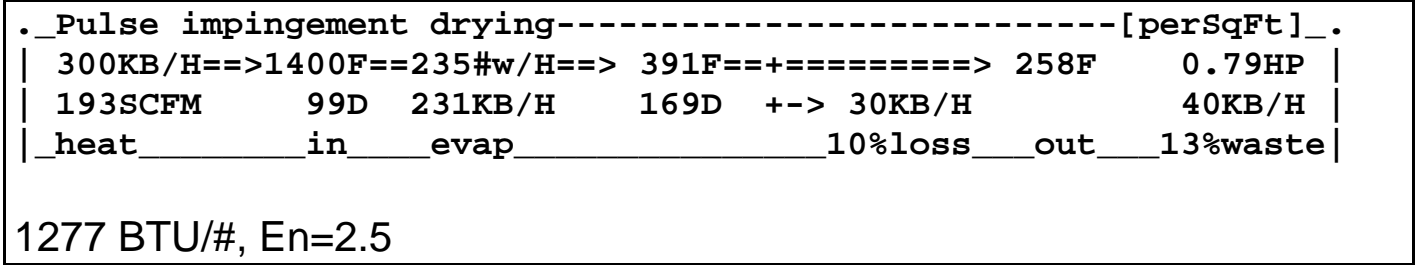


If we use this waste flow to heat ambient air, we produce a large volume of warm dry air, the perfect media for the falling rate drying region. For the $285 \mathrm{~F}$ waste stream with a $169 \mathrm{~F}$ dew point, an incoming air stream at $70 \mathrm{~F}$ and $50 \mathrm{~F}$ dew point heated to $170 \mathrm{~F}$ would contain 1292 SCFM, nearly seven time the air mass in the initial drying process. This air flow would contain $62 \%$ of the sensible heat, or heat of evaporation, in the waste stream, and would be heated to $170 \mathrm{~F}$ because the process uses a counter flow heat exchanger.

The secondary evaporation process using this $170 \mathrm{~F}, 50 \mathrm{D}$, air has a dew point differential of $130 \mathrm{~F}$, producing a large vapor pressure differential. Pulsed impingement theory produces the following heat balance for this secondary evaporation process.

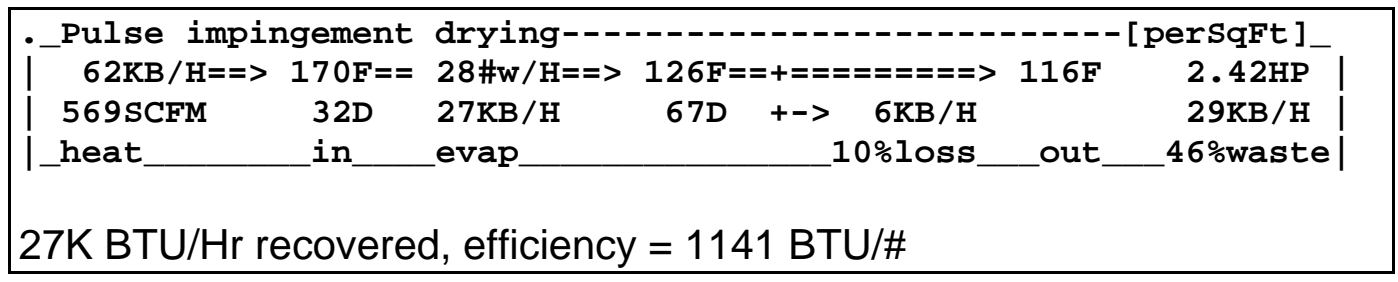

This thermodynamic balance is a crude first step in engineering this process, but yields the spectacular $1141 \mathrm{BTU} / \#$ overall thermodynamic efficiency. Were this process implemented throughout the paper manufacturing industry that currently uses steam rolls, the current evaporative energy consumption of 585 Trillion BTU/Yr would decline to $351 \mathrm{~T}-\mathrm{B} / \mathrm{Yr}$, for an industry savings of $234 \mathrm{~T}-\mathrm{B} / \mathrm{Yr}$, or a reduction of $40 \%$ in the industry's evaporative energy consumption, or a net reduction to the total US energy budget of $0.2 \%$. This translates into an annual $\mathrm{CO} 2$ reduction of 21.5 millions tons, as well as reductions of 5.8 million pounds of volatile organic compounds, and 234 million pounds of particulates.

The second requirement for driving this heat recovery process is PV work, that is, pressurized air for the Helmholtz resonators. Though one is tempted to use a conventional fan for this, the hot pulse process in this example generates excess PV work, and can be used to drive the secondary drying process. Though details of this are proprietary, the mathematical derivation of the constant entropy process which occurs in the pulse burner is given in the appendix of this report.

Significant engineering hurtles remain before this process would be ready for testing. In particular, this entire report has used Nusselt theory, that is, the ratio of heat transfer in a convection environment compared to simple conduction heat transfer. In the heat recovery process, evaporation is likely to be dominated by the mass transport version of this theory, or Sherwood theory. This theory is nearly identical to Nusselt, but the nondimensionalizing parameter is diffusion, not conduction. In the heat recovery process described above, the water vapor pressure differential between the paper fibers and the impinging gas flow has a major influence on evaporation. In the hot zone, Sherwood and Nusselt theory are nearly identical, but in the heat recovery process diffusion distances may dominate and this must be investigated. 


\subsubsection{LONG TERM MARKET IMPACT}

DE-FG36-03G013009

PC Engineering

Pulse drying has a near term use as a topping cycle that extends the production capacity of an existing paper plant for a fraction of the cost of other retrofit choices. However, beyond this, pulse drying has a significant roll in the fundamental reengineering of paper manufacturing technologies world wide. Two important companion technologies are symbiotic: gasification, and the bio-refinery model. Let us review these.

Paper mills now generate most of their process steam by burning two waste products, "hog fuel" a general term for bark, branches, leaves, and other unprocessable parts of the tree, and "black liquor", a highly alkaline by product of the pulping process. These are typically burned in a "recovery boiler" which is designed to incinerate the fuel, transfer heat to steam piping, capture the spent pulping chemicals for recycling, and scrub the stack gas to remove particulates (electrostatically) and toxins (like hydrogen sulfide). This boiler is a complex chemical factory that has been fine tuned over decades of use. Its combustion efficiency is low, typically $65 \%$, because its chemical recovery function limits combustion temperatures, and therefore thermodynamic efficiency.

Both gasification and bio-refinery models target the recovery boiler. In both cases, the pulping chemicals are still recovered, but the remainder is not simply incinerated. Instead, gasification transforms the waste streams into a low BTU gaseous fuel, primarily consisting of carbon monoxide. The bio-refinery model transforms some of the black liquor into resellable chemicals like methanol, for automobile fuel, monomers for plastics manufacturing, or other hydrocarbons. In both cases, a low value waste product, black liquor, is transformed into a higher value commercial product. Carbon monoxide can be burned in a gas turbine that generates electricity more efficiently than commercial coal fired power plants, by using the "combined cycle" process. The biorefinery model generates chemicals that normally come from fractional distillation of petroleum, so the commercial value of these by products will rise with the price of crude oil.

In both of these future paper mill models, black liquor becomes more valuable. Since pulse drying conserves the steam consumption of paper drying, it naturally reduces black liquor consumption. Let us quantify the impact pulse drying will have on an existing paper mill. We will avoid calculating economic pay back or capital costs, the technology is too immature for these to be accurate. We will, instead, perform a comprehensive thermodynamic comparison of the sources and uses of energy in a paper mill before and after it is retrofit with pulse drying. As with any complex reengineering project, the efficiencies of each stage must be re-engineered, but for simplicity's sake, we will confine the analysis to a "what if" scenario where it is assumed that retrofit equipment is competently chosen.

For representative energy consumption figures, lets use the AIChE report "Pulp and Paper Industry Energy Bandwidth Study" [7], and their "Linerboard" case. The study is poorly checked, but the linerboard case is reliable, and documents a mill which processes raw wood into finished paper, therefore including the recovery boiler thermodynamics. 
All thermodynamic values in this analysis are given in BTU's per pound of air dried paper. Though not common in paper manufacturing literature, this choice of thermodynamic variables aids in documenting major changes in plant function. The PID shows the fuel flow in a paper mill, where raw trees are separated into hog fuel (2830 BTU/\#), pulped into black liquor (6600 BTU/\#) and fed to the recovery boiler. The high pressure steam from the boiler (typically $850 \mathrm{PSI}$ ) is fed to a steam turbine, where approximately $19 \%$ of the thermal energy is converted to electricity, at a thermodynamic efficiency over $90 \%$. Turbine exhaust steam is then used in pulping and paper making operations, which also consume electricity from the turbine. In the liner board case, bio-fuels and internally generated electricity are insufficient, and purchased fuels and electricity supplement the pulp and paper making operations.

The high efficiency of the steam turbine may seem unbelievable. The Carnot efficiency of a heat engine is rarely above $35 \%$, but in this case, because waste heat is consumed as process steam that the paper plant needs anyway, the turbine functions as a topping cycle, and does in fact deliver this extraordinary thermodynamic efficiency.

The turbine is inflexible. It operates at a single mass flow and pressure drop. Even minor deviations from its design parameters sends the efficiency, and attendant electricity production, plummeting. Note that the paper plant is constantly changing paper grades, shutting down for web breaks, and performing ongoing maintenance and troubleshooting. During any of these production stoppages, the turbine must continue to operate, pumping power into the grid until the plant is back up. This is one of the reasons for supplemental fuel.

The energy flow diagram at right summarizes the sources and uses of energy as shown in the above P\&ID, but in a more accessible and graphical form. Lets briefly review the diagram.

The central pie chart is actually two halfcircles, the left being the sources of energy, the right being uses. Here, sources include 9430 BTU's from raw trees (hog fuel and black liquor), and a remaining 2500 BTU's from purchased fuel and electricity. The total sourced energy is 11,930 BTU's for each pound of air dried paper the mill produces.

The uses side of the pie shows us that 3074 BTU's are consumed in pulping the raw wood. The small "S" and "E" letters show the split between steam and electric 
consumption in the pulping process. The paper making process consumes 4247 BTU's, here heavily weighted to the drying process (2400 BTU/\#) and the high electricity demand of the mechanical dewatering section (1032 BTU/\#). Lastly, the pie shows a thermodynamic waste of $4608 \mathrm{BTU} / \#$, primarily from the recovery boiler.

An identical sources and uses diagram for a paper mill retrofit with pulse drying is shown at right. In this retrofit plant, the entire drying section is pulsed, bringing its specific heat consumption from 2410 to 1205 BTU/\#. Though the grantee has

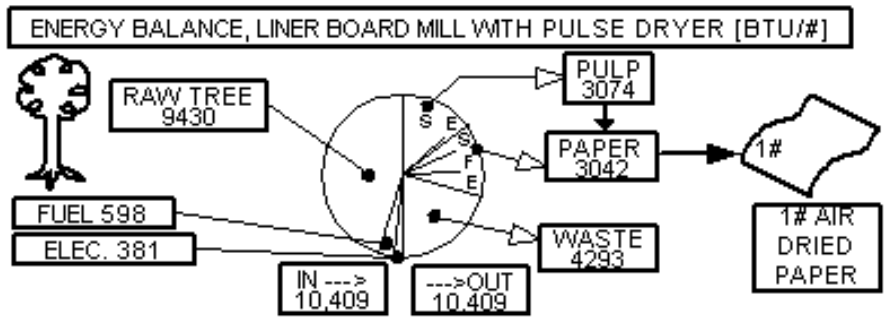
thermodynamic models which produce efficiencies near $1050 \mathrm{BTU} / \#, 1205$ is conservative. This drying section change is major surgery, and not the kind of topping cycle retrofit we have described elsewhere in this report.

The first observation is the overall reduction in size of the energy pie, from 11,930 to 10 , $409 \mathrm{BTU} / \#$, a reduction of $1521 \mathrm{BTU} / \#$, significantly above the $1205 \mathrm{BTU} / \#$ the pulse dryer saves. Why? Steam production is burdened with both the inefficiencies of the recovery boiler, and secondary steam uses. For example, the recovery boiler uses $7.5 \%$ of its steam internally to clean its own heat exchanger piping. Another $4 \%$ is used for boiler auxiliaries like fans, pumps, bark hogs, and the like. Since pulse drying is direct fired, it escapes all of these steam inefficiencies.

The second observation pertains to secondary fuel, down from 2017 to $598 \mathrm{BTU} / \#$, a $70 \%$ reduction. Savings in the recovery boiler fuel budget come directly from auxiliary fuel purchases. As mentioned above, a paper mill's steam turbine is sensitive to interruption, so these fuel savings are averaged over time. System engineering determines the packaged boiler sizing, control, and averaged use.

The pulsed drying case saves enough recovery boiler fuel to actually produce a surplus. In a bio-refinery plant, this surplus is converted into marketable hydrocarbons. In a gasified plant, the surplus carbon monoxide is cycled through the combined cycle gas turbine to produce more electrical energy for commercial sale. In either case, the net energy savings from pulse drying are a major economic boon to a re-engineered paper mill.

When the pulse dried energy balance ran out of purchased fuel for pulse drying, we had to assume new plant processes. In the above analysis, we assume the plant installs a small gasification cycle which siphons black liquor from the recover boiler, and produces carbon monoxide fuel for the pulse drying process. This is clearly an unlikely economic choice, but for comparison purposes, it does produce a meaningful energy balance. The thermodynamic efficiency of gasification is about equal to that of a recovery boiler, so the energy balances above do accurately reflect the before and after thermodynamics of a pulse retrofit paper mill. 
DE-FG36-03G013009

PC Engineering

\subsection{MILESTONE 3}

\subsection{PULSE BURNER CONSTRUCTION}

The modern pulse burner belongs to a family of intermittent combustion devices dating to the discovery of the Rijke burner in 1859. Other air valved burners have been invented since then, including the Schmidt burner, which contain no moving parts and yet support stable combustion. During World War II, Germany scaled the Schmidt burner up to use a flapper valve and powered the $\mathrm{V} 1$ jet.

Until 1988, the pulse burner had achieved virtually no acceptance in industrial markets. They were reliable, but had high gas dynamic impedance, meaning they were unable to drive industrial process that consumed gas dynamic PV work.

In the mid 1980's, NEA was formed to produce technologies designed to capitalize on the OPEC energy crisis. They produced a true breakthrough in pulse burner technology by fitting a gas dynamically balanced air valve onto a Helmholtz style pulse burner. The result was a stable and reliable burner with low gas dynamic impedance, and therefore the ability to drive industrial processes that consume PV work.

The initial use of that burner was in powder dehydration, a market still dominated by the spray dryer. The pulse burner both atomizes and dries aqueous liquids, like silica, without the drawbacks of spray drying, such as pump and nozzle wear, nozzle clogging, and long retention times at temperature that can degrade powders.

The grantee worked as the principal design engineer for the patent holder of the NEA design from 1992 through 1998, designing or renovating eight such burners, and accumulating over 2000 hours of field experience in operating this device, and testing and designing modifications to the burner and its drying process. Today, the market for pulse dried powders is still a fringe technology, far from gaining acceptance in main stream industry.

From 1998 through 2002, the grantee had intermittent contact with the Proctor and Gamble research project which used a mechanically valved Helmholtz style burner to pulse dry tissue paper. The process gained early success using a Rijke style burner, but failed during scale up tests at the IPST facility, where heat transfer rate under pulse conditions actually declined compared to equivalent steady flow conditions.

The current grant has discovered that the pulse drying process is highly sensitive to both Wave Number $(\mathrm{Wn})$ and pulse frequency. The P\&G study was not aware of these process requirements, and were equally cavalier about gas path impedance matching, turbulence control, and pulse array stability. Their development project had plenty of budget and man power, but the overall design of the experiment did not flow from a systematic understanding of pulse drying, and did not optimize the pulse burner for the impingement process.

The grantee now recognizes many of the requirements of the pulse drying process, though some are still mysteries. Of the known requirements, it is certain the Wave Number of the impinging flow must be above 2.0, and perhaps as high as 3 or 4 . These 
are all characterized by large flow reversals, and in the powder drying industry, any flow reversal forces partially dried powder up stream toward the hot atomizer, producing burned particles, sticking, or fires. In the past, flow reversals has been a danger to carefully avoid, but now has become a fundamental process requirement.

\subsection{NEA BURNER DESIGN}

The cross section at right is a public domain version of the NEA burner taken from one of their patents. To briefly describe its operation, two piped couplings at the bottom connect to air sources, a combustion fan, and a cooling fan. These pressurize the upper and lower chambers of the burner.

Inside the upper chamber, the NEA "air valve" is exposed to pressure from the combustion air fan, where it passes the "air diode", and finally enters the "combustion chamber". The valve closes during explosions, and opens during the partial vacuum stage, in phase with the resonating Helmholtz cavity.

The Helmholtz style burner has a combustion chamber and tail pipe combination that forms the resonant system. An explosion in the chamber causes gas to accelerate down the tailpipe, storing kinetic energy. When the tailpipe overshoots, a partial vacuum is drawn in the chamber, inducing reverse flow in a classic resonance pattern.

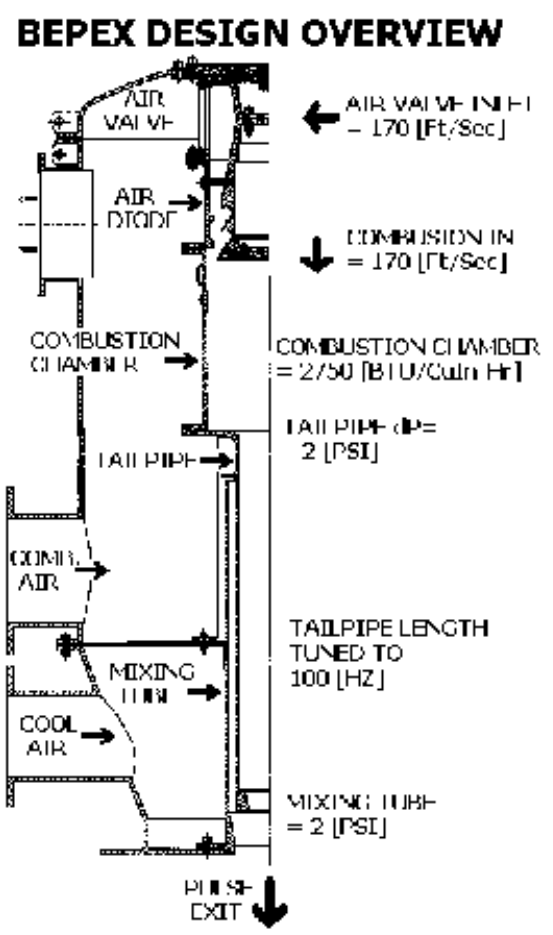

The diagram at right is a close up cut away of the NEA air valve. The stator has two layers, an inner and outer, with four rectangular holes cut in line. The rotor has four matching holes that periodically align and cover the stator holes, forming an intermittent gas path opening.

The true virtue of this design is its gas balanced closure. When the stator holes are covered by the rotor, an explosion in the combustion chamber equally loads the four openings in the inner stator, forming four balanced forces on the rotor. These four gas pressure loads will always be equal, and will be reacted against one another as ring stresses in the rotor. No matter how high the combustion gas pressure rises, they are internally reacted by the rotor, and no net forces are generated on the motor bearings that hold the rotor.

This feature of internally reacted gas forces is a characteristic of the other air valve designs that the grantee has invented over the past fourteen years. This internally reacted characteristic gives mechanically valved pulse burners an nearly infinite life, as has been experienced in the powder market.

\subsection{PULSE BURNER TUNING}


The design and control features used to tune pulse burners is beyond the scope of this grant report. But the important characteristic of the pulse burner is its single frequency of operation. Once the dimensions of the Helmholtz cavity have been chosen, the resonant frequency of the burner is fixed. This frequency changes with combustion temperature, by the familiar $a=\sqrt{ } \gamma \mathrm{RT}$, that is, the sound speed is the square root of the product of the gas heat conductivity ratio $(\gamma)$, the universal gas constant $R$, and the absolute temperature $\mathrm{T}$. So a burner with a resonance of $100 \mathrm{~Hz}$ at $2000 \mathrm{~F}$ will resonate at $82 \mathrm{~Hz}$ when running at $1200 \mathrm{~F}$.

This begins to acquaint the reader with the challenge of connecting a pulse burner with a pulse drying array. The array is picky about its frequency, and the burner only operates at a single resonance point. At first sight, this looks like an impossible match, where the system barely operates at a single temperature and frequency combination. The grantee has a variety of proprietary burner designs that permit limited frequency tuning, and there may be modifications to the impingement geometry that widen its resonance sweet spot. The grantee has been designing industrial equipment for thirty years, and the combination of opportunities and challenges in commercializing pulse drying is currently weighted in favor of its further development. Though current technical challenges look daunting, our state of process knowledge is too primitive. A bit of innovation is likely to cure or avoid many of these problems.

This emphasizes the importance of the frequency findings in the evaporator experiment. Going from $20 \mathrm{~Hz}$ to $15 \mathrm{~Hz}$ in the 4000 Reynolds number experiment decreased heat transfer rate from .23 to .18 [\#/f2-Hr], a $22 \%$ drop in water evaporation rate, paper production rate, and a similar drop in thermodynamic efficiency. We cannot build this enhancement trough into a test or production system.

This superficial introduction into burner and process tuning covers some peripheral issues, but a wide variety of other constraints must also be considered. The important observation is that these gas impedance values are locked into the design when it is still on the drawing board. Once equipment is built with an internal impedance mismatch, the system is permanently degraded. With frequencies of resonating systems enslaved to the " $\mathrm{Vk} / \mathrm{m}$ " rule, moving the resonance frequency of the pulse array, or the burner, is sluggish. A doubling of the system's spring constant " $k$ " only moves the resonant frequency by $41 \%$. Once an error is designed in, we are stuck with it.

\subsection{BURNER IMPEDANCE EXPERIMENTS}

We learned that the paper industry is slow to adopt new technology, and will require a full scale test in order to prove the system. The entire future of the technology hinges on this single test, and any error in tuning could be catastrophic to the industry's acceptance of pulse drying technology.

When this marketing behavior was discovered at the Chicago TAPPI show, the grantee abandoned the project of building a scale pulse burner as a prelude to a scaled up system, that is, a burner in the 3-M-BTU/Hr category. A full scale test will require a larger burner, in the 10-M-BTU/Hr category, and one whose gas dynamics are matched to the test manifold, array, and customer specifications. 
To make matters even worse, since we cannot predict what temperature the customer will request, and since burner's resonant frequency drifts with temperature, tuning on the drawing board is chancy. If we design for 950F, and the customer asks to push it to $1200 \mathrm{~F}$, we have just moved a $100 \mathrm{~Hz}$ burner to $118 \mathrm{~Hz}$, enough to move right out of an efficiency peak. Even if we get the system tuned in advance of the test, the customer's ongoing test parameters may take us outside the envelope of tuning. Though the grantee has proprietary designs to cope with this, they are still unbuilt and untested.

If customers have an economic incentive to place pulse drying on the falling rate part of the paper's dehydration curve, they will request much lower contact temperatures, in the $400 \mathrm{~F}$ to $600 \mathrm{~F}$ range. These are well below any stable operating temperature the NEA burner has run at in the past, and sure to create emission issues with unburned hydrocarbons, formaldehyde, and carbon monoxide. Fortunately, the grantee has a series of burner modifications designed to combat these problems, but once again they are unbuilt and untested.

\subsection{BURNER DESIGN GOALS}

If the paper drying business advances, parametric testing of Helmholtz pulse burners, and some of the grantee's inventions, is needed. To this end, the grantee fabricated a test burner, absent the burner's utilities (as specified in the grant proposal), including fuel and pilot piping trains, controls, flame relay, and ancillaries.

The burner fabricated is one of a series of three burners designed to perform impedance testing. Three heat release rates have been chosen, $10 \mathrm{~K}, 40 \mathrm{~K}$, and $120 \mathrm{~K} \mathrm{BTU} / \mathrm{Hr}$. These cover a fire rate span of 12 , and permit parametric testing in these fire rates of various burner characteristics. The diagram at right shows the combustion chamber and tail pipe sizing for these three burners, using industry standard pipe sizes.

Currently, the most important parameter to optimize is reverse flow. Recall that negative flow is required by pulse drying, and prohibited

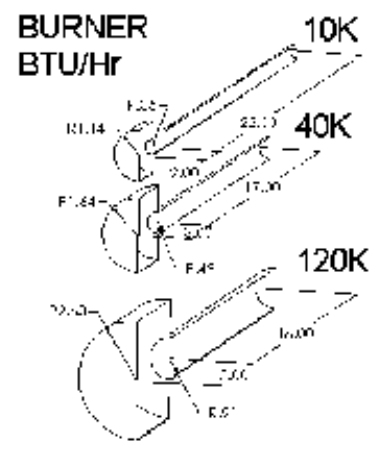
from powder drying. Exaggerated reverse flow is a characteristic of a lightly damped and over driven system. In gas dynamic terms, the gas path from the burner to the array must have low loss, a requirement ignored by the $P \& G$ design. This puts enormous constraints on the header that connects the burner to the array, but this design will not have to be optimized until later in the commercial introduction of the technology when full scale burners in the 20 to $40-\mathrm{M}-\mathrm{BTU} / \mathrm{Hr}$ size range are needed. Before then, the driving characteristics of the test burners will tell us how much gas drag we have to "spend" in the array piping.

Without becoming too specific, the currently measured pulse array requirements may actually be beyond the driving characteristics of a conventionally valved Helmholtz burner. The cure for this is expensive, particularly during the experimental stage, but the expense has only modest effect on a commercial system, adding perhaps $\$ 50 \mathrm{~K}$ to the cost of a $\$ 5 \mathrm{M}$ project. It is important to know if an expensive design is actually required by the customer well in advance of initially presenting the technology to them, 
DE-FG36-03G013009

PC Engineering

because the design is difficult to retrofit, and we need experience with the design at smaller scale before committing to a full scale unit.

The test PID for the burner is shown at right in low resolution, and full scale in the appendices of this report. The layout shows a conventional air train using constant pressure fans arranged in single [6 W.C.] up to triple series [18 W.C.] feeding the air valve. The design will test a variety of combustion and cooling air locations entering the burner. In this instrumentation layout, differential pressure venturies are depicted, but a preferable instrument would be a thermal dispersion mass flow meter, which should work as well in pulsed flow as in steady flow.

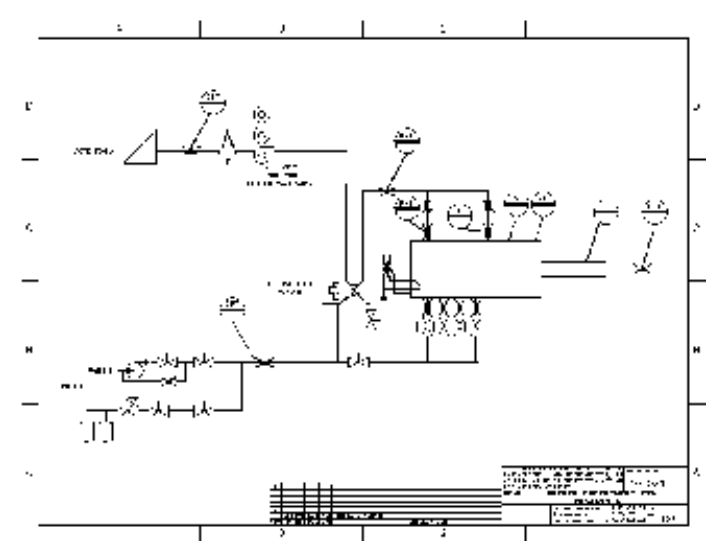

The fuel instrumentation shows dual pressure sources, one from a conventional pressure source, such as cans of methane or propane, feeding a pressure regulator and hand valves for selecting the fuel nozzle. An alternate fuel strategy shows a positive displacement pump connected to a low pressure methane source feeding the valve train.

The test stand is not designed for unattended operation, so the grantee does not envision using NFPA rated specifications for the pilot, flame relay, purge cycle, and double block and bleed piping. Instead, attended operation will manually purge, and stop the burner via manual fuel shutoff in the event of an unsafe condition.

The burner parametric study is designed for maximum flexibility in burner geometry and layout. The diagram at right shows construction details of the $40 \mathrm{~K}$ test burner, where maximum use is made of off the shelf pipe components. Though this simple configuration is shown, the test program would use a variety of internal geometries, fuel trajectories, and tail pipe configurations. With this modular construction, a large number of configurations can be tested on a minimal construction budget.

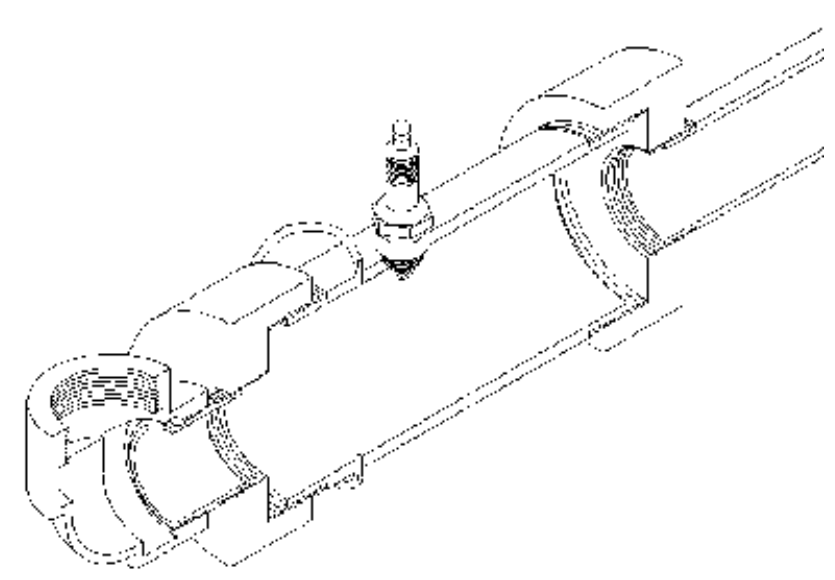




\subsection{COMMERCIAL INTRODUCTION}

This technical paper has not lingered on the market for paper making equipment domestically and world wide - this is detailed in the commercialization plan. In short, the paper manufacturing community is highly conservative and acts as though all the good ideas have been discovered, and finding any major improvement is so expensive they would prefer to let some one else look for them and be the second manufacturer to incorporate them. This market's past record for adopting innovation can be seen in dryer bars and vacuum dewatering, where both technologies were first adopted commercially ten years after being proven in the lab, and yet are now universally used.

Paper manufacturers are not satisfied with a scale test, as is common in chemical, feed milling, food, and other industries. Paper manufacturers require a production scale demonstration test, conducted on an exact replica of their paper making process, both wet and dry, using the exact wood species, coatings, post drying processing (such as calendering and embossing) and winding that they employ in their production facilities. There are a half dozen research plants around the country (GL\&V, Hearty, Voith, Western Michigan University, Rochester Institute of Technology, etc.) that will configure their equipment to match your target facility and run a production scale test, typically with a reduced web width. Such a test is expensive, particularly for pulse drying because a dedicated pulse burner, manifold, array, utilities, and controls must be constructed specifically for this one time test, and if the test fails, or performs below expectations, the technology is branded as a failure by the entire industry (news travels fast) and one can expect zero interest in the technology for another decade.

This is a tough crowd.

For the equipment engineer, this means reducing risk to a minimum before selling the process to the industry. Let's list the significant risk factors remaining in pulse drying technology.

1) The resonance phenomena is not understood, and there may be multiple drying resonances to be discovered and characterized.

2) The pulse burner that has been commercially used in the powder drying industry won't work for pulse drying of paper.

3) The dew point limits of an actual hot evaporation process are not included in current theory.

There are numerous smaller hurtles, but the three above are expensive to investigate, and necessary before technology introduction.

The grantee spent several months in 1999 proposing a joint development of pulse drying to thirteen of the largest paper manufacturing companies in North America, and never got so much as a whisper of interest.

The grantee received an enormous breakthrough in 2001 when this grant was awarded, and in the ensuing five years the technology has advanced more than with all previous 
investigator combined, including significant research investments from Proctor and Gamble [6], and the DOE I\&I research grant at Berkeley [3].

So, funding the unexplored territory between the technology and the market place is now problematic. Funding with an industry partner is both improbable, and highly risky if the first test doesn't perform. Although venture capital is an option, the lethargic pace of technology acceptance by the paper manufacturing industry makes this funding route somewhere between unattractive and repugnant. Venture capital prefers the fast and lucrative pay back of medicine, software, and hedge funds.

\subsection{SCHEDULE AND FUTURE RESEARCH OPTIONS}

The current grant was a Category 2, for which no Category 1 project was ever conducted. After the grant was half completed, the DOE stopped the project for a six month design review, during which the grantee remained unappraised of the fate of the grant's second half. In retrospect, this severely limited the grantee's ability to maximize efficient use of the budget and schedule, and required total re-engineering of the evaporation experiment's hardware. When the gas dynamic resonances were discovered, there was neither budget nor schedule left to investigate and characterize them.

Though the I\&I program has advanced the understanding of pulsed impingement significantly by funding the present study, the rapid advances made so far have placed subsequent research clearly in to post doctorate levels of gas dynamics, thermodynamics, controls, and related technologies, engineering ranges well beyond the knowledge level of the proposal which won the current funding. The grantee has since discovered that the Industrial Technologies Program at the DOE is familiar with post doctorate level projects, and a potential partner in developing pulse drying. The ITP has funded black liquor gasification for over a decade, so its symbiosis with pulse drying may spawn both public and private development interest.

\subsection{COMMERCIALIZATION PROOF TEST}

Funding for a full scale paper drying test is difficult to negotiate. The test itself, including pulse burner construction, controls, and utilities, costs about $\$ 350,000$. Though customers are understandably reluctant, if the test were funded by a Category $3 \mathrm{DOE}$ grant, paper manufacturers would be easier to coax into participating. Each company would pay lab time for a run that was specific to their product line, but no single customer would have the sunk cost of the custom designed burner, manifold, and array. This way, many manufacturers would participate, and failure with one paper species would not spell failure for the technology as a whole.

In the paper industry, a typical startup of a $\$ 2 \mathrm{M}$ project is 36 hours long. The reason for this absurdly short startup cycle is the opportunity cost of the paper plant. A typical integrated manufacturer looses $\$ 15,000$ per hour of down time. A one day delay costs the corporate owner $\$ 360 \mathrm{~K}$. A six month delay would cost a paper mill $\$ 66 \mathrm{M}$.

This means the equipment is pre-engineered to an unbelievable level, much higher than other capital intensive industries. 
PC Engineering

A production test funded by an industry consortium would not have the funding and schedule uncertainty that government funding might have. A consortium has the same risk and benefits as government funding, but no single company risks underwriting the entire test. 
DE-FG36-03G013009

PC Engineering

APPENDIX A,B. FINAL TASK SCHEDULE AND FINAL SPENDING SCHEDULE

The original task and cost matrix proposed by the grantee is given below. It has been updated for the actual finish dates, and original estimations of finish dates (given in months into the schedule).

\begin{tabular}{|l|l|l|l|l|l|}
\hline $\begin{array}{l}\text { Task } \\
\text { Number }\end{array}$ & Task Title & $\begin{array}{l}\text { Est. Finish } \\
(\text { Mos. }\end{array}$ & $\begin{array}{l}\text { Responsibl } \\
\text { e Individual }\end{array}$ & $\begin{array}{l}\text { Federal } \\
\text { Cost }\end{array}$ & $\begin{array}{l}\text { Shared } \\
\text { Cost }\end{array}$ \\
\hline Milestone 1 & Evaporator experiment & & States & & \\
\hline Task 1.1 & Build / buy parts & $3(11-05)$ & & $\$ 60,000$ & \\
\hline Task 1.2 & Assemble & $4(11-05)$ & & & \\
\hline Task 1.3 & Run manually & $6(3-06)$ & & $\$ 8,000$ & \\
\hline Task 1.4 & Program controls & $10(3-06)$ & & $\$ 59,000$ & \\
\hline Task 1.5 & Finish data runs & $15(5-06)$ & & & \\
\hline Milestone 2 & Modeling & & States & & \\
\hline Task 2.1 & Program data file transfer & $6(3-06)$ & & & $\$ 8,000$ \\
\hline Task 2.2 & Regression analysis & $16(7-06)$ & & & $\$ 34,000$ \\
\hline Task 2.3 & Data plots and report & $17(7-06)$ & & $\$ 2,000$ & $\$ 8,000$ \\
\hline Task 2.4 & ADINA model & $21(9-05)$ & & $\$ 35,000$ & $\$ 25,000$ \\
\hline Milestone 3 & Build pulse burner & & States & & \\
\hline Task 3.1 & Design burner & $21(11-06)$ & & & $\$ 25,000$ \\
\hline Task 3.2 & Supervise buyouts & $22(11-06)$ & & $\$ 36,000$ & \\
\hline Task 3.3 & Assemble & $24(11-06)$ & & & \\
\hline TOTAL & & & & $\$ 200,000$ & $\$ 100,000$ \\
\hline
\end{tabular}

The quarterly report "Approved Budget" final matrix is given below.

Project Period: $\quad 04 / 15 / 03$ to 04/15/06

Spending Schedule

\begin{tabular}{|c|c|c|c|}
\hline \multirow[t]{2}{*}{ Task } & \multirow{2}{*}{$\begin{array}{l}\text { Approved } \\
\text { Budget }\end{array}$} & \multicolumn{2}{|c|}{ Project Expenditures } \\
\hline & & This Quarter & Cumulative to Date \\
\hline Task 1 Evaporator experiment & 84,000 & $38,400.00$ & 214,615 \\
\hline Task 2 Modeling & 123,400 & 0 & 122,504 \\
\hline Task 3 Build pulse burner & 86,000 & 0 & 78,282 \\
\hline Task 4 Travel & 2,500 & 0 & 2,500 \\
\hline Task 5 Other & 4,500 & 0 & 4,500 \\
\hline Total & 300,400 & 38,400 & 422,401 \\
\hline DOE Share & 200,000 & 0 & 200,000 \\
\hline Cost Share & 100,400 & 38,400 & 222,401 \\
\hline
\end{tabular}

page - 46 -

of 64 
DE-FG36-03G013009

PC Engineering

APPENDIX C: FINAL COST SHARE CONTRIBUTIONS

\begin{tabular}{|l|l|l|l|l|l|}
\hline $\begin{array}{l}\text { Task } \\
\text { Number }\end{array}$ & Task Title & $\begin{array}{l}\text { Est. Finish } \\
(\text { Mos. })\end{array}$ & $\begin{array}{l}\text { Responsibl } \\
\text { e Individual }\end{array}$ & $\begin{array}{l}\text { Federal } \\
\text { Cost }\end{array}$ & $\begin{array}{l}\text { Shared } \\
\text { Cost }\end{array}$ \\
\hline Milestone 1 & Evaporator experiment & & States & & \\
\hline Task 1.1 & Build / buy parts & $3(11-05)$ & & $\$ 60,000$ & \\
\hline Task 1.2 & Assemble & $4(11-05)$ & & & \\
\hline Task 1.3 & Run manually & $6(3-06)$ & & $\$ 8,000$ & \\
\hline Task 1.4 & Program controls & $10(3-06)$ & & $\$ 59,000$ & $\$ 87,615$ \\
\hline Task 1.5 & Finish data runs & $15(5-06)$ & & & \\
\hline Milestone 2 & Modeling & & States & & \\
\hline Task 2.1 & Program data file transfer & $6(3-06)$ & & & $\$ 8,000$ \\
\hline Task 2.2 & Regression analysis & $16(7-06)$ & & & $\$ 34,000$ \\
\hline Task 2.3 & Data plots and report & $17(7-06)$ & & $\$ 2,000$ & $\$ 8,000$ \\
\hline Task 2.4 & ADINA model & $21(9-05)$ & & $\$ 35,000$ & $\$ 31,504$ \\
\hline Milestone 3 & Build pulse burner & & States & & \\
\hline Task 3.1 & Design burner & $21(11-06)$ & & & $\$ 53,282$ \\
\hline Task 3.2 & Supervise buyouts & $22(11-06)$ & & $\$ 36,000$ & \\
\hline Task 3.3 & Assemble & $24(11-06)$ & & & \\
\hline TOTAL & & & & $\$ 200,000$ & $\$ 222,401$ \\
\hline
\end{tabular}




\section{APPENDIX D: ENERGY SAVING MATRIX}

The energy saving matrix from the original grant proposal is given below.

SUMMARY OF ENERGY AND ENVIRONMENTAL BENEFITS FOR EACH RETROFITTED MACHINE

\begin{tabular}{|l|c|c|c|c|}
\hline & $\begin{array}{c}\text { Proposed } \\
\text { Technology }\end{array}$ & $\begin{array}{c}\text { Comparable } \\
\text { Technology }\end{array}$ & $\begin{array}{c}\text { Savings } \\
\text { Per Year }\end{array}$ & $\begin{array}{c}\text { Savings } \\
\%\end{array}$ \\
\hline Heat Release & $279 \times 10^{9} \mathrm{BTUU} / \mathrm{Y}$ & $514 \times 10^{9} \mathrm{BTU} / \mathrm{Yr}$ & $235 \times 10^{9} \mathrm{BTU} / \mathrm{Yr}$ & $46 \%$ \\
\hline Methane consumption & $13.2 \times 10^{6} \# / \mathrm{Yr}$ & $24.5 \times 10^{6} \# / \mathrm{Yr}$ & $11.2 \times 10^{6} \# / \mathrm{Yr}$ & $46 \%$ \\
\hline $\mathrm{CO}_{2}$ production & $36.3 \times 10^{6} \# / \mathrm{Yr}$ & $67.4 \times 10^{6} \# / \mathrm{Yr}$ & $30.8 \times 10^{6} \# / \mathrm{Yr}$ & $46 \%$ \\
\hline Evaporation efficiency & $1609 \mathrm{BTU} / \# \mathrm{w}$ & $3891 \mathrm{BTU} / \# \mathrm{w}$ & & $59 \%$ \\
\hline
\end{tabular}

Since then, the energy saving calculations have been refined, and the potential markets expanded.

TISSUE MACHINE ENERGY SAVING MATRIX - PER UNIT

\begin{tabular}{|l|c|c|c|c|}
\hline & $\begin{array}{c}\text { Proposed } \\
\text { Technology }\end{array}$ & $\begin{array}{c}\text { Comparable } \\
\text { Technology }\end{array}$ & $\begin{array}{c}\text { Savings } \\
\text { Per Year }\end{array}$ & $\begin{array}{c}\text { Savings } \\
\%\end{array}$ \\
\hline Heat Release & $156 \times 10^{9} \mathrm{BTU} / \mathrm{Y}$ & $449 \times 10^{9} \mathrm{BTU} / \mathrm{Y}$ & $293 \times 10^{9} \mathrm{BTU} / \mathrm{Yr}$ & $65 \%$ \\
\hline Methane consumption & $7.5 \times 10^{6} \mathrm{\#} / \mathrm{Yr}$ & $21.2 \times 10^{6} \# / \mathrm{Yr}$ & $14.0 \times 10^{6} \# / \mathrm{Yr}$ & $65 \%$ \\
\hline $\mathrm{CO}_{2}$ production & $20.5 \times 10^{6} \# / \mathrm{Yr}$ & $58.4 \times 10^{6} \# / \mathrm{Yr}$ & $38.4 \times 10^{6} \# / \mathrm{Yr}$ & $65 \%$ \\
\hline Evaporation efficiency & $1150 \mathrm{BTU} / \# \mathrm{w}$ & $4120 \mathrm{BTU} / \# \mathrm{w}$ & $2970 \mathrm{BTU} / \# \mathrm{w}$ & $72 \%$ \\
\hline
\end{tabular}

The tissue machine industry has 290 domestic machines, so potential annual heat savings are 85 Trillion-BTU/Yr.

STEAM CYLINDER ENERGY SAVING MATRIX - PER UNIT

\begin{tabular}{|l|c|c|c|c|}
\hline & $\begin{array}{c}\text { Proposed } \\
\text { Technology }\end{array}$ & $\begin{array}{c}\text { Comparable } \\
\text { Technology }\end{array}$ & $\begin{array}{c}\text { Savings } \\
\text { Per Year }\end{array}$ & $\begin{array}{c}\text { Savings } \\
\%\end{array}$ \\
\hline Heat Release & $92 \times 10^{9} \mathrm{BTU} / \mathrm{Yr}$ & $146 \times 10^{9} \mathrm{BTU} / \mathrm{Yr}$ & $53 \times 10^{9} \mathrm{BTU} / \mathrm{Yr}$ & $36 \%$ \\
\hline Methane consumption & $4.39 \times 10^{0} \# / \mathrm{Yr}$ & $6.91 \times 10^{6} \# / \mathrm{Yr}$ & $2.53 \times 10^{6} \# / \mathrm{Yr}$ & $36 \%$ \\
\hline $\mathrm{CO}_{2}$ production & $12.1 \times 10^{6} \# / \mathrm{Yr}$ & $19.0 \times 10^{6} \# / \mathrm{Yr}$ & $6.95 \times 10^{6} \# / \mathrm{Yr}$ & $36 \%$ \\
\hline Evaporation efficiency & $1150 \mathrm{BTU} / \# \mathrm{w}$ & $1900 \mathrm{BTU} / \# \mathrm{w}$ & $750 \mathrm{BTU} / \# \mathrm{w}$ & $39 \%$ \\
\hline
\end{tabular}

The steam cylinder industry has approximately 4000 domestic machines, so potential annual heat savings are 212 Trillion-BTU/Yr. 
DE-FG36-03G013009

PC Engineering

APPENDIX E- BIBLIOGRAPHY

BIBLIOGRAPHY

1) Martin, Holger, "Heat and Mass Transfer Between Impinging Gas Jets and Solid Surfaces", Advances in Heat Transfer, P1:60, V13, (1977)

2) Azevedo, L.F.A., Webb, B.W., Queiroz, M., "Pulsed Air Jet Impingement Heat

Transfer", Experimental Thermal and Fluid Science, 8:206-213 (1994)

3) Eibeck, P.A., Keller, J.O., Bramlette, T.T., Sailor, D.J., "Pulse Combustion: Impinging Jet Heat Transfer Enhancement", Combustion Science and Technology, 94:147-165, (1993)

4) Hashemi,S.J., Sidwall,S., Douglas,W. J. Murray, "Paper Drying: A Strategy For Higher Machine Speed. Ii. Impingement Air Drying For Hybrid Dryer Sections", Drying Technology, 19(10), 2509-2530 (2001)

5) Gavelin, Gunnar, "Paper Machine Design and Operation", Angus Wilde Publications, 221 pages, c1998, ISBN 0-9694628-2-4

6) Patterson,T., Ahrens, F., Stipp, G., "High Performance Impingement Paper Drying Using Pulse Combustion Technology", 2003 TAPPI Sprint Technical Conference \& Trade Fair, Proceedings, Session 62

7) American Institute of Chemical Engineers (AIChE), "Pulp and Paper Industry Energy Bandwidth Study", Jacobs Engineering, Greenville, South Carolina, and Institute of Paper Science and Technology (IPST) at Georgia Institute of Technology Atlanta, Georgia, August 2006, Project Number: 16CX8700. 


\section{APPENDIX F - AIR FLOW CALCULATIONS}

\section{AIR FLOW DEFINITIONS: NON-STEADY}

The goal of non-dimensional parameters like Duty Cycle (DS) and Wave Number (Wn), are to relate the flow characteristics of non-steady (or dynamic) flow to the easily calculated characteristics of steady flow. This section will present a family of simple examples where DS and Wn are used to predict the mass flow, peak pressure, and other characteristics of some simple dynamic flows.

Although an infinite variety of dynamic flows are theoretically possible, only two classes will be rigorously addressed here, the sinusoidal flow, and the symmetric pulsed flow. These represent two physically realizable flows found in engineering, the sinusoidal flow representing a naturally occurring flow in an oscillating system, like an organ pipe, and the pulsed flow representing a forced flow through a mechanical air valve.

\section{EQUAL MASS FLOW}

In all dynamic cases, we equate the mass flow of the steady flow case to the time averaged mass flow of the dynamic case, whether the dynamic flow is sinusoidal, pulsed, or other arbitrary wave form. For operation of the air valve, we must know the peak pressure required to create a given wave form, so the peak pressure in the dynamic case is important for fan selection, as is the peak negative pressure that must be supplied.

\section{DEFINE WAVE NUMBER AND DUTY CYCLE}

The "Wave Number" (Wn) will be defined for two types of dynamic flow, sinusoidal and pulsed. For sinusoidal flow, we only consider the zeroth and second Fourier harmonics, that is, the DC component of the flow (the only component which transports mass flow downstream), and the second Fourier harmonic, the harmonic that contains one full 360 degree sin wave (the first harmonic only contains 180 degrees of the sin wave). As the relative amplitude of the second harmonic changes, we see a corresponding

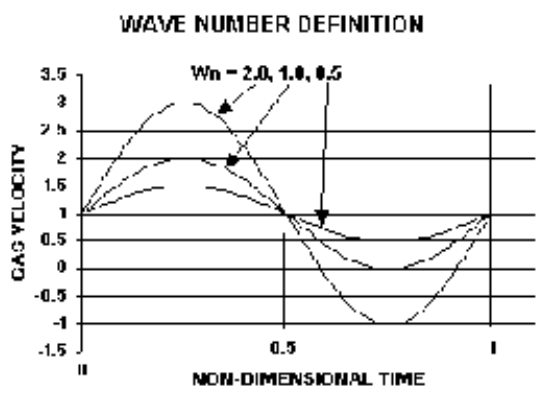
change in $\mathrm{Wn}$. For the continuous sin wave dynamic flow, there is no "duty cycle", because flow is continuous throughout the cycle.

The second dynamic case is "pulsed" flow, where a mechanical on off device modulates the flow in a discrete pattern, distinctly different from the continuous sinusoid case above. Here, the wave form is characterized by two process parameters, the Wave Number(Wn) and the "duty cycle" (DS). The DS is defined as the nondimensional time duration of the pulse, expresses as a decimal fraction of the cycle time, or expressed as a percentage. 

and second halves of the cycle, are identical in duration. As with sinusoid flows, these are normalized about an equivalent mass flow of one. The graph at right labels the flow's important variables, the maximum mass flow during the first half cycle, "M+", and the minimum mass flow during the

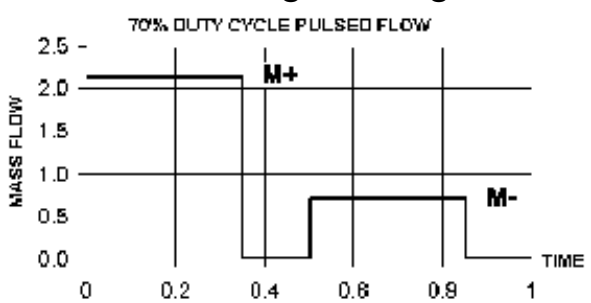
second half cycle, "M-". The example flow at right has: $\mathrm{DS}=70 \%$, and $\mathrm{Wn}=0.5$.

\section{EQUATION DERIVATION}

If the pulsed flow is normalized about unity mass flow, then the integral under the two flow phases must sum to one, which is expressed as follows.

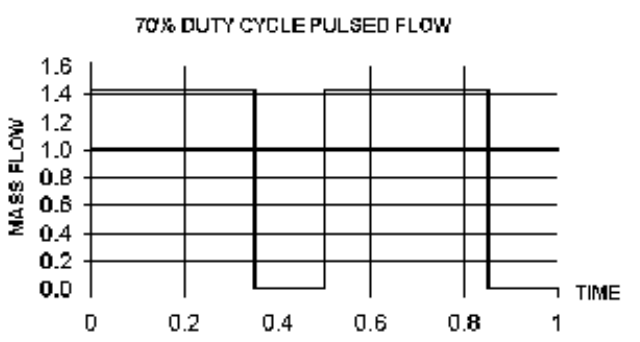

$$
1=(M-+M+) \times D S
$$

If the Wave Number is zero, then $M-=M_{+}$, and $M_{+}=1 / D S$. For $W n=0, D S=.7, M_{+}=$ 1.42 .

For pulsed flow to be symmetric, $\mathrm{M}+$ and $\mathrm{M}$ - must remain equidistant from 1/DS as the Wave Number changes. This can be expresses as follows.

$$
M+-1 / D S=M--1 / D S
$$

The Wave Number is expresses as the maximum excursion from average flow over the average flow.

$$
W n=\left(M_{+}-1 / D S\right) /(1 / D S)
$$

$$
\mathrm{Wn}=\mathrm{DS} \times \mathrm{M}+-1
$$

This now permits us to express the maximum $(\mathrm{M}+)$ and minimum $(\mathrm{M}-)$ flow rates in terms of the Wave Number (Wn) and Duty Cycle (DS).

$$
\begin{aligned}
& M_{+}=(W n+1) / D S \\
& M-=2 / D S-M_{+}
\end{aligned}
$$

EXAMPLE

Lets calculate the maximum and minimum flow rates for a typical flow condition.

$$
\begin{aligned}
& W n=1.2, D S=85 \% \\
& M+=(W n+1) / D S=2.59 \\
& M-=2 / D S-M_{+}=-0.24
\end{aligned}
$$

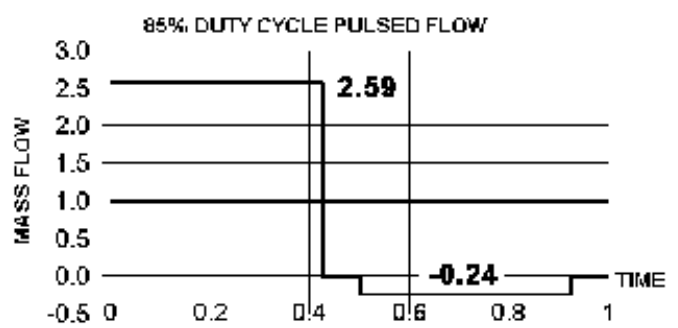




\section{APPENDIX G - FAN SELECTION}

\section{FAN SELECTION}

To size the fan, assume it must deliver dynamic pressure to the impingement nozzle, and the dynamic valving upstream only restricts pressure during non-peak velocity portions of the gas delivery. To simplify dynamic calculations, we will perform a rigorous analysis of the time dependent flow, and generate a regression model which permits a simplified calculation environment for engineering calculations.

To characterize the effects of nonsteady flow, we will analyze a unit sinusoid that is offset from zero by " $A$ ". By adjusting " $A$ ", we can create a family of flows that have any desired wave number, $\mathrm{Wn}$. The angular equation for gas velocity, denominated in Radians, is shown below.

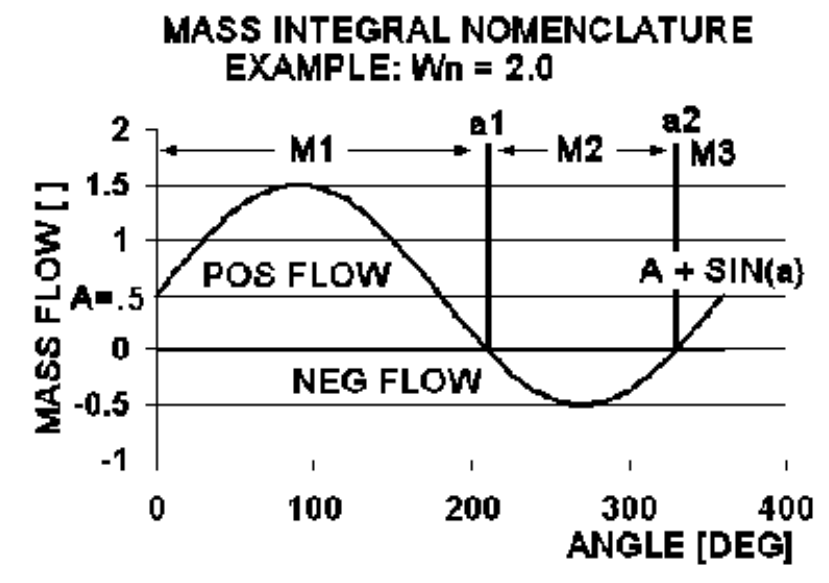

$$
\begin{aligned}
\mathrm{V}(\mathrm{x})=\mathrm{A}+\operatorname{Sin}(\mathrm{x}) \quad & \mathrm{V} \text { - velocity [ ] } \\
& \text { A - offset [ ] } \\
& \mathrm{x}-\text { angle [Rad] } \\
& \text { a1 - angle of first zero crossing } \\
& \text { a2 - angle of second zero crossing }
\end{aligned}
$$

Although calculus prefers radian angles, practical engineering prefers degrees. Reformulating the velocity equation in degrees, integrating to find mass flow, and establishing the integration limits for each integration region is shown next.

UNITS CONVERSION: $x[\mathrm{rad}], \mathrm{a}[\mathrm{deg}]=>\operatorname{Sin}(x)=\operatorname{Sin}\left(b^{*} a\right)=>x=\pi=b^{*} 180=>\underline{\mathbf{b}=\pi / \mathbf{1 8 0}}$

$$
\begin{aligned}
& M=\int V(x) d x=\int A+\operatorname{Sin}((\pi / 180) * a) d a=\left[A^{*} a-(180 / \pi) \operatorname{Cos}((\pi / 180) a)\right]{ }_{M(i)}^{M(i+1)} \\
& \text { M1 }=0 \text { to a1 } \\
& \text { M2 }=\text { a1 to a2 (the reverse flow region) } \\
& \text { M3 }=\text { a3 to } 360
\end{aligned}
$$

For our example, $\mathrm{Wn}=2, \mathrm{a} 1=210$, $\mathrm{a} 2=330$, and $\mathrm{A}=0.5$.

$$
\begin{array}{ccc}
\mathrm{M} 1= & .5^{*}(210-0)-(180 / \pi)\{\operatorname{Cos}(210)- & \operatorname{Cos}(0)\}=211.9[\mathrm{deg}] \\
+105-57.3^{*}\{-.866- & (+1)\}=211.9 \\
\mathrm{M} 2=.5^{\star}(330-210)-(180 / \pi)^{*}\{\operatorname{Cos}(330)-\operatorname{Cos}(210)\} & =-39.2[\mathrm{deg}] \\
+60-57 . *^{*}\{+.866-(-866)\} & =-39.2 \\
\mathrm{M} 3=.5^{*}(360-330)-(180 / \pi)^{*}\{\operatorname{Cos}(360)-\operatorname{Cos}(330)\} & =7.32[\mathrm{deg}]
\end{array}
$$




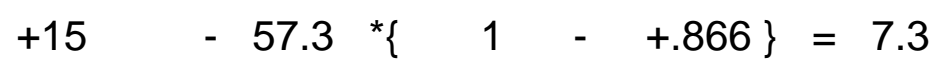

PC Engineering

Let us describe in detail the results of our example. In the initial mass flow period, M1, a total of 211.9 [Deg] of mass flows as the phase advances from zero to 210 degrees. At this point, mass flow reverses, and stays reversed until the phase advances to 310 degrees. The mass flow in this region is M2, and the integral shows the magnitude of this reverse flow is -39.2 degrees. Lastly, the flow returns to positive after the phase is at 310 degrees, and the final portion of the sinusoid contributes 7.3 degrees of mass flow.

Although these mass flows are denominated in "Degrees", they are proportional to the nondimensional mass flow of the wave form. For $A=0.5$, the steady flow equivalent of this flow pattern is $.5 \times 360=180$ [Deg]. This means that in the initial mass flow region, M1, $117 \%$ of the steady equivalent mass flows $(211.9 / 180)$, followed by a reverse flow region of $-22 \%$, followed by another positive flow region containing $4 \%$ of the steady equivalent mass flow, for a combined flow of $100 \%$.

If one is sizing a real world process for this nonsteady flow, the process's positive region is flowing $122 \%$ of the steady flow equivalent, and the negative flow region is conducting $-22 \%$ of the steady flow equivalent. Since these values are unique to the wave number, $\mathrm{Wn}=2.0$, it would save effort if there were a simple relationship between Wave Number and the total positive and negative flow regions. Although the author is aware of no simple algebraic relationship, it is possible to generate a simplified regression equation to achieve this goal.

FLOW FACTORS K+ AND K-

We will now solve the M1, M2, and M3 flow regions for a family of wave numbers, and generate the Excess Flow values $\mathrm{K}+$ and $\mathrm{K}$-. In short, if we desired a $\mathrm{Wn}=2$, and knew that $\mathrm{K}+=1.22$, and $\mathrm{K}-=-0.22$, then we could size piping quickly.

Please note that this excess piping size holds for two different piping conditions, common reverse flow piping, and separate reverse flow piping. For example, if one generated positive flow with a fan, and negative flow with a separate fan (as shown in the illustration), and ducted them together with an air valve that combined the flows, then the flow before the valve would be separate, and the flow after the valve would be combined. The

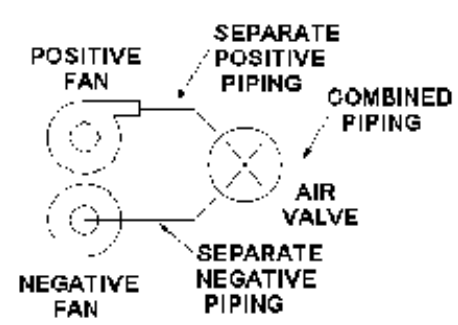
negative piping conducts less flow than the equivalent steady flow, and can be sized smaller. However, the separate positive piping, and combined piping, will see a maximum flow rate that is larger than the equivalent steady flow, and must be sized larger.

The table below summarizes the calculation of $\mathrm{K}+$ and $\mathrm{K}$ - for wave numbers from 1 through 10. The table calculates the individual mass flows $M 1, M 2$, and $M 3$, as well as the zero crossing angles a1 and a2. As the table shows, $W n=2$ generates $K+=1.22$, and $\mathrm{K}-=-0.22$. 
DE-FG36-03G013009

$\mathrm{PC}$ Engineering

\begin{tabular}{|c|c|c|c|c|c|c|c|c|}
\hline $\begin{array}{l}\text { A } \\
\text { [ ] }\end{array}$ & $\begin{array}{c}\text { M1 } \\
\text { [Deg] }\end{array}$ & $\begin{array}{c}\text { M2 } \\
\text { [Deg] }\end{array}$ & $\begin{array}{c}\text { M3 } \\
\text { [Deg] }\end{array}$ & $\begin{array}{c}W n \\
{[]}\end{array}$ & $\begin{array}{c}\text { a1 } \\
\text { [Deg] }\end{array}$ & $\begin{array}{c}\text { a2 } \\
\text { [Deg] }\end{array}$ & $\begin{array}{c}\mathrm{K}+ \\
\text { [] }\end{array}$ & $\begin{array}{l}\mathrm{K}- \\
\text { [] }\end{array}$ \\
\hline 0.95 & 314.4 & -1.1 & 0.502 & 1.05 & 251.8 & 288.1 & 1.003 & -0.0035 \\
\hline 0.9 & 302.0 & -2.9 & 0.443 & 1.11 & 244.2 & 295.8 & 1.01 & -0.0105 \\
\hline 0.8 & 278.2 & \begin{tabular}{|c|}
-9.7 \\
\end{tabular} & 0.341 & 1.25 & 233.1 & 306.8 & 1.033 & -0.0338 \\
\hline 0.7 & 255.3 & \begin{tabular}{|c|}
-17.8 \\
\end{tabular} & 0.256 & 1.43 & 224.4 & 315.5 & 1.071 & -0.0715 \\
\hline 0.6 & 233.3 & $\mid-27.5$ & 0.186 & 1.67 & 216.9 & 323.1 & 1.129 & -0.1292 \\
\hline 0.5 & 211.9 & -39.0 & 0.127 & 2 & 210.0 & 330.0 & 1.217 & -0.2179 \\
\hline 0.4 & 191.2 & -51.6 & 0.081 & 2.5 & 203.6 & 336.4 & 1.36 & -0.3603 \\
\hline 0.3 & 171.1 & -65.3 & 0.045 & 3.33 & 197.5 & 342.5 & 1.609 & -0.6091 \\
\hline 0.2 & 151.7 & -80.8 & 0.02 & 5 & 191.5 & 348.4 & 2.123 & -1.1234 \\
\hline 0.1 & 132.9 & -96.8 & 0.005 & 10 & 185.7 & 354.3 & 3.699 & -2.699 \\
\hline
\end{tabular}

Let us present a regression model which simplifies the generation of $\mathrm{K}+$ and $\mathrm{K}$ - values from simple knowledge of the wave number.

$$
\begin{aligned}
& \mathrm{K}_{+}=0.7+0.275^{*} \mathrm{Wn} \\
& \mathrm{K}-=0.38-0.3^{*} \mathrm{Wn}
\end{aligned}
$$

The plots at right show deviation from theoretical for these two regression lines. The $\mathrm{K}+$ regression is within $3 \%$ of theoretical throughout the range, but slightly underpredicts $\mathrm{Wn}=10$ by $6 \%$. The $\mathrm{K}$ regression is within $3 \%$ of the theoretical for $2<\mathrm{Wn}<10$, where reverse flows are above $10 \%$ of equivalent steady mass flow.
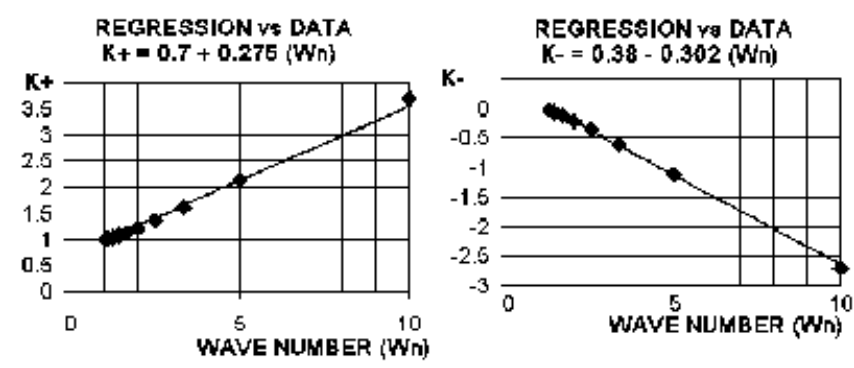

The tables below compare theoretical to regression values of $\mathrm{K}+$ and $\mathrm{K}$ -

\begin{tabular}{|r|rrr|}
\hline \multicolumn{4}{|c|}{$\mathrm{K}+=0.7+0.275^{*}$} \\
\hline $\mathrm{Wn}$ & \multicolumn{1}{|c|}{$\mathrm{K}+$} & REG K+ & Error \\
\hline 1.05 & 1.003 & 0.989 & $-1.4 \%$ \\
1.11 & 1.01 & 1.005 & $-0.5 \%$ \\
1.25 & 1.033 & 1.043 & $1.0 \%$ \\
1.43 & 1.071 & 1.092 & $2.0 \%$ \\
1.67 & 1.129 & 1.158 & $2.6 \%$ \\
2 & 1.217 & 1.25 & $2.7 \%$ \\
2.5 & 1.36 & 1.387 & $2.0 \%$ \\
3.33 & 1.609 & 1.616 & $0.4 \%$ \\
5 & 2.123 & 2.075 & $-2.3 \%$ \\
10 & 3.699 & 3.45 & $-6.7 \%$ \\
\hline
\end{tabular}

\begin{tabular}{|r|crr|}
\hline \multicolumn{4}{|c|}{$\mathrm{K}-=0.38-0.3^{*} \mathrm{Wn}$} \\
\hline $\mathrm{Wn}$ & \multicolumn{1}{|c|}{$\mathrm{K}-$} & \multicolumn{1}{c|}{$\mathrm{REG}$} & \multicolumn{1}{c|}{ Error } \\
\hline 1.25 & -0.034 & 0.005 & $-114.7 \%$ \\
1.43 & -0.072 & -0.0485 & $32.5 \%$ \\
1.67 & -0.129 & -0.12 & $7.0 \%$ \\
2 & -0.218 & -0.22 & $0.9 \%$ \\
2.5 & -0.36 & -0.37 & $2.8 \%$ \\
3.33 & -0.609 & -0.62 & $1.8 \%$ \\
5 & -1.123 & -1.12 & $0.3 \%$ \\
10 & -2.699 & -2.62 & $2.9 \%$ \\
\hline
\end{tabular}


DE-FG36-03G013009

PC Engineering

\section{APPENDIX H - VARIABLE SPACE}

\section{EVAPORATION EXPERIMENT VARIABLE SPACE}

\section{AIR VALVE SIZING FOR A NOZZLE PRESSURE DROP OF 1.3 VELOCITY HEADS}

\begin{tabular}{|c|c|c|c|c|c|c|c|c|c|c|}
\hline \multicolumn{5}{|c|}{ FAN SIZING } & \multicolumn{4}{|c|}{ +Fan: G1G144-AE13-50 } & \multicolumn{2}{|c|}{ FAN CURVE } \\
\hline Alt $F$ & 0 & & Dens $=$ & 0.0753 & & & & & CFM & พC \\
\hline Temp $\mathrm{E}$ & 70 & & & 4003.3 & -Fan: & 20 & 6 & & 2 & 5.79 \\
\hline$p=$ & 0.074 & {$[\# / \mp 3]$} & & & & [CFM] & [wC] & & 10 & 5.54 \\
\hline $\mathbf{u}=$ & $1 E-05$ & {$[\# \mathrm{~m} / \mathbf{f}-$} & $-\mathbf{s}]$ & & & & & & 50 & 4.70 \\
\hline & & & & $\mathrm{fL} / \mathrm{D}=$ & 1.3 & & & & & \\
\hline $\operatorname{Re}$ & Wn & D & $\mathbf{v}$ & Msted & Psted & $\mathbf{M}-$ & P- & M+ & $\mathrm{P}+$ & FAN \\
\hline [ ] & [ ] & [In] & [FPS ] & [CFS] & [WC] & [CFM] & [WC] & [CFM] & [WC] & [WC] \\
\hline 25.02 & 2 & 0.5 & 97.38 & 0.133 & 2.77 & 2.18 & 0.692 & 10.1 & 11.07 & 11.08 \\
\hline 12.6 & 4 & 0.5 & 49.07 & 0.067 & 0.70 & 3.38 & 0.395 & 7.4 & 11.25 & 11.24 \\
\hline 8.4 & 6 & 0.5 & 32.79 & 0.045 & 0.31 & 3.78 & 0.218 & 6.5 & 11.30 & 11.30 \\
\hline 36.4 & 2 & 0.75 & 94.53 & 0.290 & 2.61 & 4.75 & 0.652 & 22.2 & 10.43 & 10.43 \\
\hline 18.5 & 4 & 0.75 & 47.93 & 0.147 & 0.67 & 7.42 & 0.377 & 16.2 & 10.73 & 10.73 \\
\hline 12.4 & 6 & 0.75 & 32.12 & 0.099 & 0.30 & 8.33 & 0.209 & 14.24 & 10.84 & 10.84 \\
\hline 19.0 & 2 & 0.375 & 98.55 & 0.076 & 2.84 & 1.24 & 0.709 & 5.77 & 11.34 & 11.34 \\
\hline 9.5 & 4 & 0.375 & 49.49 & 0.038 & 0.72 & 1.92 & 0.402 & 4.19 & 11.44 & 11.44 \\
\hline 4.8 & 8 & 0.375 & 24.79 & 0.019 & 0.18 & 2.26 & 0.137 & 3.40 & 11.49 & 11.49 \\
\hline 30.0 & 1.663 & 0.5 & 116.7 & 0.159 & 3.98 & 1.69 & 0.633 & 11.25 & 11.01 & 11.01 \\
\hline 8.4 & 6.0 & 0.5 & 32.79 & 0.045 & 0.31 & 3.78 & 0.218 & 6.46 & 11.30 & 11.30 \\
\hline
\end{tabular}

AIR VALVE SIZING FOR A NOZZLE PRESSURE DROP OF 1.0 VELOCITY HEADS

\begin{tabular}{|c|c|c|c|c|c|c|c|c|c|c|}
\hline \multicolumn{5}{|c|}{ FAN SIZING } & \multicolumn{4}{|c|}{ +Fan: G1G144-AE13-50 } & \multicolumn{2}{|c|}{ FAN CURVE } \\
\hline Alt $F$ & 0 & & Dens $=$ & 0.0753 & & & & & CFM & WC \\
\hline Temp $\mathrm{E}$ & 70 & & & 4003.3 & -Fan: & 20 & 6 & & 2 & 5.79 \\
\hline $\mathrm{p}=$ & 0.074 & {$[\# / \pm 3]$} & & & & [CFM] & [WC] & & 10 & 5.54 \\
\hline \multirow[t]{2}{*}{$\mathrm{u}=$} & $1 E-05$ & {$[\# \mathrm{~m} / \mathrm{f}-$} & $-s]$ & & & & & & 50 & 4.70 \\
\hline & & & & $\mathrm{fL} / \mathrm{D}=$ & $=1$ & & & & & \\
\hline $\operatorname{Re}$ & Wn & $\mathbf{D}$ & $\mathbf{V}$ & Msted & Psted & $\mathbf{M}-$ & P- & M+ & P+ & FAN \\
\hline [ ] & [ ] & {$[\operatorname{In}]$} & [FPS] & [CFS] & [WC] & [CFM] & [WC] & [CFM] & {$[w C]$} & [WC] \\
\hline 28.4 & 2 & 0.5 & 110.5 & 0.151 & 2.74 & 2.47 & 0.686 & 11.5 & 10.97 & 11.00 \\
\hline 14.3 & 4 & 0.5 & 55.79 & 0.076 & 0.70 & 3.84 & 0.393 & 8.4 & 11.18 & 11.18 \\
\hline 9.6 & 6 & 0.5 & 37.27 & 0.051 & 0.31 & 4.30 & 0.216 & 7.3 & 11.23 & 11.25 \\
\hline 41.3 & 2 & 0.75 & 107.0 & 0.328 & 2.57 & 5.38 & 0.643 & 25.1 & 10.29 & 10.29 \\
\hline 20.9 & 4 & 0.75 & 54.34 & 0.167 & 0.66 & 8.41 & 0.373 & 18.4 & 10.61 & 10.62 \\
\hline 14.1 & 6 & 0.75 & 36.45 & 0.112 & 0.30 & 9.46 & 0.207 & 16.17 & 10.74 & 10.74 \\
\hline 21.6 & 2 & 0.375 & 112.1 & 0.086 & 2.82 & 1.41 & 0.705 & 6.57 & 11.29 & 11.29 \\
\hline 10.9 & 4 & 0.375 & 56.34 & 0.043 & 0.71 & 2.18 & 0.401 & 4.77 & 11.41 & 11.41 \\
\hline 5.4 & 8 & 0.375 & 28.23 & 0.022 & 0.18 & 2.57 & 0.137 & 3.87 & 11.46 & 11.46 \\
\hline 23.8 & 2.4 & 0.5 & 92.52 & 0.126 & 1.92 & 2.93 & 0.654 & 10.50 & 11.07 & 11.06 \\
\hline 9.6 & 6.0 & 0.5 & 37.31 & 0.051 & 0.31 & 4.30 & 0.217 & 7.35 & 11.25 & 11.24 \\
\hline
\end{tabular}




\section{APPENDIX I - ISENTROPIC EXPANSION SOLUTION}

ISENTROPIC EXPANSION SOLUTION

$\underline{2 / 04}$

Solve the isentropic gas equations for the case of an initial pair of gas volumes $A$ and $B$, separated by a massless membrane, that is in pressure disequilibrium, into gas volumes $C$ and $D$ that are in pressure equilibrium.

$V-\left[\right.$ feet $\left.{ }^{\wedge} 3\right]$

$v-\left[\right.$ feet $\left.{ }^{\wedge} 3 / \#\right]$

$p-\left[\# /\right.$ feet $\left.^{\wedge} 2\right]$

$\mathrm{m}-[\#]=$ density ${ }^{*} \mathrm{Vol}=$ Volume $/$ specific volume

CONSERVATION OF TOTAL VOLUME
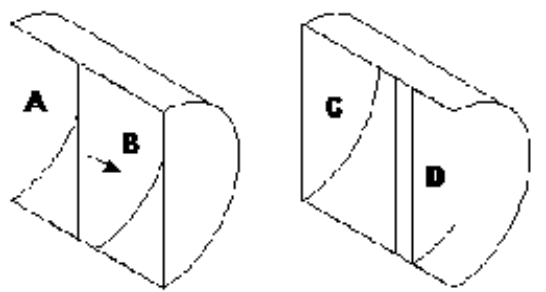

$\mathrm{Va}+\mathrm{Vb}=\mathrm{Vc}+\mathrm{Vd}$

CONSERVATION OF MASS

$\mathrm{Ma}=\mathrm{Mc}$

$\mathrm{Mb}=\mathrm{Md}$

SOLVE USING THESE MASS CONSERVATION EQUATIONS

$M=V / v \quad(v[f 3 / \#], V[f 3], M[\#])$

$\mathrm{Va} / \mathrm{va}=\mathrm{Vc} / \mathrm{vc}$

$\mathrm{Vb} / \mathrm{vb}=\mathrm{Vd} / \mathrm{vd}$

POST-EXPANSION PRESSURE EQUILIBRIUM

$P c=P d$

ISENTROPIC EXPANSION EQUATIONS

$A$ expands into $C$, and $B$ contracts into $D$, via the isentropic expansion laws.

$\mathrm{T} 2 / \mathrm{T} 1=(\mathrm{V} 1 / \mathrm{V} 2)^{\wedge}(\mathrm{Cp}-\mathrm{Cv})=(\mathrm{P} 2 / \mathrm{P} 1)^{\wedge}(\mathrm{Cp}-\mathrm{Cv}) / \mathrm{Cp}$

Write exponent in terms of pressure exponent "pe", and volume exponent "ve".

$$
\begin{aligned}
& \mathrm{ve}=(\mathrm{Cp}-\mathrm{Cv})=\mathrm{v}-1<========\text { GAMMA NOMENCLATURE IN EXPONENT } \\
& \text { pe }=(\mathrm{Cp}-\mathrm{Cv}) / \mathrm{Cp}=(\mathrm{v}-1) / \mathrm{v}<==\text { GAMMA NOMENCLATURE IN EXPONENT } \\
& (\mathrm{vc} / \mathrm{va})^{\wedge} \mathrm{ve}=(\mathrm{Pa} / \mathrm{Pc})^{\wedge} \mathrm{pe} \\
& (\mathrm{vd} / \mathrm{vb})^{\wedge} \mathrm{ve}=(\mathrm{Pb} / \mathrm{Pd})^{\wedge} \mathrm{pe}
\end{aligned}
$$

SOLUTION STEP 1: SOLVE ISENTROPIC EQUATIONS FOR PC $=\mathrm{Pd}$ 
DE-FG36-03G013009

PC Engineering

$\mathrm{Pa} / \mathrm{Pc}=(\mathrm{vc} / \mathrm{va})^{\wedge} \mathrm{ve} / \mathrm{pe}=>\mathrm{ve} / \mathrm{pe}=(\mathrm{v}-1)^{*}(\mathrm{v} /(\mathrm{v}-1))=\mathrm{v}<===$ exponent simplifies

$\mathrm{Pb} / \mathrm{Pd}=(\mathrm{vd} / \mathrm{vb})^{\wedge} \mathrm{ve} / \mathrm{pe}$

$\mathrm{Pc}=\mathrm{Pa}(\mathrm{vc} / \mathrm{va})^{\wedge}-\mathrm{v}$

$\mathrm{Pd}=\mathrm{Pb}(\mathrm{vd} / \mathrm{vb})^{\wedge}-\mathrm{v}$

$P c=P d<$

pressure equilibrium at process end

$\mathrm{Pa}(\mathrm{vc} / \mathrm{va})^{\wedge}-\mathrm{v}=\mathrm{Pb}(\mathrm{vd} / \mathrm{vb})^{\wedge}-\mathrm{v}$ isentropic press equilibrium for $\mathrm{Pc}=\mathrm{Pd}$

SOLUTION STEP 2: SOLVE FOR vc

$$
\begin{aligned}
& (\mathrm{vc} / \mathrm{va})^{\wedge}-\mathrm{v}=(\mathrm{Pb} / \mathrm{Pa})^{*}(\mathrm{vd} / \mathrm{vb})^{\wedge}-\mathrm{v} \\
& \mathrm{vc} / \mathrm{va}=(\mathrm{vd} / \mathrm{vb})^{*}(\mathrm{~Pb} / \mathrm{Pa})^{\wedge} \mathrm{v} \\
& \mathrm{vc}=\left(\mathrm{vd}{ }^{*} \mathrm{va}\right) / \mathrm{vb} *(\mathrm{~Pb} / \mathrm{Pa})^{\wedge} \mathrm{v}<================================ \\
& \text { vc isolated from } \mathrm{vd}
\end{aligned}
$$

SOLUTION STEP 3: SOLVE FOR vd

$$
\begin{aligned}
& \mathrm{Va}+\mathrm{Vb}=\mathrm{Vc}+\mathrm{Vd}<==\text { conservation of volume } \\
& \mathrm{Va} / \mathrm{va}=\mathrm{Vc} / \mathrm{vc} \quad<==\text { conservation of mass } \\
& \mathrm{Vb} / \mathrm{vb}=\mathrm{Vd} / \mathrm{vd} \\
& =======\mathrm{ALGEBRAIC} \text { MANIPULATION } \\
& \mathrm{Vc}=\mathrm{vc} / \mathrm{va}{ }^{*} \mathrm{Va} \\
& \mathrm{Vd}=\mathrm{vd} / \mathrm{vb}{ }^{*} \mathrm{Vb} \\
& \mathrm{Va}+\mathrm{Vb}=\mathrm{vc} / \mathrm{va}{ }^{*} \mathrm{VA}+\mathrm{Vd} / \mathrm{vb}{ }^{*} \mathrm{Vb} \\
& \mathrm{vd}=\mathrm{vb} / \mathrm{Vb} *\left(\mathrm{Va}+\mathrm{Vb}-\mathrm{Va}{ }^{*} \mathrm{Vc} / \mathrm{va}\right)
\end{aligned}
$$

SOLUTION STEP 4: SUBSTITUTE vd INTO vc EQUATION - GIVES vc EXPLICITLY

$$
\begin{aligned}
& \mathrm{vc}=\mathrm{va} / \mathrm{vb} \mathrm{*}^{*}(\mathrm{~Pb} / \mathrm{Pa})^{\wedge} \mathrm{v}{ }^{*} \mathrm{vd} \\
& =v a / v b *(P b / P a)^{\wedge} v^{*} \forall b / V b *(V a+V b-V a * v c / v a) \\
& \mathrm{vc}+\mathrm{Va}{ }^{*} \mathrm{vc} / \mathrm{va}{ }^{*} \mathrm{va} / \mathrm{Vb}{ }^{*}(\mathrm{~Pb} / \mathrm{Pa})^{\wedge} \mathrm{v}=(\mathrm{va} / \mathrm{Vb}){ }^{*}(\mathrm{Va}+\mathrm{Vb}){ }^{*}(\mathrm{~Pb} / \mathrm{Pa})^{\wedge} \mathrm{v} \\
& v c^{*}\left(1+\mathrm{Va} / \mathrm{Vb}{ }^{*}(\mathrm{~Pb} / \mathrm{Pa})^{\wedge} \mathrm{v}\right)=\mathrm{va} / \mathrm{vb}{ }^{*}(\mathrm{Va}+\mathrm{Vb}){ }^{*}(\mathrm{~Pb} / \mathrm{Pa})^{\wedge} \mathrm{v}
\end{aligned}
$$




$$
\mathrm{vc}=\mathrm{va} / \mathrm{vb} *(\mathrm{Va}+\mathrm{Vb}){ }^{*}(\mathrm{~Pb} / \mathrm{Pa})^{\wedge} \mathrm{v} /\left(\left(1+(\mathrm{Va} / \mathrm{Vb}){ }^{*}(\mathrm{~Pb} / \mathrm{Pa})^{\wedge} \mathrm{v}\right)\right.
$$

SIMPLIFIED VERSIONS OF vc, SPECIFIC VOLUME OF END STATE

$$
\begin{aligned}
& \mathrm{vc}=(\mathrm{Va} / \mathrm{Vb})^{*}(\mathrm{Va}+\mathrm{Vb}) /\left[(\mathrm{Pb} / \mathrm{Pa})^{\wedge}-\mathrm{v}+(\mathrm{Va} / \mathrm{Vb})\right] \\
& <========================== \\
& \left.\mathrm{vc}=(\mathrm{Va}+\mathrm{Vb}) /\left[(\mathrm{Vb} / \mathrm{va}) *(\mathrm{~Pb} / \mathrm{Pa})^{\wedge}-\mathrm{v}+\mathrm{Va} / \mathrm{Va}\right)\right]<====================
\end{aligned}
$$

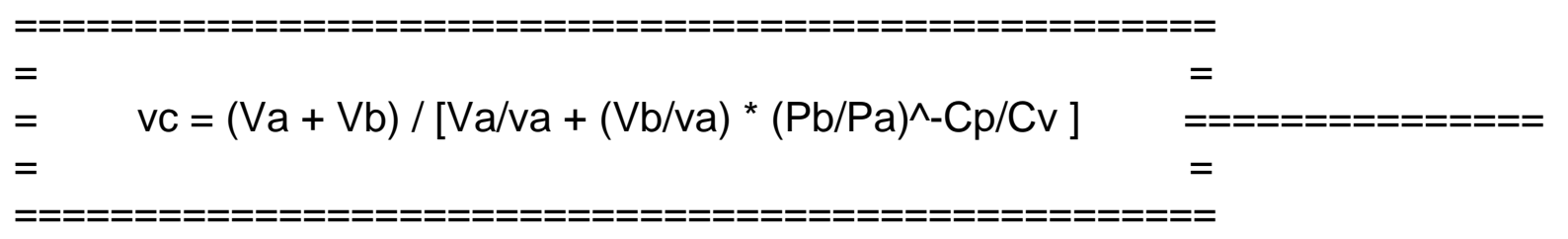

USEFUL EQUATIONS

$$
\begin{aligned}
& \mathrm{Vd}=\mathrm{Va}+\mathrm{Vb}-\mathrm{Va}^{*} \mathrm{Vc} / \mathrm{va} \\
& \mathrm{Vd}=(\mathrm{Vd} / \mathrm{Vb})^{*} \mathrm{Vb} \\
& \mathrm{Vc}=\mathrm{Va}+\mathrm{Vb}-\mathrm{Vd}
\end{aligned}
$$

SOLVE FOR TEMPERATURES

$$
\begin{aligned}
& \mathrm{T} 2 / \mathrm{T} 1=(\mathrm{P} 2 / \mathrm{P} 1)^{\wedge}((\mathrm{v}-1) / \mathrm{v}) \\
& \mathrm{Tc} / \mathrm{Ta}=(\mathrm{Pc} / \mathrm{Pa})^{\wedge}((\mathrm{v}-1) / \mathrm{v})
\end{aligned}
$$

$==========================$
$=\quad \mathrm{Tc}=\mathrm{Ta}{ }^{*}(\mathrm{Pc} / \mathrm{Pa})^{\wedge}((\mathrm{v}-1) / \mathrm{v})=$
$=\quad \mathrm{Td}=\mathrm{Tb}{ }^{*}(\mathrm{Pd} / \mathrm{Pb})^{\wedge}((\mathrm{v}-1) / \mathrm{v})=<=================================$
$========================$
calculates post expansion temperatures




\section{APPENDIX $\mathbf{J}$ - THERMODYNAMIC BALANCE SUMMARY}

THERMODYNAMIC BALANCE SUMMARY

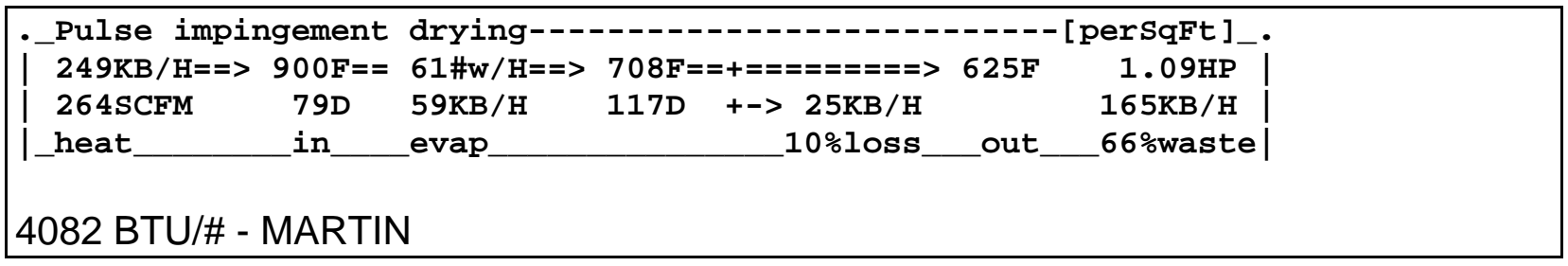

\begin{tabular}{|c|c|c|c|c|c|c|}
\hline $249 \mathrm{~KB} / \mathrm{H}==>$ & $900 \mathrm{~F}$ & $=153 \# w / H==>$ & $407 \mathrm{~F}=$ & $=+========>$ & $324 \mathrm{~F}$ & $1.09 \mathrm{HP}$ \\
\hline $\begin{array}{l}264 \text { SCFM } \\
\text { heat }\end{array}$ & $\begin{array}{l}79 D \\
\text { in }\end{array}$ & $\begin{array}{l}\text { 150KB/H } \\
\text { evap }\end{array}$ & $142 D$ & $\begin{array}{r}+\rightarrow 25 \mathrm{~KB} / \mathrm{H} \\
10 \% 10 \mathrm{ss}\end{array}$ & & $\begin{array}{c}74 \mathrm{~KB} / \mathrm{H} \\
30 \% \text { waste }\end{array}$ \\
\hline
\end{tabular}

1627 BTU/\# - En=2.53 - 14\% savings over steam cylinders

\begin{tabular}{|c|c|c|c|c|c|}
\hline \multicolumn{6}{|c|}{-_Pulse impingement drying-- } \\
\hline $249 \mathrm{~KB} / \mathrm{H}==>$ & $900 \mathrm{~F}=$ & $=170 \# \mathrm{w} / \mathrm{H}==>$ & $351 \mathrm{~F}=$ & $=+========\Rightarrow 268 \mathrm{~F}$ & $1.09 \mathrm{HP}$ \\
\hline 264SCFM & $79 D$ & $167 \mathrm{~KB} / \mathrm{H}$ & $146 \mathrm{D}$ & $+>25 \mathrm{~KB} / \mathrm{H}$ & $58 \mathrm{~KB} / \mathrm{H}$ \\
\hline _heat__ & in & _evap & & $10 \% 10 s s_{2}$ & $23 \%$ waste \\
\hline
\end{tabular}

1465 BTU/\# - En=2.81 - 23\% savings over steam cylinders 


\section{APPENDIX K - BURNER TEST PID}

\section{BURNER TEST PID - FULL RESOLUTION}

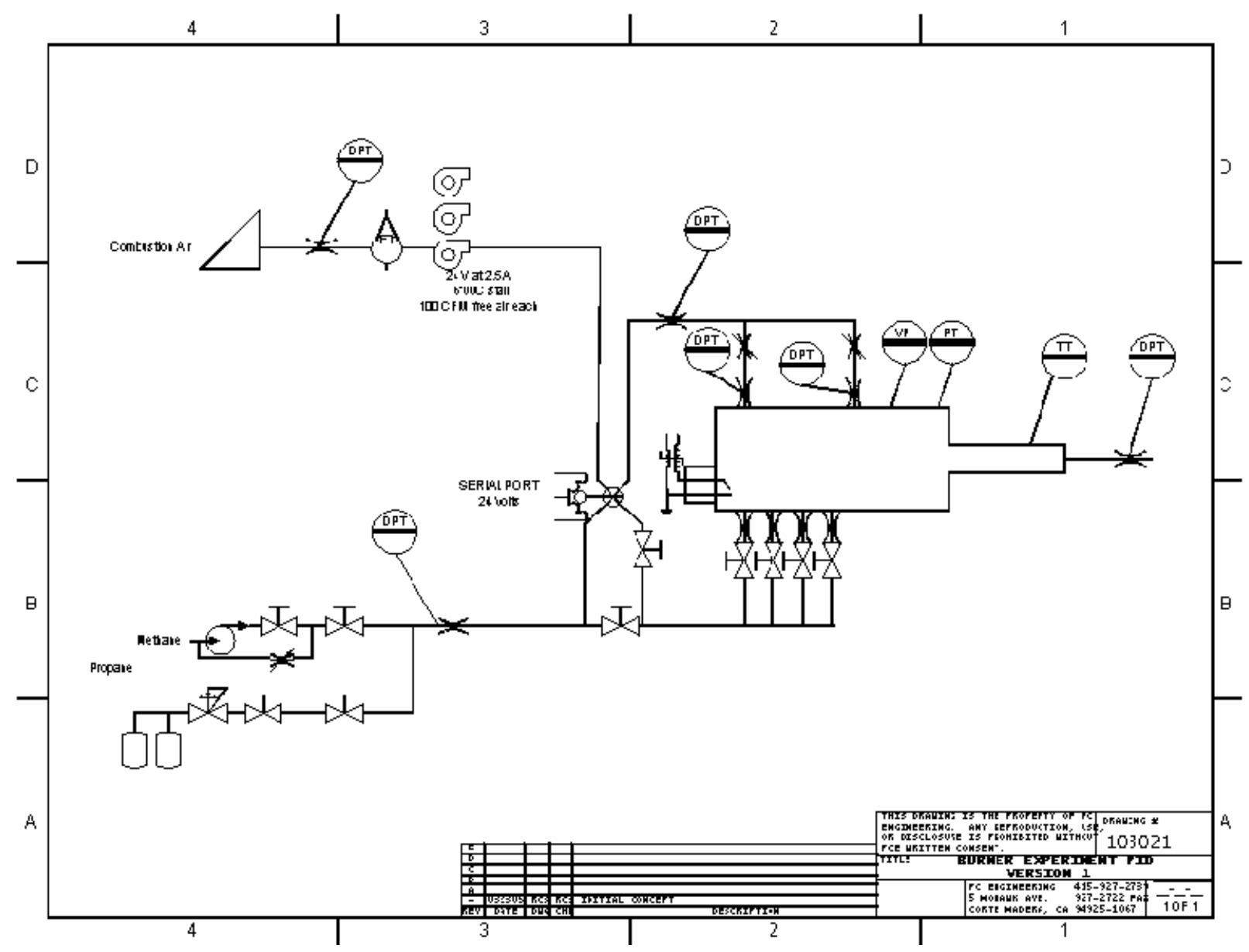




\section{APPENDIX L - EVAPORATOR TEST PID}

\section{EVAP EXPERIMENT P\&ID - FULL RESOLUTION}

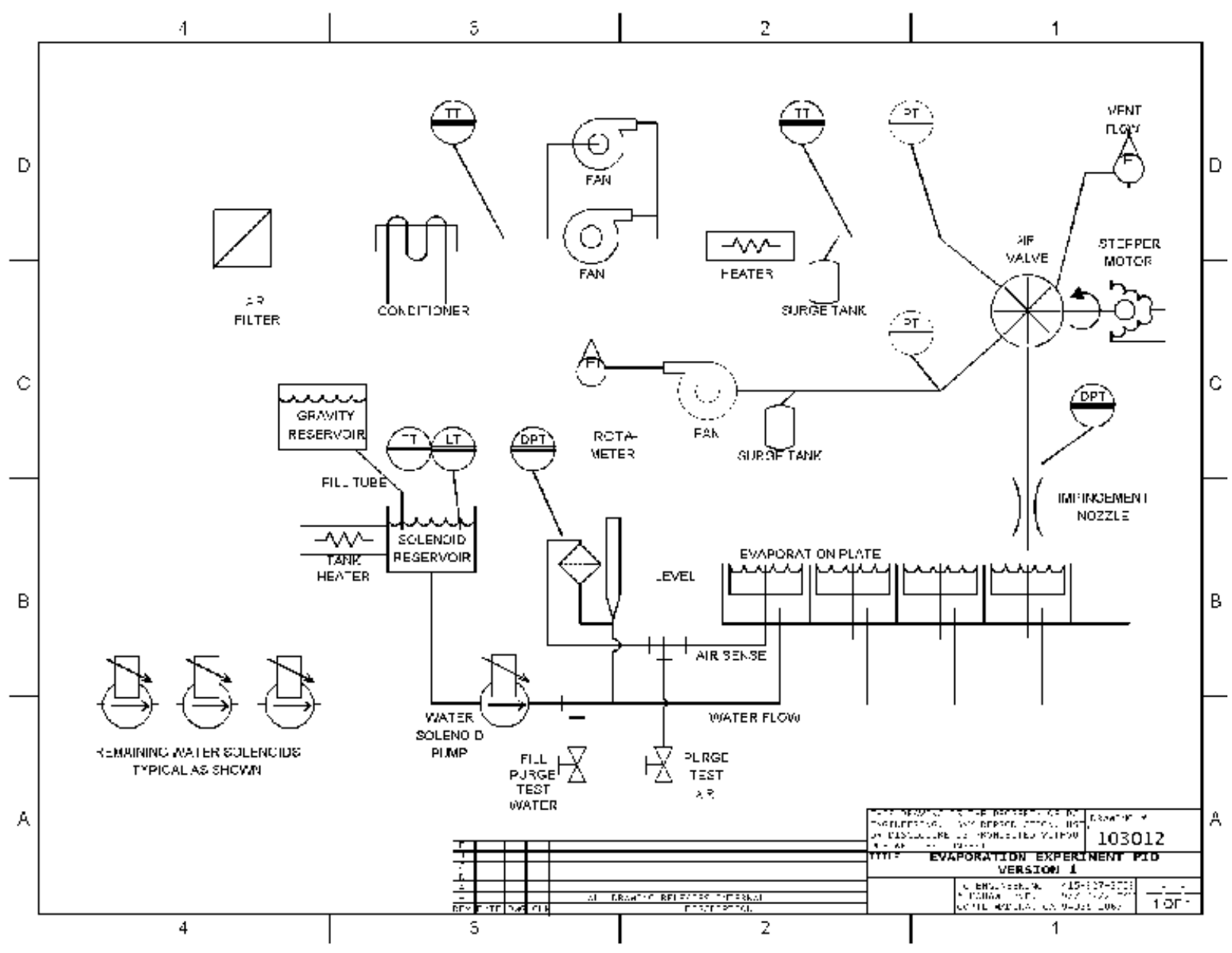




\section{APPENDIX M - EVAPORATOR RAW DATA}

\section{RAW DATA SUMMARY}

\begin{tabular}{|c|c|c|c|c|c|c|c|c|}
\hline \multicolumn{4}{|c|}{ DATA SUMMARY } & \multirow[b]{2}{*}{ SEG2 } & \multirow[b]{2}{*}{ SEG3 } & \multirow[b]{2}{*}{ SEG4 } & \multirow[b]{2}{*}{ DATE } & \multirow[b]{2}{*}{ FILE } \\
\hline $\operatorname{Re}$ & Wn & AV & SEG1 & & & & & \\
\hline [] & {[]} & $\mathrm{Hz}$ & $\begin{array}{l}\# / \text { SF- } \\
\mathrm{Hr}\end{array}$ & $\# / \mathrm{SF}-\mathrm{Hr}$ & \#/SF-Hr & \#/SF-Hr & & \\
\hline 5 & & & 0.1162 & 0.0831 & 0.05603 & 0.02728 & MARTIN & \\
\hline 5 & 0 & 0 & 0.18 & 0.16 & 0.09 & 0.037 & Fri30 & Steady5K \\
\hline 3.9 & 0 & 0 & 0.1028 & 0.0728 & 0.0485 & 0.02328 & MARTIN & \\
\hline 3.91 & 1 & 10 & 0.18 & 0.17 & 0.077 & & Fri30 & Wn1Re5Av1K \\
\hline 3.91 & 1 & 10 & 0.180 & 0.170 & 0.110 & 0.060 & Fri30 & Wn1Re5Av1KB \\
\hline 3.91 & 3 & 10 & 0.37 & 0.19 & 0.085 & 0.041 & Fri30 & Wn3Re5av1GOOD \\
\hline 3.91 & 3 & 10 & & & 0.086 & & Fri30 & Wn3Re5av1K \\
\hline \multirow[t]{2}{*}{3.91} & 3 & 20 & & & 0.07 & 0.03 & Fri30 & Wn3Re5av2k \\
\hline & & & & & & & & \\
\hline 5 & 10 & 0 & & 0.13 & 0.07 & 0.037 & $6-\mathrm{Jul}$ & 5KSteady.xls \\
\hline 3.91 & 1 & 10 & & 0.14 & 0.07 & 0.035 & 6-Jul & Re5KWn1Av1K.xls \\
\hline 3.91 & 11 & 20 & & 0.17 & 0.087 & 0.032 & $6-J u l$ & Re5KWn1Av2K.xls \\
\hline 3.91 & 1 & 30 & & 0.17 & & 0.046 & 6-Jul & Re5Wn1Av3K.xls \\
\hline 3.91 & 3 & 10 & & 0.21 & & 0.08 & 6-Jul & Re5Wn3Av1K.xls \\
\hline 3.91 & 3 & 15 & & 0.18 & & & 6-Jul & Re5Wn3Av15K.xls \\
\hline 3.91 & 3 & 20 & & 0.23 & & 0.07 & 6-Jul & Re5Wn3Av2K.xls \\
\hline 3.91 & 3 & 25 & & 0.19 & & 0.08 & 6-Jul & Re5Wn3Av25K.xls \\
\hline 3.91 & 3 & 30 & & 0.18 & & 0.06 & 6-Jul & Re5Wn3Av3K.xls \\
\hline 3.91 & 3.5 & 10 & & 0.13 & 0.12 & & $7-\mathrm{Jul}$ & Re5Wn35Av1.xls \\
\hline 3.91 & 3.5 & 20 & & 0.17 & 0.11 & 0.03 & 7-Jul & Re5Wn35Av2.xls \\
\hline \multirow[t]{2}{*}{3.91} & 3.5 & 30 & 0.17 & 0.14 & 0.1 & 0.023 & 7-Jul & Re5Wn35Av3.xls \\
\hline & & & & & & & & \\
\hline 3.91 & 3.5 & 10 & & 0.15 & 0.11 & & 7-Jul & Re5Wn35Av1Sharp.xls \\
\hline 3.91 & 3.5 & 20 & 0.25 & 0.21 & 0.09 & & 7-Jul & Re5Wn35Av2Sharp.xls \\
\hline 3.91 & 3.5 & 30 & 0.26 & 0.21 & & & 7-Jul & Re5Wn35Av3Sharp.xls \\
\hline 7 & & & 0.1372 & 0.0997 & 0.06838 & 0.034 & MARTIN & \\
\hline 7 & 0 & 0 & & 0.15 & 0.09 & 0.028 & Sat31 & SteadyRe7 \\
\hline 5.47 & & & 0.1215 & 0.0872 & 0.05906 & 0.02892 & MARTIN & \\
\hline 5.47 & 1 & 30 & & 0.12 & 0.09 & & Sat31 & Re7Wn1Av3k.xls \\
\hline 5.47 & 3.5 & 30 & 0.28 & 0.22 & 0.08 & & Sat31 & Re7Wn37Av3K \\
\hline 10 & & & 0.1635 & 0.1212 & 0.08486 & 0.04323 & MARTIN & \\
\hline 10 & 10 & 0 & 0.23 & 0.14 & & & Tues27 & LiveData10K.xls \\
\hline 7.81 & 1 & 10 & & 0.14 & & & Tues27 & LieData10kav4 \\
\hline 7.81 & 11 & 10 & 0.19 & 0.10 & & & Tues27 & LiveData10av5 \\
\hline 7.81 & 1 & 30 & 0.21 & 0.13 & 0.12 & & Tues27 & Livedata10Kav3 \\
\hline 7.81 & 3 & 20 & 0.29 & 0.19 & & & Tues27 & LiveData10Kav \\
\hline \multirow[t]{2}{*}{7.81} & 3 & 30 & 0.29 & 0.12 & & & Tues27 & LiveData10Kav2 \\
\hline & & & & & & & & \\
\hline 15 & & & 0.20 & 0.1519 & 0.10922 & 0.05732 & MARTIN & \\
\hline 15 & 0 & 0 & 0.25 & 0.21 & & 0.06 & 8-Jul & STEADYRe15k.xls \\
\hline 11.7 & 1 & 30 & 0.27 & 0.25 & 0.18 & & 8 -Jul & Re15Wn1Av30.xls \\
\hline 11.7 & 2.75 & 30 & 0.29 & 0.25 & 0.037 & 0.038 & 8-Jul & Re15Wn275Av3K.xls \\
\hline 11.7 & 3.5 & 30 & 0.26 & 0.21 & 0.11 & 0.07 & 8-Jul & Re10kWn35Av30.xls \\
\hline
\end{tabular}


DE-FG36-03G013009

PC Engineering

APPENDIX N: PHOTOGRAPHS

EVAPORATOR

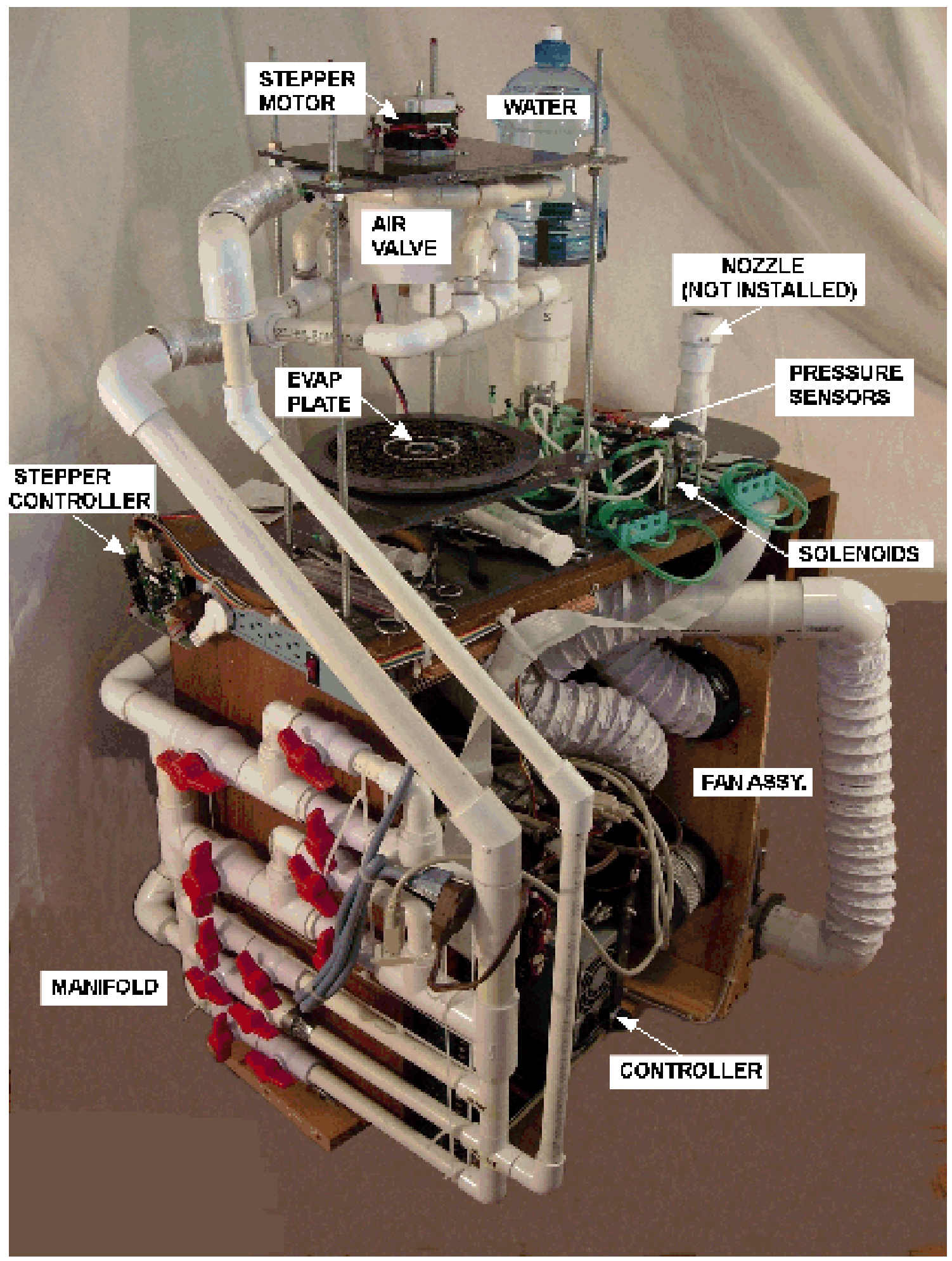

page - 63 -

of 64 


\section{DE-FG36-03G013009}

BURNER

Attached to air valve, but absent utilities.

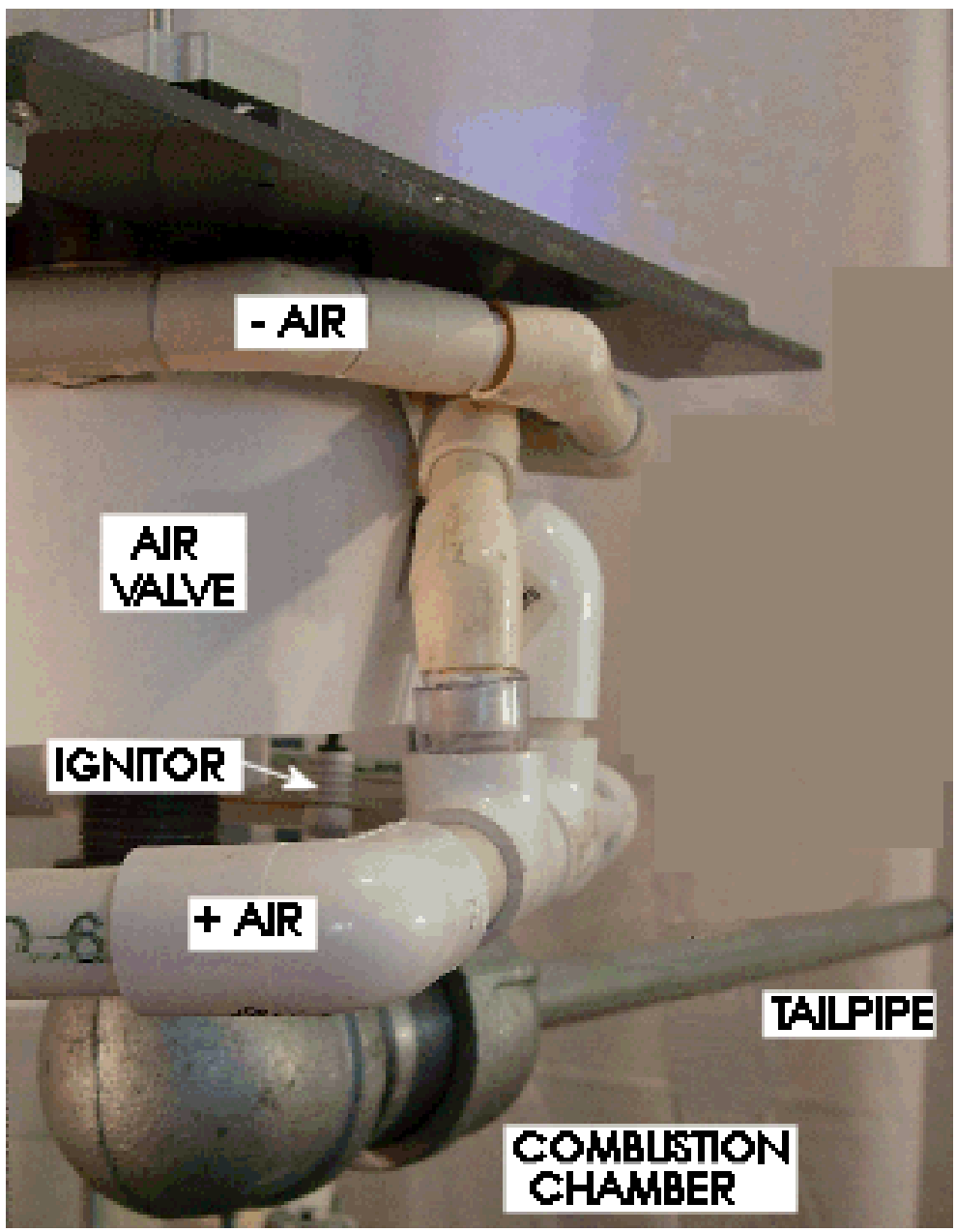

